\title{
INSPECTION AND RATING OF MITER LOCK GATES
}

\author{
by \\ Lowell Greimann \\ James Stecker \\ Kevin Rens \\ ENGINEERING RESEARCH INSTITUTE \\ lowa State University \\ Ames, lowa 50011

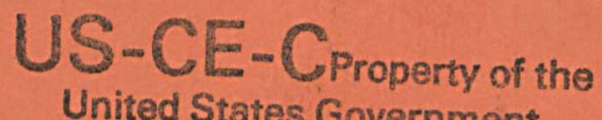 \\ United States Government

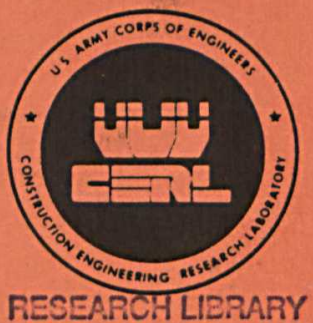 \\ US ARMY ENCIN=-TIUTERWAYS \\ EXPE.........NT STATISN \\ VICKSDURG, MISSISSIPPI
}

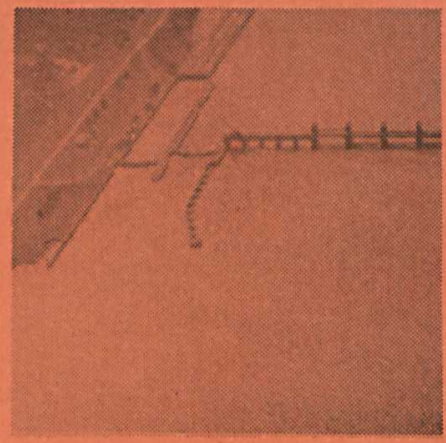

\section{August 1990 \\ Final Report}

Approved For Public Release; Distribution Unlimited

Prepared for DEPARTMENT OF THE ARMY

US Army Corps of Engineers

Washington, DC 20314-1000

Under Civil Works Research Work Unit 32280

Monitored by Engineering and Materials Division

US Army Construction Engineering Research Laboratory

P.O. Box 4005, Champaign, Illinois $61824-4005$ 
The following two letters used as part of the number designating technical reports of research published under the Repair, Evaluation, Maintenance, and Rehabilitation (REMR) Research Program identify the problem area under which the report was prepared:

\section{Problem Area}

CS Concrete and Steel Structures

GT Geotechnical

HY Hydraulics

co Coastal
Problem Area

EM Electrical and Mechanical

El Environmental Impacts

OM Operations Management

The contents of this report are not to be used for advertising, publication, or promotional purposes. Citation of trade names does not constitute an official endorsement or approval of the use of such commercial products.

COVER PHOTOS:

TOP - Miter lock gate at Old Hickory Lock and Dam on the Cumberland River in the Nashville District.

BOTTOM - Aerial view of Mississippi River Lock and Dam No. 16 in the Rock Island District.

USACEWES 


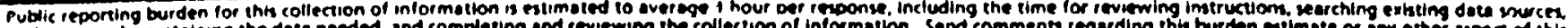

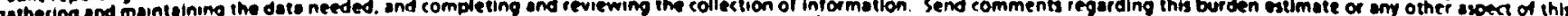

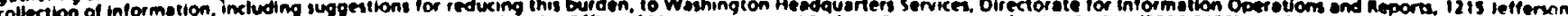

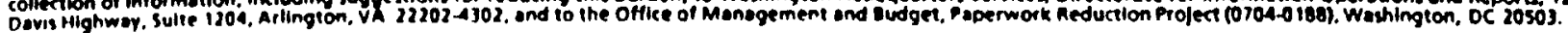

\begin{tabular}{|c|c|c|}
\hline 1. AGENCY USE ONLY (Leave blank) & $\begin{array}{l}\text { 2. REPOAT DATE } \\
\text { August } 1990\end{array}$ & $\begin{array}{l}\text { 3. REPORT TYPE ANC } \\
\text { Fina } 1\end{array}$ \\
\hline
\end{tabular}

4. TITLE AND SUETITLE

Inspection and Rating of Miter Lock Gates

6. AUTHOA(S)

Gre1mann, Lowe11; Stecker, James; and Rens, Kevin
5. FUNDING NUMBERS

Research Unit: 32280

$$
\begin{aligned}
& \text { Ty } \\
& 10= \\
& n: \therefore ;
\end{aligned}
$$

6. PERFORMING ORGANIZATION REPOAT MUMDER

Engineering Research Institute

Iowa State University

Ames, IA 50011

\section{SPONSORING/MIONITORING AGENCY NAME(S) AND ADDRESS(ES)}

Engineering and Materials Division

US Army Construction Engineering Research Laboratory

P.0. Box 4005

Champaign, IL 61824-4005

\section{SPONSORING/MONITOAING} AGENCY REPORT NUMBER

Technical Report REMR-OM-7

11. SUPPLEMENTARY NOTES A report of the Operations Management problem area of the Repair, Evaluation, Maintenance, and Rehabilitation (REMR) Research Program. Avallable from National Technical Information Service, 5285 Port Royal Road, Springfield, VA 22161.

\begin{tabular}{l|l}
\hline 12a. DISTRIBUTION/AVAILABILITY STATEMENT & 12b. DISTRIOUTION CODE
\end{tabular}

Approved for public release; distribution unlimfted.

13. AGSTRACT (Maximum 200 words)

The obfectlves of this work are (1) to develop an inspection and rating system that uniformly and consistently describes the current condition of miter lock gate structures and (2) to develop guidelines for the maintenance and repair of these structures. Only the first objective is addressed in this report.

This report gives a general description of the current inspection and rating system. This includes the definition of a condition index and a description of miter lock gate distresses. A detailed description of the inspection process follows. Once the inspection data have been gathered, they

\begin{tabular}{|c|c|c|c|}
\hline \multirow{2}{*}{$\begin{array}{l}\text { 14. SUaifC TERMS } \\
\text { miter lock gate } \\
\text { maintenance } \\
\text { repair }\end{array}$} & \multirow[t]{2}{*}{ Inspection } & & $\begin{array}{l}\text { 15. NUMBER OF PAGES } \\
105 \\
\end{array}$ \\
\hline & & & 16. PAICE CODE \\
\hline $\begin{array}{l}\text { 17. SECURITY CLASSIFICATION } \\
\text { OF REPOAT } \\
\text { UNCLASSIFIED }\end{array}$ & $\begin{array}{l}\text { 18. SECUAITY CLASSIFICATION } \\
\text { OF THIS PAGE } \\
\text { UNCLASSIFIED }\end{array}$ & $\begin{array}{l}\text { 19. SECURITY CLASSIFICATION } \\
\text { OF ABSTRACT } \\
\text { UNCLASSIFIED }\end{array}$ & $\begin{array}{l}\text { 20. LIMITATION OF AESTRACT } \\
\text { SAR }\end{array}$ \\
\hline
\end{tabular}
are filed on a computer disk through a microcomputer program. The program then computes the structural and functional condition indexes for miter lock gates. 
This study was authorized by Headquarters, US Army Corps of Engineers (HQUSACE), under Civil Works Research Unit 32280, "Development of Uniform Evaluation for Procedures/Condition Index for Deteriorated Structures and Equipment," for which Dr. Anthony M. Kao was Principal Investigator. This work unit was part of the Operations Maintenance Problem Area of the Repair, Evaluation, Maintenance, and Rehabilitation (REMR) Research Program sponsored by HQUSACE. Mr. Jim Crews (CECW-OO) was the REMR Technical Monitor.

Mr. Jesse A. Pfeiffer, Jr., (CERD-C) was the REMR Coordinator at the Directorate of Research and Development, HQUSACE; Mr. Jim Crews and Dr. Tony C. Liu (CEEC-ED) served as the REMR Overview Committee; Mr. William F. MCCleese (CEWES-SC-A), US Army Engineer Waterways Experiment Station, was the REMR Program Manager; and Dr. Kao was also the Problem Area Leader for the Operations Management Problem Area.

The study was performed by the College of Engineering, Iowa State University, under contract to the US Army Construction Engineering Research Laboratory (USACERL). Principal Investigators for ISU were Professors Lowell Greimann and James Stecker. Kevin Rens was the research assistant.

The study was conducted under the general supervision of $D r$. $R$. Quattrone, Chief of Engineering and Materials Division (EM), USACERL, and under the direct supervision of Dr. Anthony M. Kao, EM, who was the Contracting officer's Representative. The technical editor was Patrick o'Hayer, Information Management office.

COL Everett $R$. Thomas was the Commander and Director of USACERL and Dr. L. R. Shaffer was Technical Director. 
PART I : INTRODUCTION

Background abectives and scope

Mode of Technology Transfer

Overview

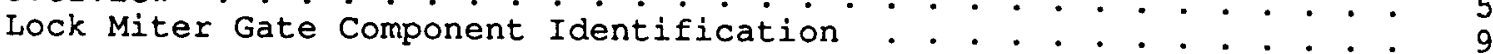

PART II: FIELD INSPECTION . . . . . . . . . . . . . . . . . . . . . 17

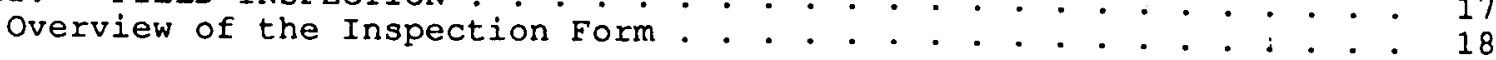

PART III: STRUCTURAL CONDITION INDEX . . . . . . . . . . . . . . . . . . 44

Structural Analysis... . . . . . . . . . . . . . . . . . . . . . . . 44

Loads . . . . . . . . . . . . . . . . . . . . . . . . . . . . . . . . 45

Component Condition Index for Each Load Case . . . . . . . . . . . . . . . . . 47

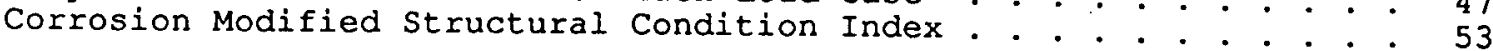

PART IV: FUNCTIONAL CONDITION INDEX . . . . . . . . . . . . . . . . . 55

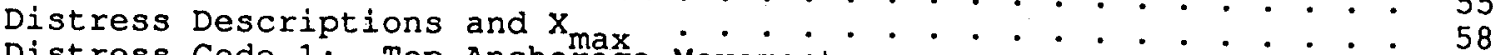

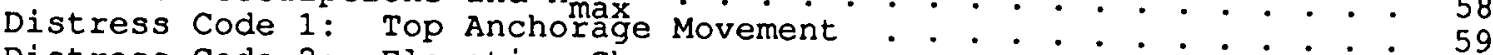

Distress Code 2: Elevation Change . . . . . . . . . . . . . . . . . . . . . . 62

Distress Code 3: Miter offset . . . . . . . . . . . . . . . . . . 65

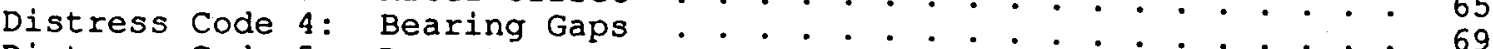

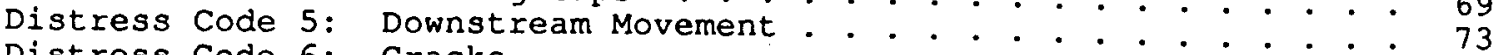

Distress Code 6: Cracks . . . . . . . . . . . . . . . . . . . . . 75

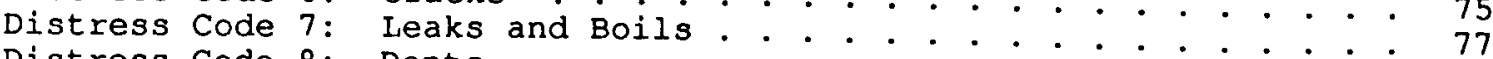

Distress Code 8: Dents . . . . . . . . . . . . . . . . . . . . . . . . . . . . . . 80

Distress Code $9:$ Noise and vibration . . . . . . . . . . . . . . . . . . . . . . 82

Distress Code 10: Corrosion ............... . . . . . . . . . . . 83

Multiple Distresses . . . . . . . . . . . . . . . . . . . . . . . . . . . 89

Field Testing. . . . . . . . . . . . . . . . . . . . . . . . . . . 90

PART V: SUMMARY AND CONCLUSIONS . . . . . . . . . . . . . . . . . . . 102

Summary jons and

REFERENCES

103

APPENDIX: SAMPLE COMPUTER RESULTS 
Condition Index Scale

Condition Index zones

Distresses in Lock Miter Gates

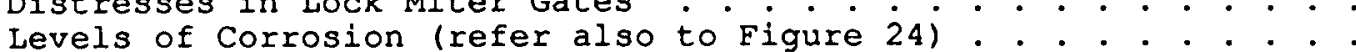

Unadjusted Weighting Factors for Distresses

\section{LIST OF. FIGURES}

Maintenance and repair analysis of miter lock gate . . . . . . . 6

Lock and dam facility. . . . . . . . . . . . . . . . . . . . . 10

Horizontally framed miter lock gate. . . . . . . . . . . . . . . 11

Vertically framed miter gate . . . . . . . . . . . . . . . . . . 11

Tapered end and quoin post . . . . . . . . . . . . . . . . 12

Floating pintle assembly . . . . . . . . . . . . . . . . . . 13

Upper anchorage assembly . . . . . . . . . . . . . . . . . . . . 15

Double linkage pin assembly (dimensions) . . . . . . . . . . . . . . 16

Inspection form... . . . . . . . . . . . . . . . . . . . 20

Double linkage pin assembly (components) . . . . . . . . . . . . 38

Miter block offset . . . . . . . . . . . . . . . . . . . . 39

Gaps, downstream movement . . . . . . . . . . . . . . . . . . . 40

Leaf geometry... . . . . . . . . . . . . . . . . . . . . . . 41

Water elevations (computer input) . . . . . . . . . . . . . . . 42

Component geometry .. . . . . . . . . . . . . . . . . . . . . 43

Water elevations . . . . . . . . . . . . . . . . . . 4 46

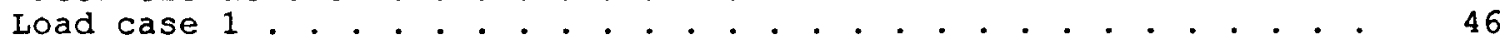

Relationship between factor of safety and safety condition index $(E q 1)$. . . . . . . . . . . . . . . . 49

Three-hinged arch . . . . . . . . . . . . . . . . . . . . . . . 49

Forces and reactions on miter lock gate . . . . . . . . . . . . . 50

Contributory area for intercostal . . . . . . . . . . . . . . . 52

Functional condition index related to $\mathrm{x} / \mathrm{x}_{\max }(\mathrm{Eq} 14)$. . . . . . 57

Miter block offsets (contact and angular) . . . . . . . . . . 66

Corrosion inspection areas . . . . . . . . . . . . . . . . . . 83

Level 1: Minor surface scale or widely scattered small pits

Level 2: Considerable surface scale andor moderate pitting. . . . . . . . . . . . . . . . . . .

Level 3: Severe pitting in dense pattern, thickness reduction in local areas .................... . 87

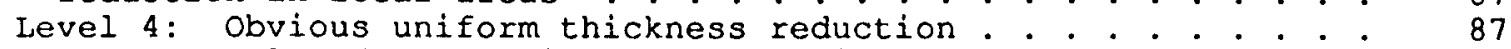

Level 5: Holes due to thickness reduction and general thickness reduction... . . . . . . . . . . . . . . 88

Weight adjustment factor for subjective condition index . . . . . 91

Anchor movement distress . . . . . . . . . . . . . . . . . . . . 94

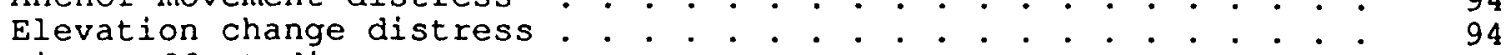

Miter offset distress. . . . . . . . . . . . . . . . . . . . . . 95

Gaps at bearing surface distress . . . . . . . . . . . . . . . . 96

Downst ream movement . . . . . . . . . . . . . . . . . . . . . . . 96

Crack distress . . . . . . . . . . . . . . . . . . . . . . . . . 97

Leak and boil distress . . . . . . . . . . . . . . . . . . . . 98

Dent distress... . . . . . . . . . . . . . . . . . . . . . . . 99

Noise, jump, and vibration distress. . . . . . . . . . . . . . . 99

Corrosion distress . . . . . . . . . . . . . . . . . . . . . . . 100

overall ratings....................... . . . . . 101 


\section{PART I: INTRODUCTION}

\section{Background}

1. The US Army Corps of Engineers has acquired and completed a large inventory of civilian projects over the past 100 years. For much of this time the corps concentrated on design and construction of new facilities, such as locks and dams on navigable inland waterways and coastal systems, as well as power generation. Recently the mission of the Corps has been shifting from construction of new facilities to maintenance of existing facilities because many existing structures are nearing the end of their design life, and fewer opportunities for expansion of Corps projects are available. The corps has addressed its changing role by instituting a Repair, Evaluation, Maintenance, and Rehabilitation (REMR) program. As this name implies, maintenance encompasses several stages. To some extent, each stage requires the development of a new technology and methodology.

2. As a part of this program, the project team at Iowa State University (ISU) performed research focusing on evaluation and repair of miter lock gate structures in the Corps' civilian projects. Miter lock gates are an important operating component of a lock and dam facility. If they fail to function or function improperly, the operation of the lock is severely affected. Often, only one lock is available at a dam site, and if it does not function, navigation along the entire river can be delayed, with subsequent large user costs. Miter lock gates are probably the most frequent cause of lock shutdown for repair and maintenance.

\section{Objectives and scope}

3. The overall objectives of this work are twofold:

a. To develop a uniform procedure to describe the current condition of miter lock gate structures.

b. To develop guidelines for the maintenance and repair of these structures.

The scope of this report is limited to the first objective. A complete report summarizing work on both objectives is scheduled for later this year. 
4. It is recommended that the inspection procedures for miter lock gates developed in this study be incorporated into Engineer Regulation (ER) 1110-2-100, "Periodic Inspection and Continuing Evaluation of Completed Civil Works Structures."

\section{Overview}

5. The concepts presented for the maintenance management of miter lock gates rely heavily on a similar project for steel sheet pile structures (Greimann and Stecker 1989). During that earlier work, ideas such as structural and functional condition indexes, safety and serviceability, quantification of distresses by field measurements, limiting values of distresses, and repair and maintenance alternatives began to evolve. As these concepts were applied to miter lock gates, several enhancements became apparent, and some new ideas appeared.

6. The project team at ISU held many meetings with Corps personnel and conducted site visits and field investigations at many lock and dam facilities, and several considerations for miter lock gates were identified. Corps experts conveyed their opinions on the critical components of miter lock gate operation and repair. They suggested means of quantifying these components and relating them to the overall condition of the miter gates. The project team took the experts' comments and formulated them into an inspection procedure and a tentative set of rating rules. Field tests of the inspection form and rating rules were conducted at five gate sets. At each test site, improvements to the rules and inspection process were suggested by the experts. Insofar as was possible, except for cases of conflicting expert opinion, the suggestions were incorporated into this work.

Field inspection

7. The maintenance and repair procedure is illustrated schematically in Figure 1. The process is based on a good field inspection of the miter lock gate structure. During this inspection, current physical attributes of the systems are obtained. Data, such as the location of the gate, inspection history, historical water level, and maintenance history; are recorded on thefirst two pages of the inspection form. Other inspection form pages are used to describe some structural details such as girder cross sections, skin plate, and intercostal size. The information on these pages is used as the basis for a structural evaluation of the gate. Additional pages provide space for several field measurements such as anchorage movements, elevation changes, downstream movement, cracks, dents, and corrosion. These measurements are used directly to rate the condition of the gate. 


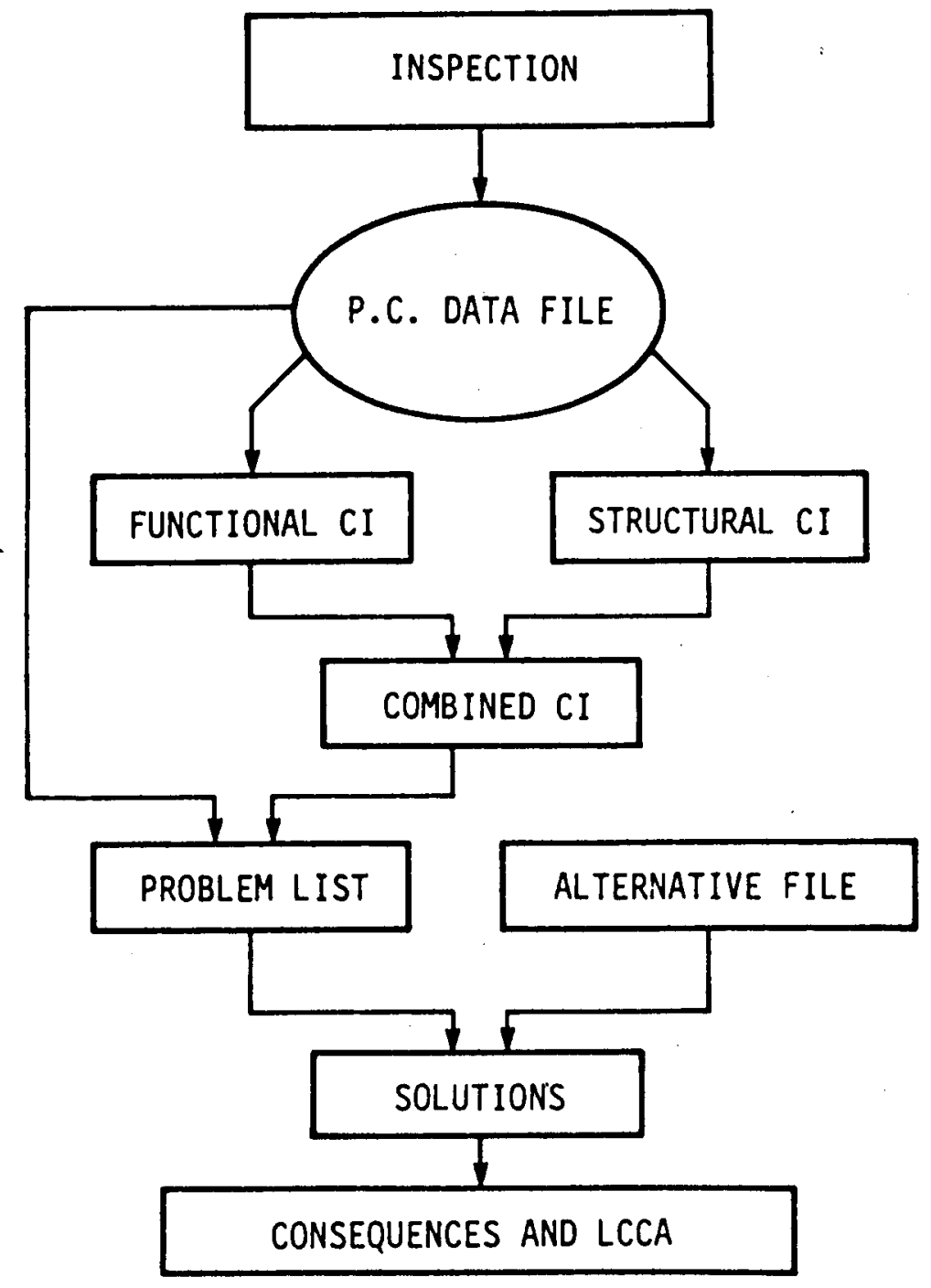

Figure 1. Maintenance and repair analysis of miter lock gate

8. The information collected on the inspection form is entered into a data file through a program called MITER on a microcomputer. The program permits file editing and handles the data for all succeeding steps.

Condition index

9. The rating process is the next step. Information in the inspection data is used in MITER to calculate a condition index (CI) for the structure. A condition index is a numerical measure of the current state of a structure. It is part of the goal of this project to define a condition index that uniformly and consistently describes and ranks the condition of miter lock gate structures. The condition index is primarily a planning tool, with the index values serving as an indicator of the general condition level of the 
structure. The index is meant to focus management attention on those structures most likely to warrant immediate repair or further evaluation. In addition, the $C I$ values can be used to monitor change in general condition over time and can serve as an approximate comparison of the condition of different structures.

10. A common CI definition for the REMR work has evolved: The REMR condition index is a numbered scale, from 0 to 100 , indicating the relative need to perform REMR work because of functional and structural deterioration. The condition index scale in Table 1 has been adopted. For management purposes, the condition index scale is calibrated to group structures into three categories or zones (Table 2).

11. Two general structural criteria for evaluating the condition index are available: safety and serviceability. Safety relates to structures' performance beyond normal service conditions; for example, under abnormal conditions such as excessive load. Serviceability relates to the performance of a structure under normal service conditions, such as, excessive leakage. Two condition indexes were formulated to describe the structure relative to these criteria. The first, the structural condition index, is based on a structural analysis of the miter lock gate structure. It primarily includes safety aspects. The second, the functional condition index, is based on field measurements of the distresses and the opinion of experts. It includes both safety and serviceability aspects. (Parts III and IV deal with these two condition indexes in more detail.)

12. As the condition index zones in Table 2 indicate, one purpose of the condition index is to draw attention to a particular problem that may require further investigation (e.g., zone 3 ). In this regard, the combined condition index or, simply, the condition index will be defined as follows:

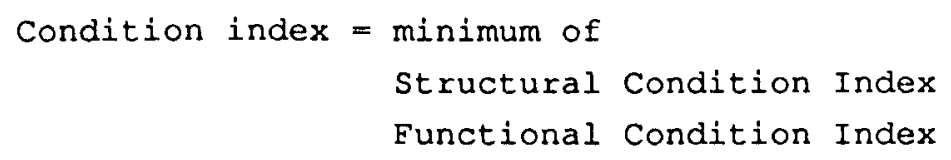

if the structure has a poor condition index, the engineer is alerted and can trace back to determine whether the cause is a low structural or functionai condition index. Indeed, the engineer would presumably trace back through the entire rating process and possibly conduct a more detailed field inspection or structural analysis to establish the basic cause. Experience indicates that major structural and mechanical problems sometimes develop without warning. Therefore, a District should not become complacent about the condition of a gate as a result of a favorable condition index. Experienced engineers should be relied upon to make judgments regarding the significance of the condition index. 
Table 1

Condition Index Scale

\begin{tabular}{|c|c|}
\hline Value & Condition Description \\
\hline $85-100$ & Excellent--No noticeable defects, some aging or wear visible \\
\hline $70-84$ & Very Good--Only minor deterioration or defects evident \\
\hline $55-69$ & $\begin{array}{l}\text { Good--Some deterioration or defects evident, function not } \\
\text { impaired }\end{array}$ \\
\hline $40-54$ & Fair--Moderate deterioration, function not seriously impaired \\
\hline $25-39$ & $\begin{array}{l}\text { Poor--Serious deterioration in at least some portions of } \\
\text { structure, function seriously impaired }\end{array}$ \\
\hline $10-24$ & Very Poor--Extensive deterioration, barely functional \\
\hline $0-9$ & $\begin{array}{l}\text { Failed--General failure or failure of a major component, no } \\
\text { longer functional }\end{array}$ \\
\hline
\end{tabular}

Table 2

Condition Index Zones

\begin{tabular}{|c|c|l|}
\hline Zone & CI Range & \multicolumn{1}{|c|}{ Action } \\
\hline \hline 1 & $70-100$ & Immediate action not required \\
\hline 2 & $40-69$ & $\begin{array}{l}\text { Economic analysis of repair alternatives } \\
\text { recommended to determine appropriate maintenance } \\
\text { action }\end{array}$ \\
\hline 3 & $0-39$ & $\begin{array}{l}\text { Detailed evaluation required to determine the } \\
\text { need for repair, rehabilitation or } \\
\text { reconstruction, safety evaluation required }\end{array}$ \\
\hline
\end{tabular}


13. After an evaluation of the current condition of the structure, the user will want to evaluate different maintenance and repair alternatives. This subject will be addressed in a subsequent report.

\section{Lock Miter Gate Component Identification}

14. To inspect and rate miter lock gate structures, the user must clearly identify their components; definitions for these components are presented in the following paragraphs. Figure 2 illustrates a typical lock and dam facility.

15. Horizontal girders are plate steel sections that span horizontally. Their main function is to transfer load to the quoin. In the horizontally framed miter lock gate (Figure 3), the load is transferred from the skin plate through the horizontal girders and back into the lock wall. The bottom horizontal girders on a horizontally framed gate does not transfer load into framed gate (Figure 4), two horizontal girders carry the load from the vertical girders. The top girder then transmits the load to the lock wall. Figure 3. Horizontally framed miter lock gate vertical girders. The top girder then transmits the load to the lock wall. The bottom horizontal member transfers the load directly into the sill.

16. Vertical girders are plate steel sections that span vertically to transfer load to the horizontal girders. In the vertically framed gate (Figure 4), the load is transferred from the skin plate through the vertical girders to the top and bottom horizontal girder.

17. A skin plate is welded (sometimes riveted) between girders to provide vertical stiffness to the gate leaf. The skin plate dams the water and acts as part of the upstream flange of the girders.

18. The horizontal girders are connected vertically by several intermediate diaphragms and two end diaphragms, one at the quoin end and one at the miter end of the horizontally framed miter lock gate in Figure 3 . The end diaphragms also serve to dam the water in the tapered end section (Figure 5). The vertically framed gate contains no diaphragms.

19. Intercostals are provided between diaphragms on the horizontally framed gate (Figure 3) and between girders on the vertically framed gate (Figure 4). Intercostals serve to stiffen and support the skin plate.

20. The thrust diaphragm shown in the tapered end section of Figure 5 distributes the horizontal girder reactions from the quoin block into the girder webs.

21. The quoin block (located on the gate leaf) and the wall quoin (located on the concrete monolith) transmit bearing forces from the gate to the lock wall. The wall quoin has a concave surface and the quoin block has a 


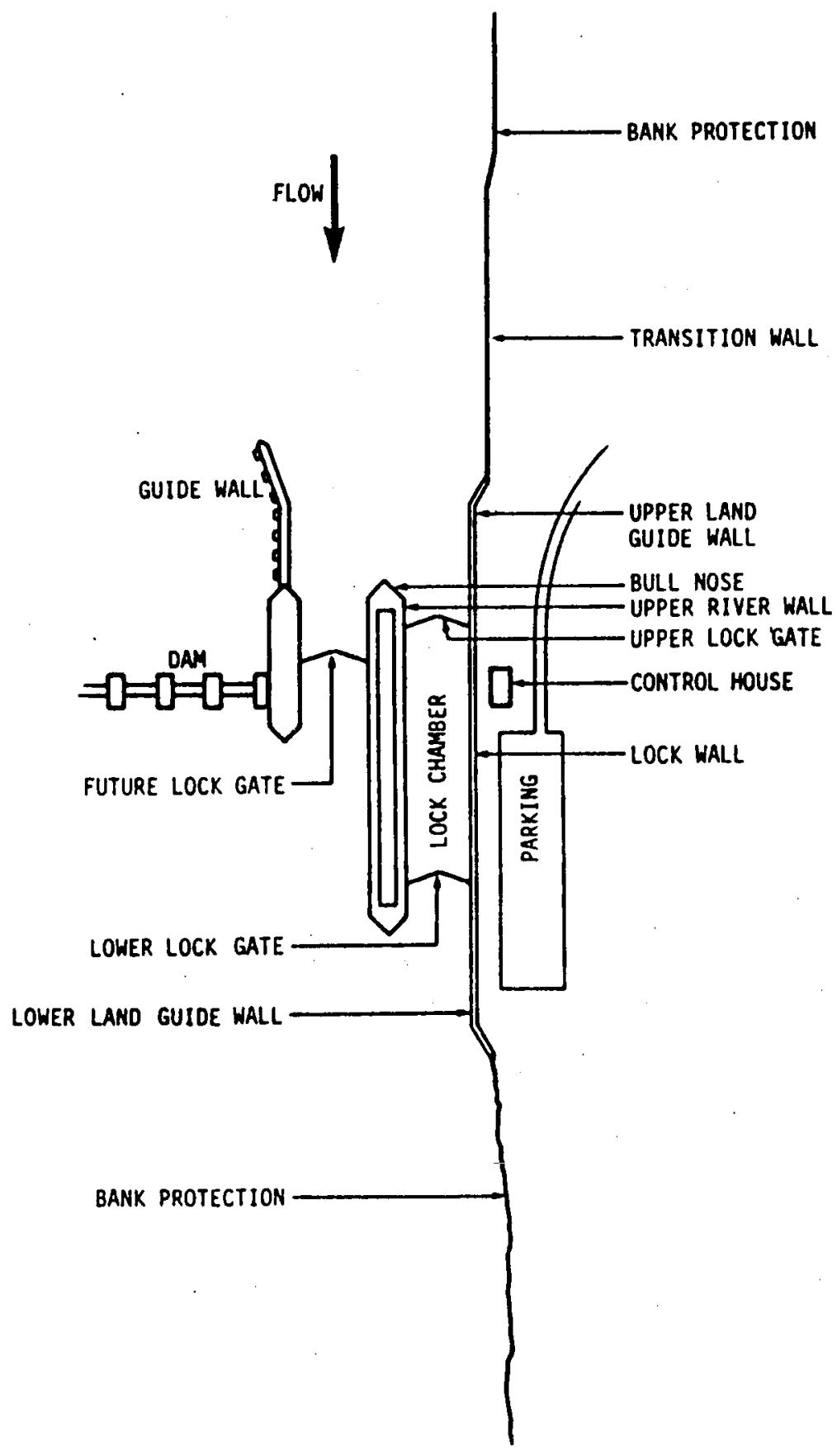

Figure 2. Lock and dam facility 


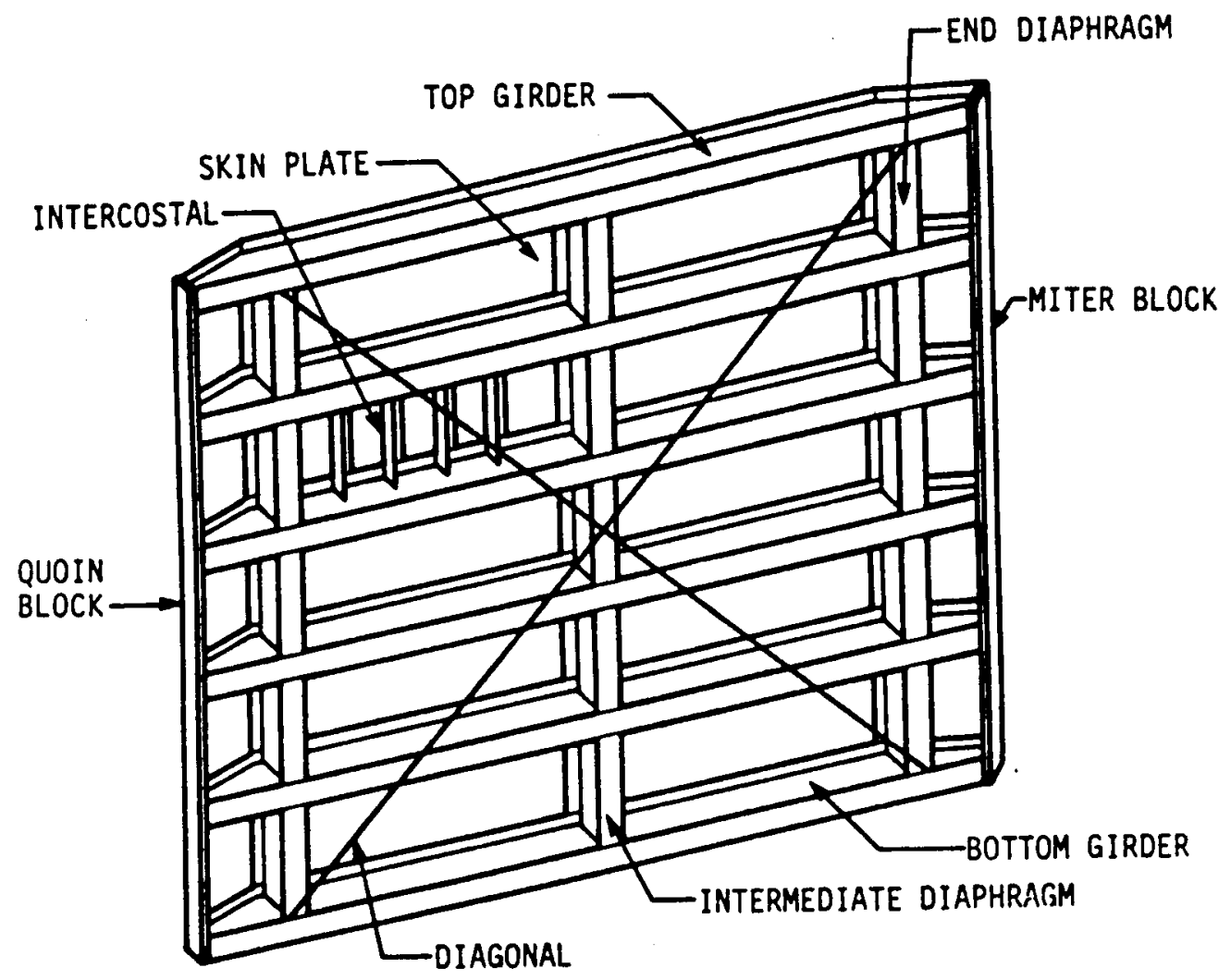

Figure 3. Horizontally framed miter lock gate

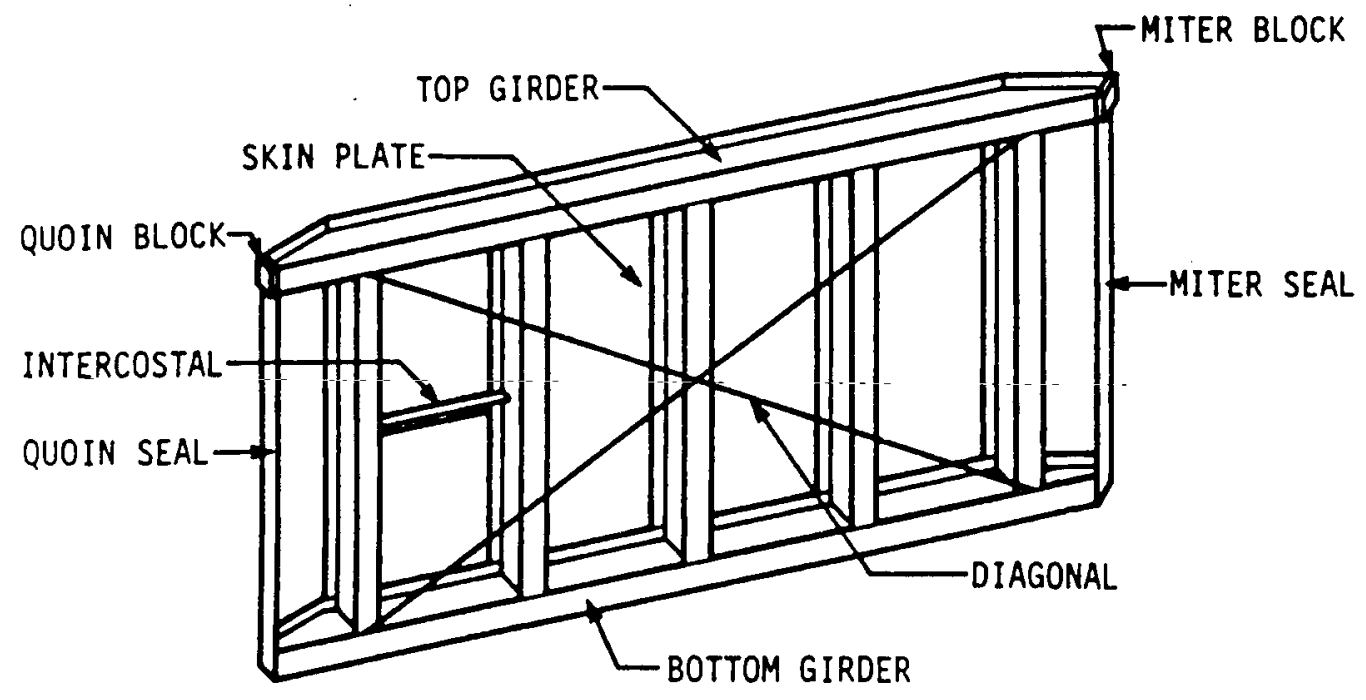

Figure 4. Vertically framed miter gate 


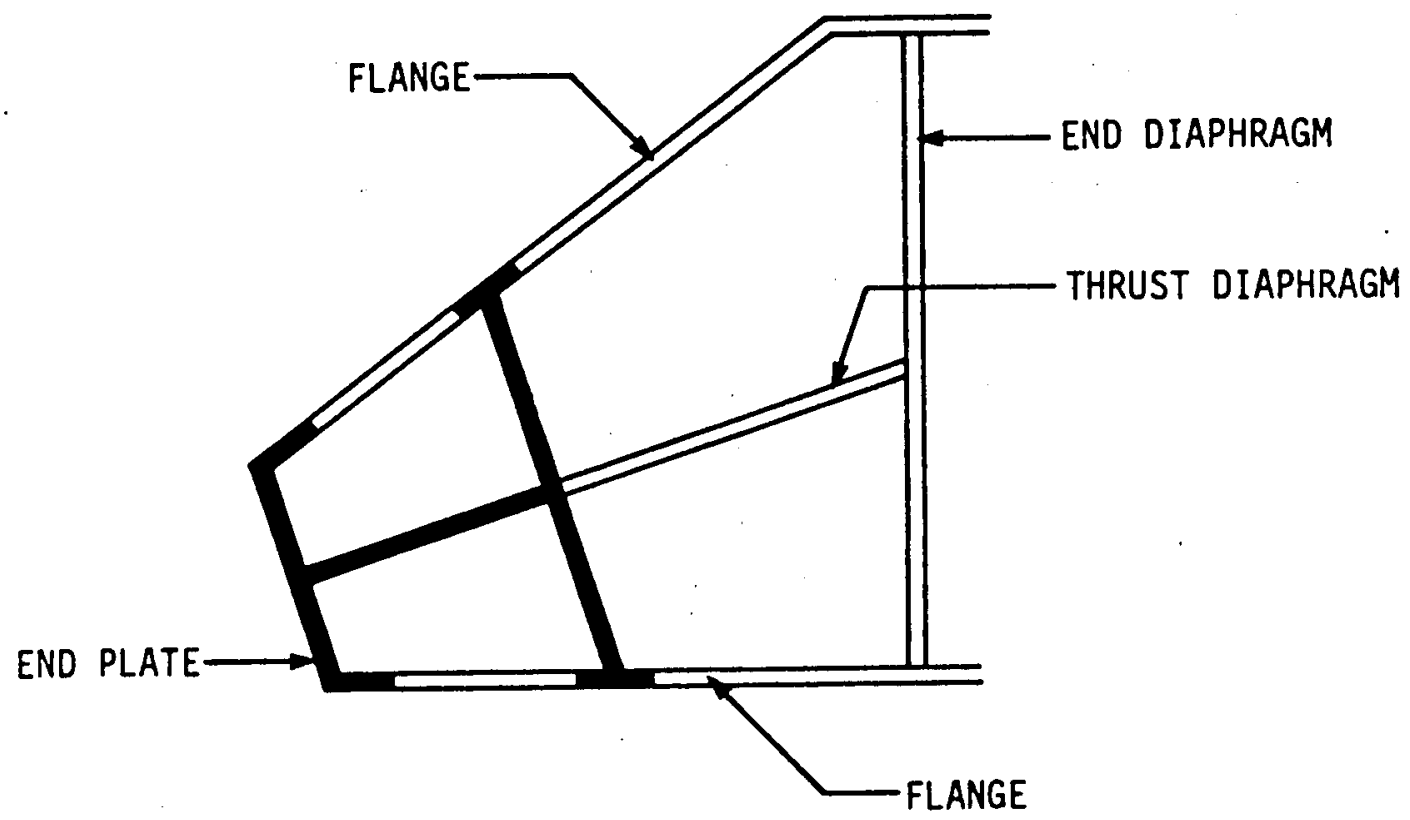

Figure 5. Tapered end and quoin post

convex surface of about the same radius. These two surfaces bear on each other when the gate is in the mitered position. On horizontally framed gates, the quoin block and wall quoin are continuous from the top of the gate to the bottom (Figure 3). On vertically framed gates (Figure 4), load is transferred into the lock wall at the top and bottom horizontal girder, and the quoin block and wall quoin are present only at these locations.

22. The miter blocks are located at the miter end of the horizontal girders. Miter blocks serve to transmit the axial load of the girders between the two leaves in the mitered position. On horizontally framed gates, miter blocks (like quoin blocks) are continuous along the entire height of the gate. on vertically framed gates, miter blocks (like quoin blocks) are present only at the top and bottom horizontal girder.

23. Pintle assemblies used for both horizontally and vertically framed miter lock gates consist of two types: floating and fixed. The floating pintle (Figure 6) fits into a cast steel shoe that is not fastened to the pintle base, allowing the lower corner of the gate leaf to move outward if debris is lodged in the quoin. The fixed pintle fits into a cast steel shoe that is bolted to the pintle base. Keyed pintles, which permit sliding in only one direction, are also used. 
24. Strut arms that open and close the gates apply a concentrated force at the top of the gate. This force and the dead weight of the gate are eccentric with respect to the center of gate stiffness, and they cause the leaf to twist out of plumb. On most horizontally framed gates, the skin is located on the upstream side of the leaf. Adjustable diagonals on the downstream side are pretensioned to keep the gate plumb. For some vertically framed gates, the skin plate is located at the center of the gate, and diagonals are used on both sides of the gate. Some gates have skin on both the upstream and downstream face and do not have diagonals.

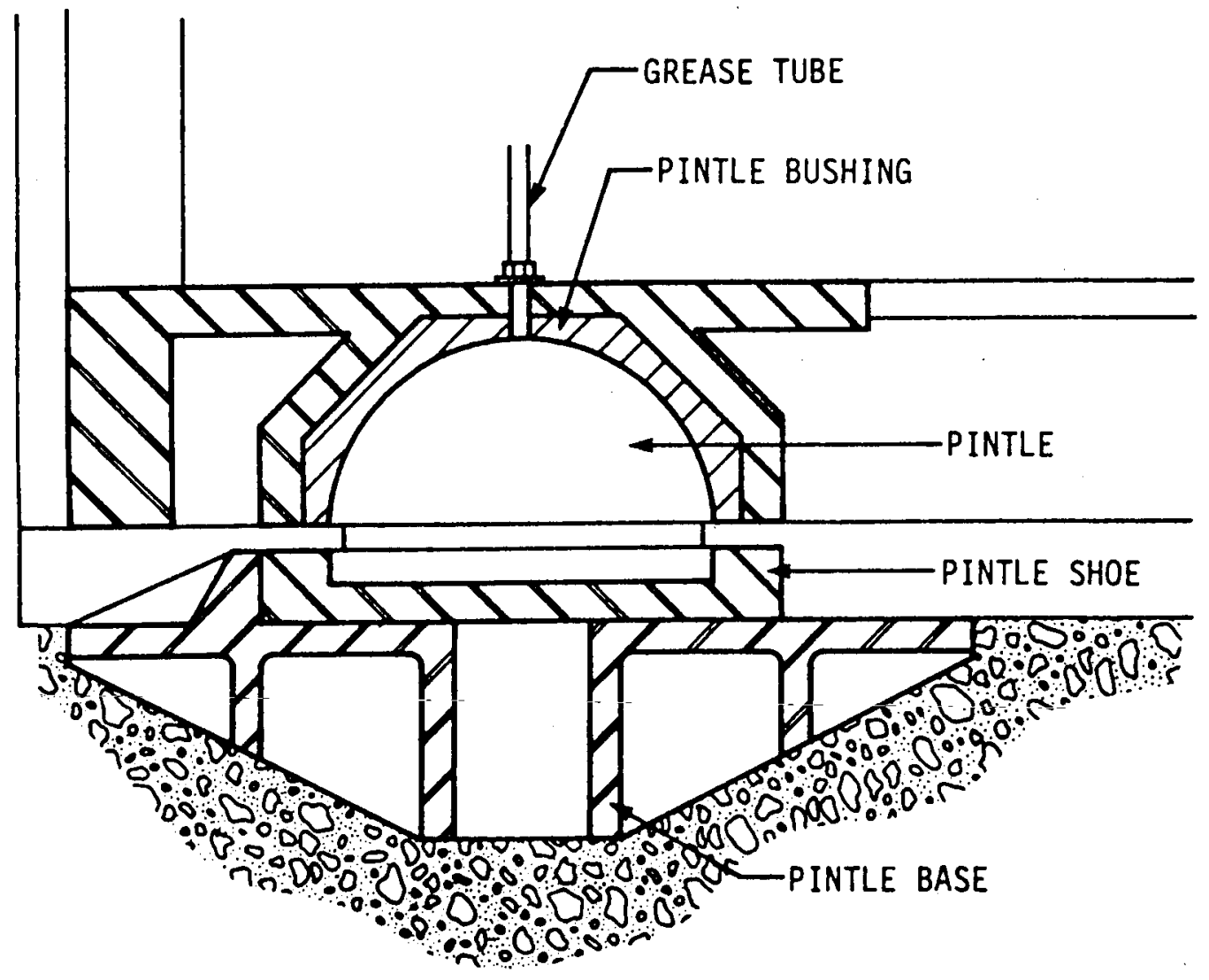

Figure 6. Floating pintle assembly 
25. Embedded anchorages distribute the top reaction of the leaf into the concrete wall (Figure 7).

26. The parallel and perpendicular anchorage links are made up of pinned ends connecting the gudgeon pin to the embedded anchorage. Most anchorage links have an adjustable length, typically either a threaded section or wedges (Figure 7). An alternative parallel anchorage is shown in Figure 8 . This assembly is made of two anchor links connected by a linkage pin.

27. Gudgeon pins are large-diameter pins of forged alloy steel (Figure 7). The gudgeon pin fits into a bronze bushing (Figure 7). This assembly serves as the only connection between the top of the gate and anchorage links. 28. Rubber seals are used on the bottom of horizontally framed gates. Various types of seals are used, but the most common is the round rubber seal, which is used in regions having a wide range of temperature, and the "J" seal. Seals are used at the quoin and miter on vertically framed gates. 


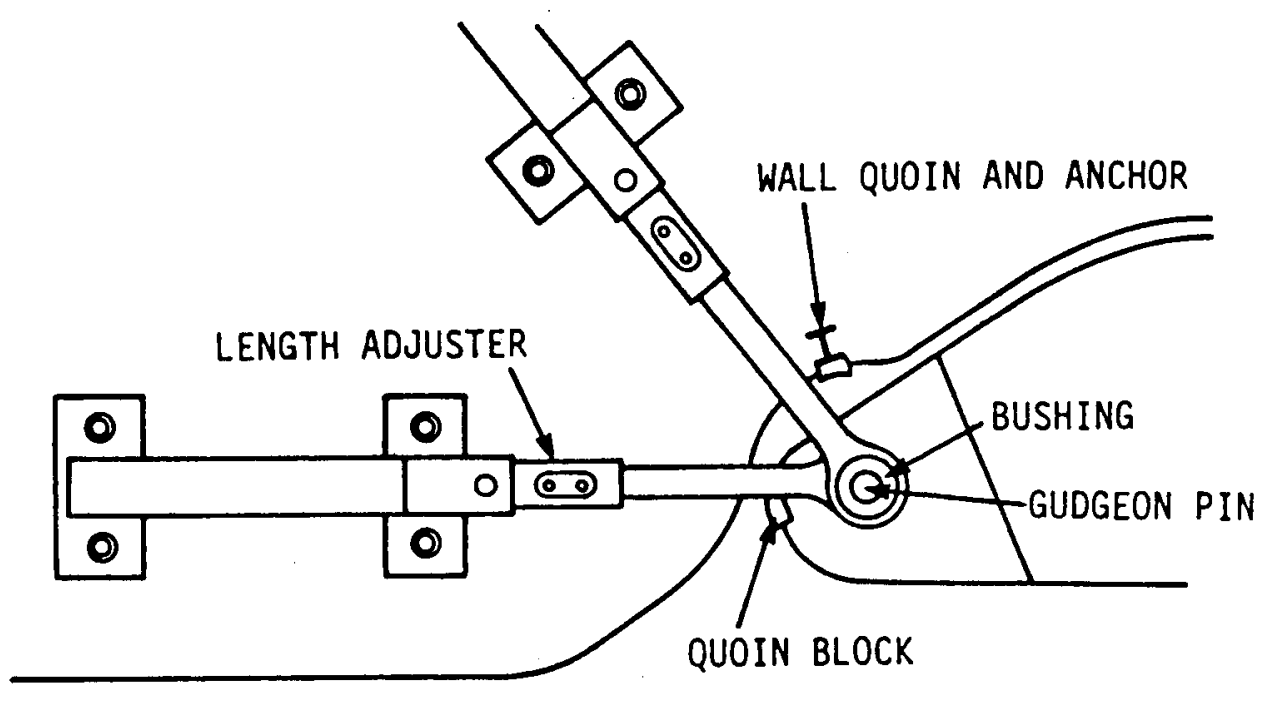

a. PLAN VIEW

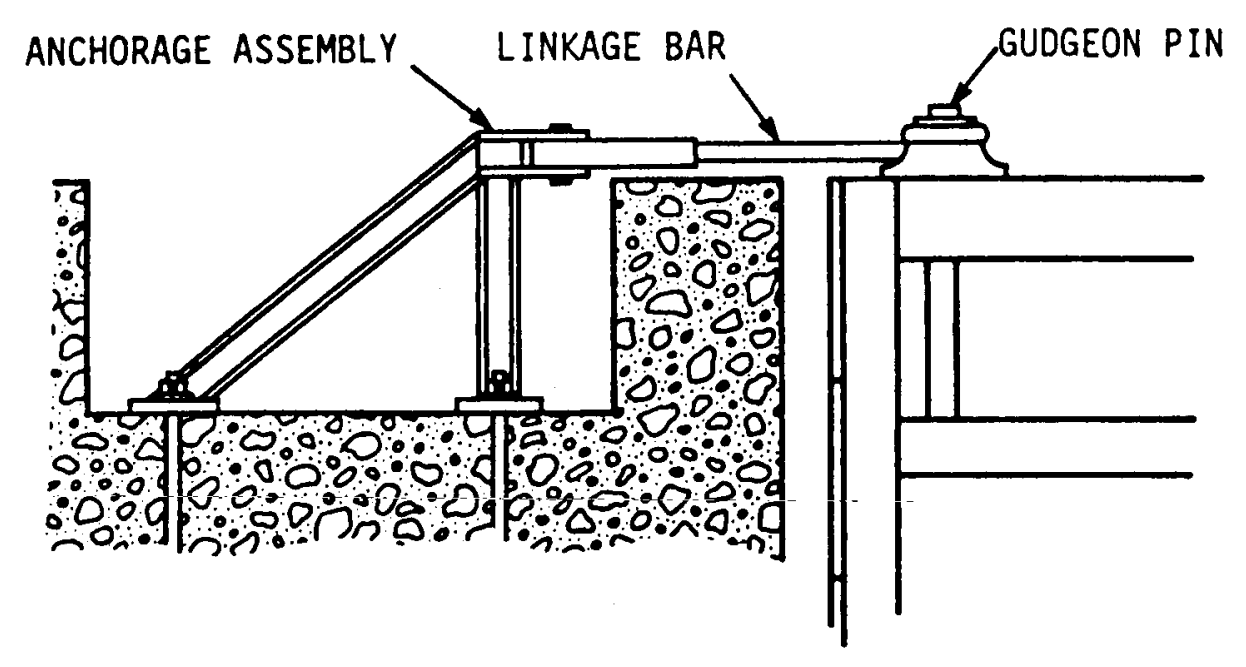

b. SECTION VIEW

Figure 7. Upper anchorage assembly 


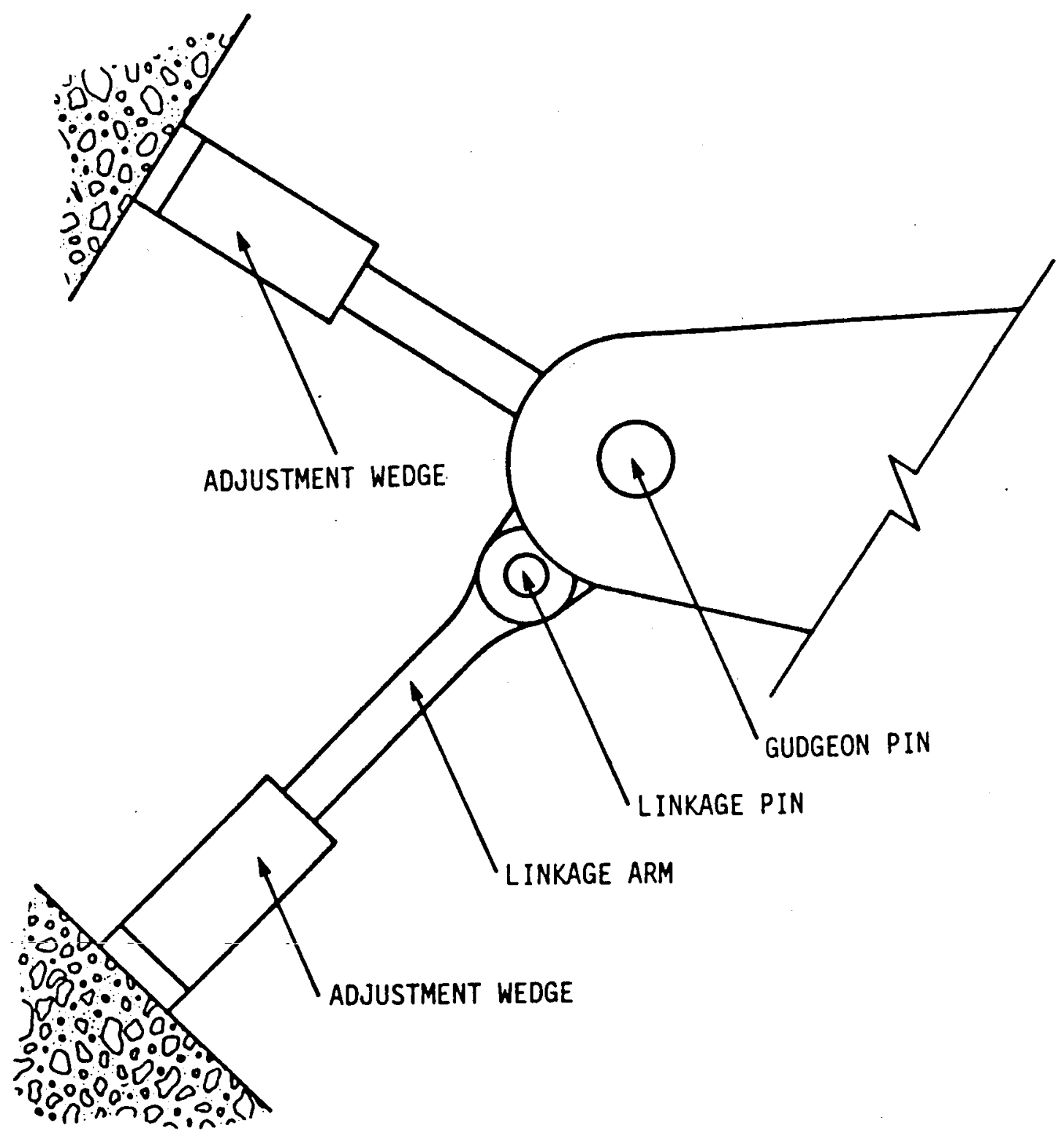

Figure 8. Double linkage pin assembly (components) 
29. The ideas behind the inspection procedure are simplicity and adaptability. As meetings and field tests with Corps personnel progressed, it became increasingly clear that any miter lock gate inspection program must be simple to learn and adaptable to different heights of gates. Current inspection procedures varied significantly among the various districts. For high-lift locks, inspection procedures tended to be more extensive, with less tolerance for misalignments and imperfections. For low-lift locks, inspection procedures were not as rigid, and more deviations from the perfect case could be tolerated.

30. With these restrictions, the field inspection had to be based on easily obtainable data, which were taken to be those obtainable from on top of the gate or the lock wall or from a boat in the lock chamber. The normal inspection would involve no underwater diving. No ultrasonic or other sophisticated devices could be used. All data would be measured by subjective observation (poor, average, good, excellent, etc.), a tape measure, a level, a ruler, dial gages, a camera, and the like. As a goal, the data would be recorded by technicians having no specific engineering training or experience in the design or construction of miter lock gate structures. Data would be collected from the gate with the lock in an operating mode, that is, not unwatered. Minimal disturbance to lock traffic was a requirement.

31. Of course, if the inspection can be conducted in conjunction with a dewatering or divers, the additional information would be useful. Inspection by diving teams would help to validate the visual inspection suggested herein. At meetings with Corps personnel, some suggested that diving be a part of the inspection while many stated that diving inspections were not warranted. For the time being, the authors have decided to go with the simplest approach.

32. The inspection process generally follows this pattern:

a. Historical information, such as drawings and previous inspections, is reviewed and recorded before a site visit.

b. A site inspection is conducted and specific visual data are recorded.

c. The inspection data are entered into a personal computer program (MITER).

33. The results of the inspection (e.g., the condition index)-areintended to be indicative only of the existing condition and must be viewed as such. For some cases, it may be necessary to return and conduct a more detailed inspection that might include diving or surveying. This will clearly be the case if a dangerous condition is indicated by the initial inspection. It is beyond the scope of this report to describe a detailed inspection and evaluation. 
34. The inspection form (Figure 9) has been designed to provide flexibility in documenting a variety of field conditions within one standard form. Though there are nine pages in the inspection form, data for the last four pages can be entered prior to the initial inspection and do not change for subsequent inspections. These pages need be entered only if the structural condition index is required. The following section illustrates the use of the inspection form; the following paragraphs briefly outline the inspection form. Historical information

35. Historical information related to the miter lock gate structure is recorded on pages 1 and 2 of the inspection form. Information includes project reference data to identify and locate the specific structure. Further data categorize the structure into a particular type and function. The information is also used to sort through the expert rules in the evaluation model. The recent history of maintenance, modifications, inspections, and the like is recorded. Finally, a section to record present-day physical conditions of nonessential miter lock gate accessories is also provided. Field measurements

36. Pages 3 to 5 of the inspection form are for recording measurements made in the field. Several measurements are requested, such as anchorage movements, bearing block gaps and offsets, downstream movements, elevations, dents, cracks, noises, leaks, and corrosion levels. All of these field measurements are used with the expert rules described in Chapter 4 to determine the functional condition index for the gates.

37. Some measurements on these pages are made at four different leaf positions:

a. Recessed: For this case, the leaf is completely open.

b. Near miter: For this position the gates are brought to and held at a location with about 4 . ft between the mitex blocks.

c. Miter, 1-ft head: The gates are brought to full miter and the valves are opened to place a nominal $1 \mathrm{ft}$ of head on the gates. The small head closes some gaps and stabilizes the gate during the measurement process.

d. Miter, full head: Full hydraulic head is applied to the gate. Structurāi components

38. Information relative to the structural components of specific, horizontally framed miter lock gate structures is recorded on pages 6 through 9 of the inspection form. If a vertically framed gate is selected on page 1 of the inspection form, pages 6 through 9 of the inspection form need not be completed. The information compiled on these pages provides the basis for an elementary review of the structural adequacy of the leaf. Most of the structural data will be recorded on the form prior to the site visit; it can be 
verified during field inspection. The information may be taken from original design drawings, as-built construction drawings, or drawings of field modifications to the structure.

\section{General notes}

39. The layout of the inspection form in Figure 9 has been designed to facilitate both the data collection process and also the computer input and evaluation model. After the initial inspection and computer modeling of a structure, the data on pages 6 through 9 of the inspection form will become relatively permanent and will require only nominal editing of computer data files to keep them current. Pages 1 through 5 of the inspection form, however, are data pages that in general must be filled out in the field during the inspection because the information is subject to change. The following pages of this manual duplicate the inspection form, with entries from a test inspection. The side-by-side arrangement of the following pages displays specific explanations adjacent to the entry on the inspection form. Pages 3 through 9 of the inspection form also have notes on how to measure and record critical data. 
NAME OP CIVIL WORKS PROJECT:
BARKLEY
LOCK ANO DAN

UPPER

GATE

LOCATION OP CIVII WORKS PROJECT: (1. BOdY of water, 2. Nearest town)

1. BARKLEY LAKE

2. GRAND PIUER, R

INSPECTION DATE: $10 / 25 / 88$ INSPECTED BY: $\frac{\text { GREIMANN, STECKER }}{\text { PENS }}$

GATE IDENTIPICATION:

1. Opper gate

2. Lower gate

GATE ID

(no.)

TYPE OP STRUCTURAL PRAMING PRESENT:

1. Horlzontal

2. Vertical

STRUCTORE TYPE (no.)

TYPE OP PINTLE:

1. Fixed

2. Ploating

PINTLE SYSTEM (no.) L

TYPE OP SKIN PLATE:

1. Single

2. Double

SKIN TYPB

(no.)

LENGTH OP LOCK CAAMBER: (ft)

WIDTH OP IOCK CHAMBER: (ft)

REIGHT OP GATE IEAP?

(ft)

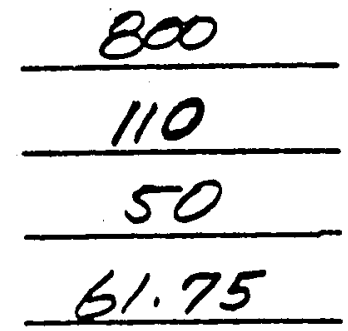

GATE WIDTH:

(ft)

PRESENT POOL WATER ILVELS: (ft) UPPER POOL $\$ 57,1$ LOWER POOL 323.3

RECORD LOW WATER LEVEL:

(ft), UPPER POOL 35.90 LOWER POOL $20.2 . ?$

RECORD HIGR WATER ILVEL: (ft).OPPER POOL 370.8 LOWER POOL 342.3

DO YOU ROUTINELY DEWATER THE LOCX ChAMBER? (Y/N) YES IF YES, WHAT YEAR WAS THE LOCK LAST DEWATERED? 1983 INTERVAL PERIOD? 5 -'S YPS

CONSTRUCTION DATE: 1966 
Page 1 Comments: Historical or Recordkeeping Data.

Completed prior to the site inspection and verified or changed during the site inspection.

Data blanks on page 1 prefaced by (No.) __ must be recorded as numbers.

Enter in NAME the Corps of Engineer Project Title.

Indicate the BODY OF WATER. This may be a river, canal or improved channel, lake, or coastline.

Indicate GATE IDENTIFICATION, TYPE OF FRAMING, TYPE OF PINTLE, and TYPE OF SKIN PLATE by entering the appropriate number in the blank following each name. Refer to the section called "Miter Lock Gate Component Identification" for descriptions and illustrative figures if additional information is required.

Enter nominal LENGTH and WIDTH of lock chamber (e.g., $600 \mathrm{ft}$. or $1200 \mathrm{ft}$.) Enter nominal WIDTH and HEIGHT of gate leaves.

Water level gage readings referenced to mean sea level. PRESENT and RECORD LOW and HIGH WATER LEVELS are important for reference.

Lock chamber dewatering periods and construction information may be important for reference. 
ARE ORIGINAL GATE LEAVES CORRENTLY IN PLACE?

ARE DRAWINGS AVAILABLE POR GATE LEAVES IN PLACE?

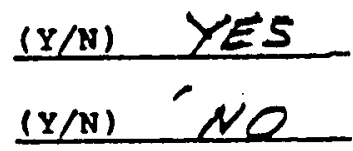

ARE THE DRAWINGS INCLUDED WITH THIS FILE?

PAST 10 YEAR RISTORY

MAJOR MAINTENANCE, REPAIRS, OR OTHER MODIPICATIONS DATE DESCRIPTION

(1):

$(2):$

(3):

(4):

PREVIOUS INSPECTIONS OR STROCTURAI REVIEWS (attach coples if avallable)
(1):
DATE DESCRIPTION
(2):
(3):
(4):
TYPE OP FENDER PROTECTION AND CONDITION OF FENDERS:
DENT IV STEEL FENDER

TYPE OF WALKWAY ON GATE LEAF AND CONDITION OP WALKWAY:

OTHER COMMENTS :

Eigure 9. Inspection form (cont.) 
Page 2 Comments: Historical or General Data.

Completed prior to the site inspection and verified or changed during the site inspection.

Gate leaves are sometimes replaced or removed during rehabilitation. It is important for later reference to record the history of the in-place gate.

The next two sections are expanding records and can record up to 10 lines of data. Dates and descriptions are entered on one line as one record. Each record is limited to 70 characters.

Record major MAINTENANCE, REPAIRS, OR OTHER MODIFICATIONS performed on the structure within the last 10 years.

Record PRESENT DAY type (steel or timber) and condition of fender protection.

Record PRESENT DAY type and condition of walkway and hand rails on gate leaf. The items noted in this section are for information only and do not affect the condition index rating of the structure. They are recorded in the inspection file for reference and so that changes can be observed. 
PACING DOWNSTREAM AT UPPER GATE, IDENTIPY IEAF AS LAND OR RIVER SIDE IEPT GATE LEAF = RIGET GATE IEAF -

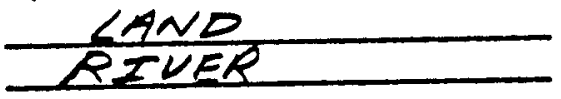

OPBNIIIG AMD CLOSIMG OF GATS IBAVBS

$\begin{array}{ll}\text { DO THE DIAGONALS PLAP? } & \frac{\text { LEFT GATE }}{(Y / N)} \\ \text { DOES THE GATE JUMP? } & \frac{(Y / N)}{(Y / N) N} \\ \text { IS THERE GATE NOISE? } & \frac{(Y / N) /}{\text { DOES THE GATE VIBRATE? }}\end{array}$
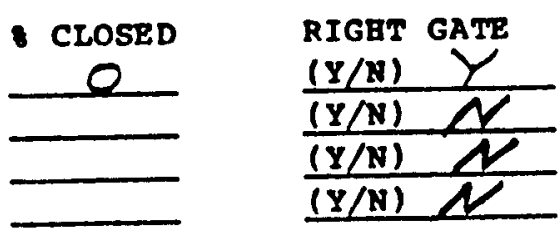

- CLOSED

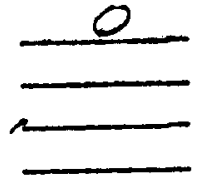

ELEVATIOAS OF GATB IBAP

IEFT LEAF

QUOIN

MITER

RECESSED

$$
\text { NEAR }
$$
MITER
MITER

I'HEAD
MITER

POLL READ

RIGHT LEAF

QUOIN $\frac{4.46}{4.53} \frac{4.47}{4.56} \frac{4.47}{4.55} \frac{4.48}{4.54}$

\section{AMCBORAGS SYSTBM MBASURBMBRT (DIm. 1, 2, 3)}

IS THE CONCRETE CRACKED OR SPALLED AT LOCATION $1 ?$

\begin{tabular}{|c|c|c|}
\hline & IEPT GATE & RIGAT GATE \\
\hline$=$ & $Y(N)$ & $(x / N) Y$ \\
\hline
\end{tabular}

IEFT GATE

ARM DIM.(in)

PARALIEL 1 :

PARALIEL 2:

PARALIEL 3:

PERP. 1:

PERP. 2:

PERP. 3:

RIGHT GATE

ARM DIM.(in)

PARALIEL 1:

PARALLEL 2:

PARALIEL 3 :

PERP. 1 :

PERP. 2:

PERP. 3 :
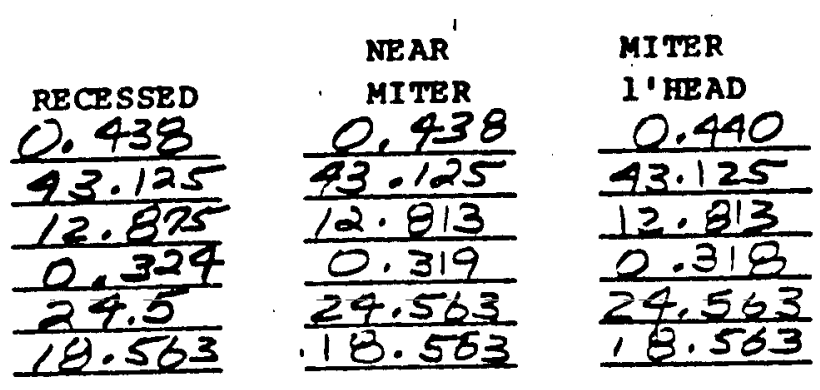

NEAR

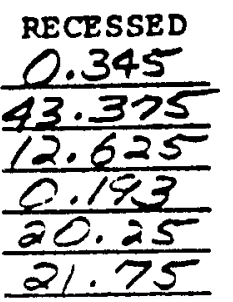

MITER

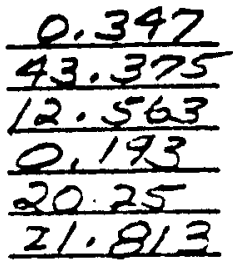

MITER

PULL HEAD

$\frac{\frac{0.441}{43.125}}{\frac{12.313}{2.320}} \frac{0.5}{18.563}$

MITER

PULL READ

1. HEAD

$\frac{0.398}{13.325}$

$\frac{12 \cdot 56}{0.194}$

20.25

$\frac{2.25}{21.875}$

Eigure 9. Inspection form (cont.) 
Page 3 Comments: Field data.

Completed at site inspection.

Record the orientation of the lock chamber relative to the land by facing downstream and identifying the left and right gate as the land or river side.

OPENING AND CLOSING OF GATE LEAVES: Observation of the gate leaves during operation (opening and closing) is a good indicator of problems. If the diagonals make a flapping noise, or if the gate vibrates (chatters), indicate the approximate positions at which the noise or vibration occurs. Similarly, record the occurrence and positions of any unusual noises or jumping movement.

ELEVATIONS OF GATE LEAVES: When the gate leaves are in the recessed position (1), measure the miter and quoin elevations of each leaf. A specific point should be identified and marked at each of the four locations, usually on the walkway, near the quoin and miter. Measurement should be made with a rod and level. Repeat this process for three additional positions: (2) near miter (approximately $4 \mathrm{ft}$ from miter), (3) miter with 1 ft of head in chamber, and (4) mitered with full head. Measurement should be recorded or interpolated to nearest $0.005 \mathrm{ft}$, e.g., 1.115 .

ANCHORAGE SYSTEM MEASUREMENT: The parallel and perpendicular anchorage arms are parallel and perpendicular, respectively, to the lock chamber. Indicate the presence of excessive concrete cracking at location 1 where the anchorage enters the concrete (Figure 10). Excessive concrete spalling may indicate that a displacement occurred at this location at some point in time and may or may not show up at a current measurement. Hairline cracks, probably caused by thermal expansion or contraction of the concrete, should be ignored in this analysis.

Measurements must be made on both parallel and perpendicular anchorage arms at four leaf positions: (1) recessed, (2) near miter (approximately 4 ft from miter), (3) mitered with $1 \mathrm{ft}$ of head, (4) and mitered full head. Dimension 1 can be measured with a dial gage attached to a magnet. The magnet is placed on the steel of the anchorage arm with the dial gage plunger pushing on the concrete wall. Displacements should be recorded to 0.001 in.

Dimension 2 can be measured with a ruler or tape measure between two scribe. marks. One scribe mark should be on each side of the length adjustment device (turnbuckle, wedges, etc.). Connection pins should be between the two scribes. As noted in Chapter 1, some anchorages have an additional pin. Measurement 2 should be made across this pin also. Measurement 2 must include movement in all linkage pieces except the concrete/steel interface (Dimension 1) and at the gudgeon pin (Dimension 3). In some cases, the measurement cannot be made between two scribe lines because of geometrical interferences. In these cases, the authors have contrived assemblages of $\mathrm{C}$ clamps and straps of steel to obtain the change in length between the two points.

Dimension 3 is also measured with a ruler or a tape measure. In the simplest case, the measurement is between a scribe point on the-gudgeon pin arm and $a^{-}$ point at the center of the gudgeon pin. The measurement is intended to detect wear in the pin and/or bushing. In most cases, the simple approach is not available because of geometric interferences. Often it is necessary to project the point on the gudgeon pin area upward, above interferences with the leaf or other obstructions. C clamps and strap steel have been used for this. often the center of the gudgeon pin is not accessible. Steel plates may have to be removed. A grease pipe may be at the pin center. A bolt or pipe may be screwed into the center, if threads are present, to extend this measurement point upward. Ingenuity is often required for this important measurement. 


\section{MITBR LOCR GATB STRDCTURE IRSPECTION}

\section{MITBR AND QDOTA BBARIMG MBASURRMBRTS}

OFFSET OF MITER BLOCKS WITH GATES AT MITER (1'HEAD), (DIM. 4, 5)

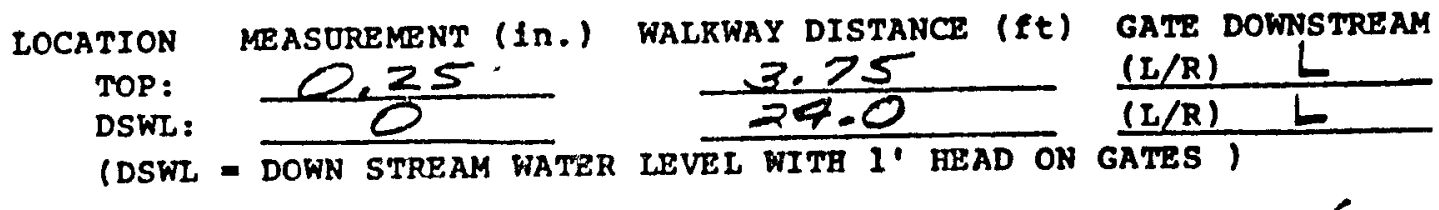
GAP BETWEEN BEARING BLOCKS WITR GATES AT MITER (1'HEAD), (DIM. 6, 7)

LOCATION

LEFT QUOIN $Q$ TOP:

LEFT QUOIN O DSWL:

RIGHT QUOIN $A$ TOP:

RIGHT QUOIN DSWL:

MITER O TOP:

MITER P DSWL:
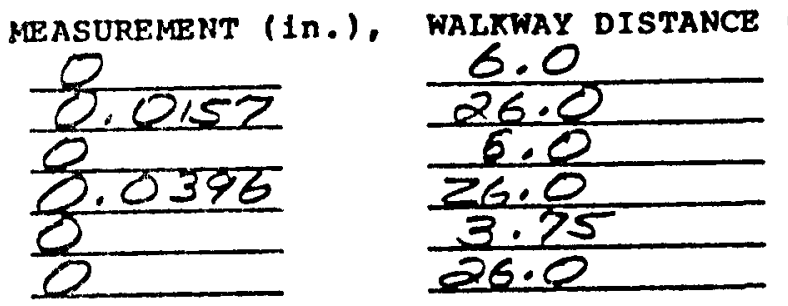

LONGITUDINAL POSITION OF MITER POINT (DIM. 8)

MEASUREMENT (In.)

LOCATION
TOP:
DSWL:

LOCK CAAMBBR PILLIHG (OR BMPTYIMG)

DOES THE GATE VIBRATE?

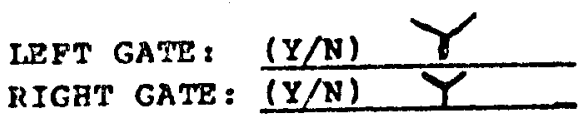

DOES A IEAK POLLOW THP RISING (OR EMPTYING)

WATER LEVEL AND THEN CLOSE NGR.IN AS THE WATER

CONTINUES TO RISE (EMPIY)?

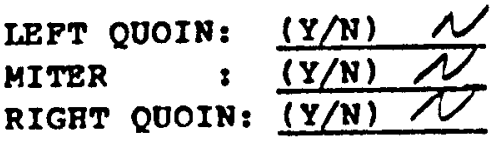

DOES THE GAP BETWEEN MITER BLOCKS CHANGE?

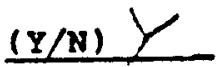

IF YES, SELECT PROM THE POLLOWING CHOICES THE MOST ACCURATE DESCRIPTION OF THE -CRANGE- (NOS) 4

1. TOP GAP INITIALLY OPTN BUT CLOSES UNDER POLL HEAD.

2. TOP GAP OPENS WIDER BU' CLOSES UNDER PULL HEAD.

3. TOP GAP OPENS AND REMAINS OPEN.

4. TOP OP MITER IS CLOSED BUT GAP OPENS BETWEEN WATER LINE AND TOP.

5. TOP OP MITPR IS CLOSED AND GAP BETWEEN WATER LINE AND TOP CLOSES.

ESTIMATE THE MAXIMUM WIDTH OF GAP (YN.)

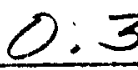

ESTIMATE THE LOCATION OP THE MAXIMUM GAP FROM THE WALKWAY (PT.)

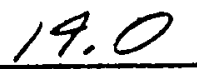


Page 4 Comments: Field data.

MITER BLOCK OFFSET: The offset of miter blocks at the top of the gate, Dimension 4, and at the downstream water level (DSWL), Dimension 5, along with the vertical distance from the walkway to each measurement can be made with a ruler and tape. See Figure 11 for illustration of miter offsets. The gate leaves should be in the mitered position with 1 foot of head in the chamber to stabilize the gates. In addition, record the relative orientation of the leaves by indicating which gate is farther downstream, left (L) or right (R), at each measurement.

BEARING BLOCK GAPS: Bearing blocks include the land quoin (LQ), river quoin (RQ) (Dimension 6, Figure 11), and the miter (Dimension 7, Figure 12). The gap measurement between bearing blocks at the top of the gate and at the downstream water level (DSWL) along with the vertical distance from the walkway to each measurement can be made with a feeler gauge or ruler and a tape measure. The gate leaves should be in the mitered position with one $\mathrm{ft}$ of head in the chamber to stabilize the gates.

LONGITUDINAL POSITION OF MITER POINT: The longitudinal position of the miter point at the top of the gate and at the downstream water level (DSWL) along with the vertical distance from the walkway to each measurement are recorded. To make this measurement, the authors have attached rulers near the miter block on a leaf at both the top and the DSWL. The rulers are oriented such that the readings increase downstream. A transit is located on the lock wall such that both rulers can be read over the edge of the wall. The vertical cross hair establishes a vertical plane from which the readings are made. These measurements should be made with the gate leaves closed with 1 ft of head in the chamber and at full head.

LOCK CHAMBER FILLING OR EMPTYING: As the lock chamber is filling, water passing underneath the gate may cause the seals to flutter (vibrate). Placing your ear near the walkway railing will amplify this noise as the gate vibrates.

Changing characteristics of the gaps may help an experienced engineer identify the cause and/or magnitude of bearing block problems. A leak between the blocks indicates a gap. If the leak stops as the water rises or falls, the gap has closed. If a LEAK FOLLOWS THE RISING (OR EMPTYING) WATER LEVEL AND THEN CLOSES AGAIN, record this occurrence. Chapter 4 discusses the implications of changing gaps.

For the visible portion of the gap above the water, answer whether THE GAP BETWEEN MITER BLOCKS CHANGES? If the answer is YES, provide the most accurate description of the gap opening and closing changes. Also, estimate the MAXIMUM WIDTH OF GAP and its LOCATION. 


\section{OBSERVATIORS FROA BOAT}

CORROSION AT SPLASH ZONE (LEVEL $0,1,2,3,4$, OF 5)

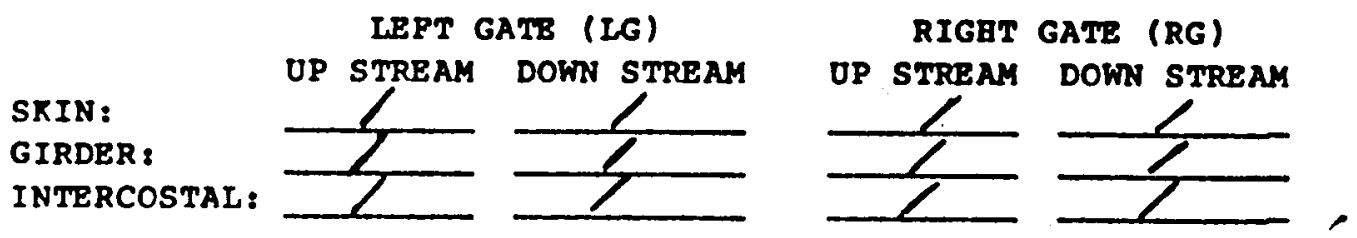

DENTS -- SRIN PLATE (S), GIRDERS (G), Or INTERCOSTALS (I) GATE COMPONENT
LOCATION, DISTANCE PROM
SIZE (ft)

(1):

$I$ or $R \quad S, G$, or I

WALKWAY ( $f t$ ) QUOIN ( $f t$ ) HEIGHT WIDTR

(2):

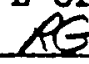

(3):

(4):

(5):
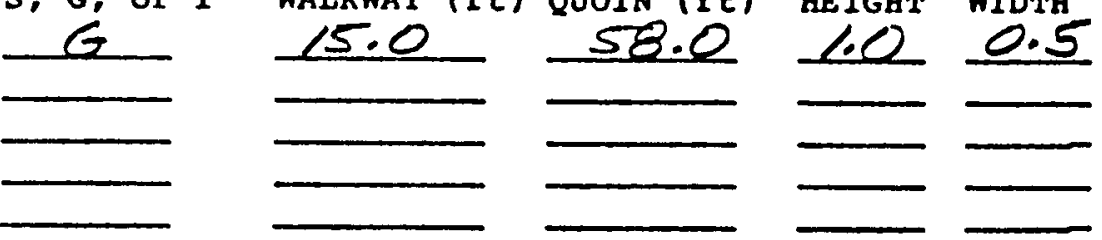

CRACRS -- SKIN PIATE (S), GIRDERS (G), Or INTERCOSTALS (I) GATE COMPONENT IOCATION, DISTANCE PROM: SIZE (ft)

$L$ or $R \quad S, G$, or I HALRWAY (ft) QUOIN (ft) LENGTH

(1):

(2):

(3):

(4):

$(5):$

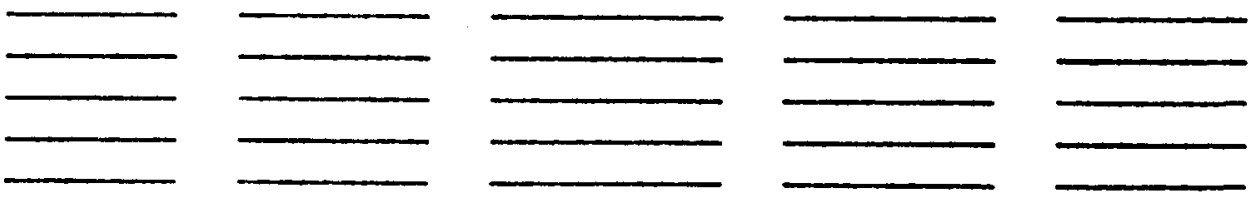

BEARING BLOCK LEATS LEPT (L), MITER (M), OY RIGET (R)

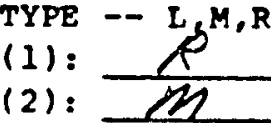

(3):

(4):

(5):

DISTANCE PROM WALKWAY (ft)

IENGTR (ft)
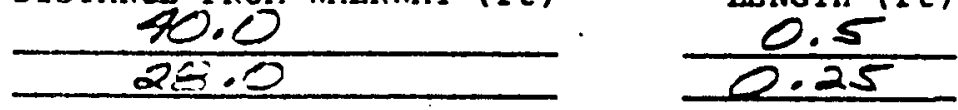

SRIN LEAKS

GATE

LEPT GATE (I), RIGHT GATE (R)

$\begin{array}{lll}L \text { OF } R \text { (H)OR OR (V)ERT } & \end{array}$

SHORTEST DISTANCE PROM

(1):

$(-2)=$

(3):

$(4):$

$(5):$
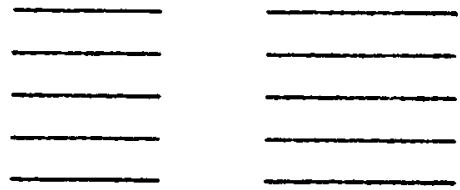

WALRWAY (ft) QDOIN (ft) LENGTH ( $f t$ )

BOILS A LEFT GATE (L), RIGHT GATE (R), MITER (M)

(1): TYPE (L,R, OF $M$ ) DISTANCE PROM QUOIN (ft)

(2):
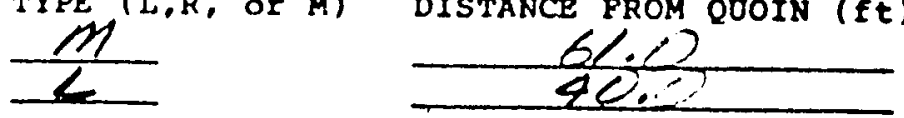

(3):

(4):

(5):
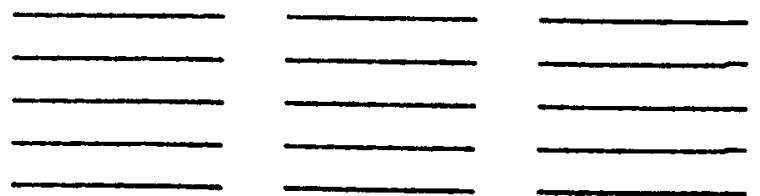

Figure 9. Inspection form (cont.) 
Page 5 Comments: Field Data.

CORROSION AT SPLASH ZONE: The corrosion of the skin plate, girders, and intercostals is rated in a visual subjective manner. Refer to Chapter 4 for more details on the rating scheme. Selection of the corrosion level observed at the splash zone (air/water interface) is made by comparing the observed condition to the standards in Table 4 and/or visually comparing it to the photographs in Figures 25 to 28 . There are five levels of deterioration. Level 0 is new or nearly equal to new. Upstream and downstream levels are recorded.

DENTS: The location and dimension of skin plate, intercostal, and girder dents are determined by a ruler or tape measure. The coordinates of the dent are taken as the distance from the walkway and quoin corresponding to the specific gate leaf.

CRACKS: The location and length of skin plate, intercostal, and girder cracks is made with a ruler or tape measure. The coordinates of the crack are taken as the distance from the walkway and quoin on the specific gate leaf to the nearest point of the crack.

BEARING BLOCK LEAKS: The location and length of the left quoin (L), right quoin (R), or miter (M), bearing block leaks are measured with a tape measure. The location of the leak is determined as the distance from the walkway to the top of the leak. A leak of length zero indicates a point or local leak.

SKIN LEAKS: The location and dimension of skin plate leaks are measured by a tape measure. Two types of skin plate leaks usually exist: horizontal (H) indicates a horizontal leak and vertical (V) indicates a vertical leak. The coordinates of the leak are taken as the distance from the walkway and quoin to the top of the leak. The corresponding gate leaf, right (R) or left (L), is also recorded.

BOILS: The existence of boils from below the water surface on the right gate (R), left gate (L), or at the miter (M) will be noted by location (distance from the quoin). 
calculation date: $10 / 25 / 88$ calculated bys AENS

RBQOIRED OVBRALI VBRTICAL GBOMBTRY -- (FIG. 13.)

Positive elevation of sill above any datum, ELSILI (ft): 333.0

sill to bottom of skin plate, GBOT (ft): 0.75

sill to overflow elevation at top of gate, GTOP (ft): 44.75

REQUIRED OVBRALI IBAP GBOMBTRY - (FIG.13.)

Leaf between contact points, GLENG $(f t): 6.0$

Gate leaf slope, GSLOPE:

Working line to downstream edge of girder webs, GWORKL $(f t): 0.325$ Quoin contact point to guageon pin, GQuoIN (ft): 1.93

Working line to gudgeon pin (positive when contact point is downstream from gudgeon $p(n), \operatorname{GPINI}(f t): \angle 25$

COMMON GIRDBR GBOMBTRY DIMBRSIONS -- (FIG. 13.)

Girder web depth, GWEBD (in):

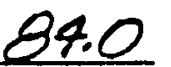

Quoin contact point to center of nearest end diaphragm along working line, DQPED (in): 48.0

Center of end diaphragm at miter end of gate to miter contact point along working line, DEDMP (in): 48.0

Bottom girder downstream flange extension below web centerline, BGDPD (in): 3

GIRDER BIBVATIONS -- (FIG. 13.)

Number of girders in the gate leaf, NGIRDS: $\frac{/}{1 /}$
Girder Number, NGIRD
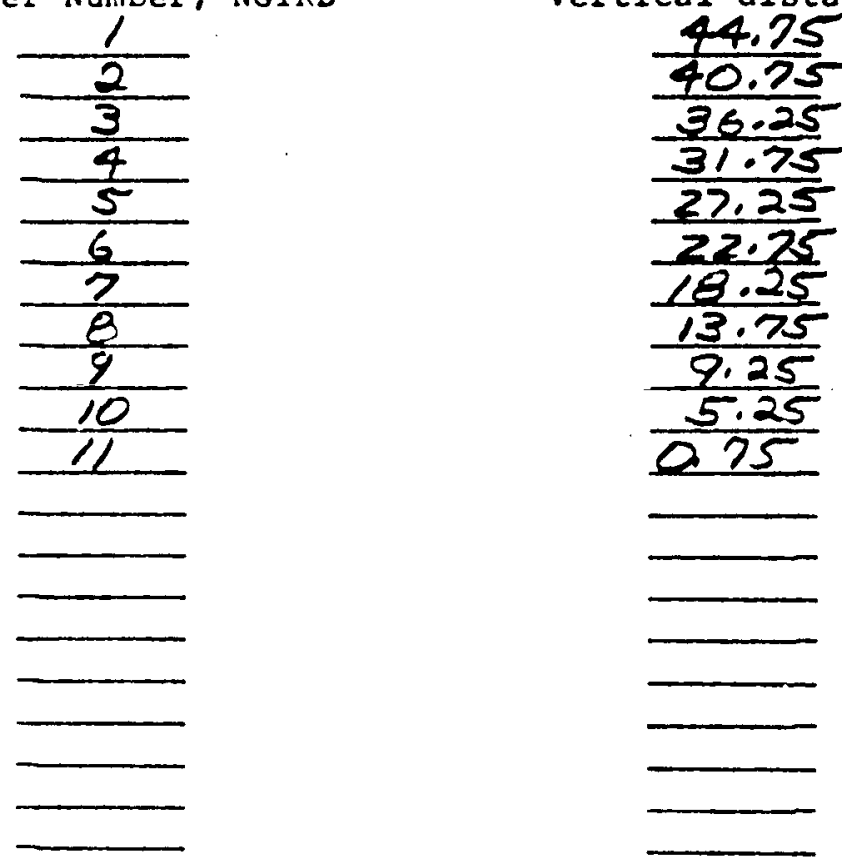

Figure 9. Inspection form (cont.) 


\section{Page 6 Comments: Structural Components Data}

Complete prior to the site inspection and verify or change data during the site inspection. Data must be recorded in the indicated units.

REQUIRED OVERALL VERTICAL GEOMETRY: Provide the overall vertical leaf dimensions based on the available design drawings. ELSILL is the positive elevation of the sill above any datum, usually referenced to mean sea level. GBOT is the clear space between the sill and the bottom of the gate, and GTOP is the distance from the sill to the overflow elevation (top of skin plate). See Figure 13 for illustration.

REQUIRED OVERALL LEAF DIMENSIONS: Provide the overall leaf dimensions based on the available design drawings. GLENG is the length of leaf between quoin and miter contact points. GWORKL is the distance from the working line to the downstream edge of the girder web. GQUOIN is the distance along the gate leaf working line from the quoin contact point to the gudgeon pin, and GPIN1 is the distance from the working line to the gudgeon pin. See Figure 13 for illustration.

GIRDER COMMON DIMENSIONS: Provide the overall girder dimensions based on the available design drawings. GWEBD is the depth of the web plate or the clear distance between girder flanges. DQPED is the distance along the gate leaf working line from the quoin contact point to the end diaphragm. DEDMP is the distance along the gate leaf working line from the miter contact point to the end diaphragm. DQPED and DEDMP are usually equal. BGDFD is the bottom-girder downstream flange, downward extension below the web centerline. See Figure 13 for illustration.

GIRDER WEB ELEVATIONS: Indicate the number of girders, NGIRDS, and provide the girder number, NGIRD, and the vertical distance, VD, above the sill, ELSILL, for each girder. See Figure 13 for illustration.

NOTE: The information furnished on this page serves as input to the CMINV module (see Chapter 3 ). The notation is identical to the CMINV documentation referred to in Chapter 3. 
MITER LOCK GATB STROCTURB SAFBTY IMSPBCTTON

GIRDBR DIAPERAGM SPACING - (FIG. 13.)

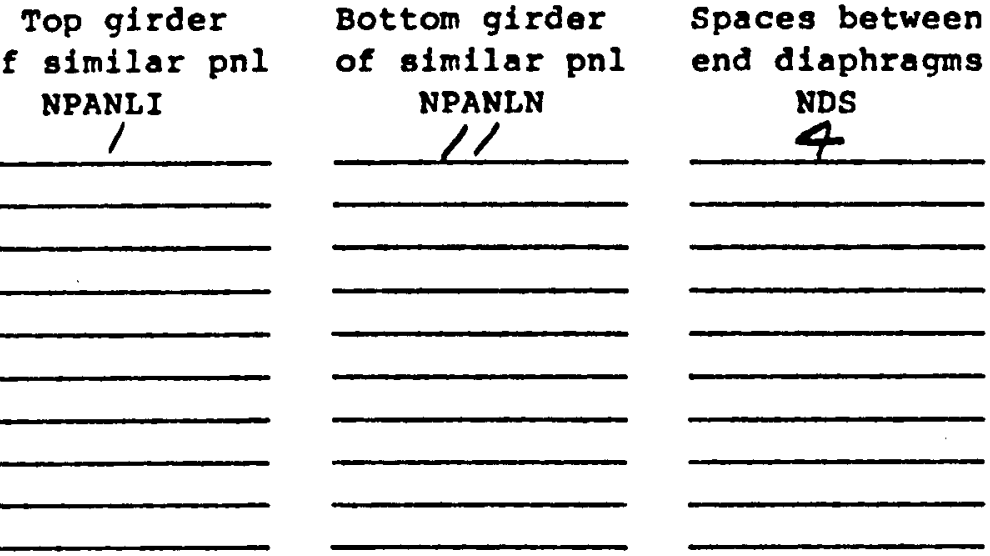

Itrcstl spaces

btwn adj dphrgms NIS 6

DEAD ARD ITVB LOADS:

Additional dead load, Including ice, mud walkway, gusset plates, etc, ADEAD (Ibs.): GG42

Quoin contact point to centrold of ADEAD along working line, XDEAD ( $f t): 31.0$

Downstream edge of girder web to controld of ADEAD, ZDEAD (1n.): Bouyancy force acting on dry welght of gate, ABUOY (lbs.): Quoin contact point to centrold of ABDOY along working line, XBOUY (ft.): $3 /$

Downstream edge of glrder web to centrold of ABOUY, zBOUY $(1 \mathrm{n}):. 3 / .0$ Concentrated live load, including walkway and bridgeway. ALIVE (1b.): 2

RBQUIRBD MATER BLBVATIONS -- (FBBT ABOVB BISILL) (EIG. 14.)

Elevation of upper pool, ELOP (ft): Elevation of lower pool, $\operatorname{ELLP}(f t)$ : Fuli submerge elevation, EuPs (ft): $378-125$ Operating water elevation, ELOW $(\mathrm{ft}): 375.0$

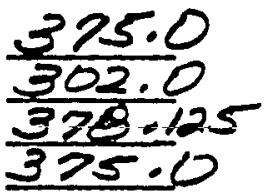

STBBL YBILD STRBNGTE (KST):

Miscellaneous steel yleld strength 36,0

\begin{tabular}{|c|c|c|c|c|c|c|}
\hline $\begin{array}{l}\text { Webs } \\
36.0\end{array}$ & $\begin{array}{c}\text { Flanges } \\
36.0\end{array}$ & $\begin{array}{l}\text { skin } \\
36.0\end{array}$ & $\begin{array}{c}\text { stiffeners } \\
36.0\end{array}$ & $\begin{array}{c}\text { Intercostals } \\
36.0\end{array}$ & $\begin{array}{l}\text { Quoin } \\
36.0\end{array}$ & Diaphragms \\
\hline
\end{tabular}


GIRDER DIAPHRAGM SPACING: Provide the girder diaphragm spacing on the basis of the available design drawings. For each similar group of skin plate panels, record the top girder, NPANLI, and the bottom girder, NPANLN, along with the number of diaphragm spaces between end diaphragms, NDS, and the number of intercostal spaces, NIS, between adjacent diaphragms. See Figure 13 for illustration.

DEAD AND LIVE LOADS: Provide the dead and live load on the basis of the available design data. ADEAD is a concentrated dead load, ice, mud, walkway, intermediate stiffeners, gusset plates, etc., applied at (1) XDEAD, the distance along the working line measured from the quoin contact point, and (2) ZDEAD, the distance from the downstream edge of the girder web. ABUOY is the concentrated buoyancy force acting on the dry weight of the gate applied at (1) XBUOY, the distance along the working line measured from the quoin contact point, and (2) ZBUOY, the distance from the downstream end of the girder web. ALIVE is the concentrated live load including the walkway and bridgeway. See Figure 13 for illustration.

REQUIRED WATER ELEVATIONS: Record the elevations of the upper pool, ELUP, the lower pool, ELLP, the full submergence elevation, ELFS, and the operating water elevation, ELOW. The elevations are referenced to the same datum as ELSILL, the elevation of the sill. This may duplicate information on page 1. See Eigure 14 for illustration of water elevations.

YIELD STRENGTH: Several yield strengths are used in miter lock gates. Record the yield strengths of the components listed and a miscellaneous yield strength for all of the steel components not specifically listed. 
GIRDBR VBB THICKRBSSBS (IM.) (FIG. 15.)

Groups of similar girders

Top girder NGIRDI

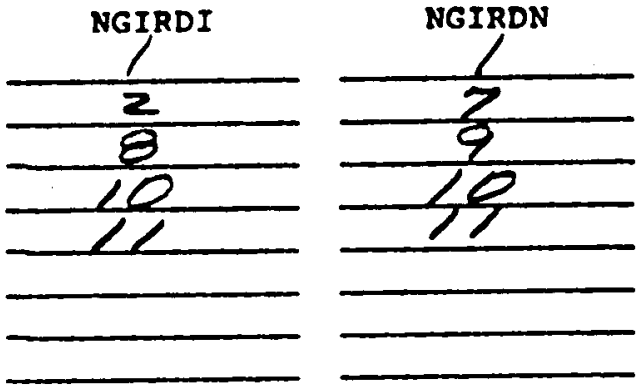

Web end zone thickness GWET

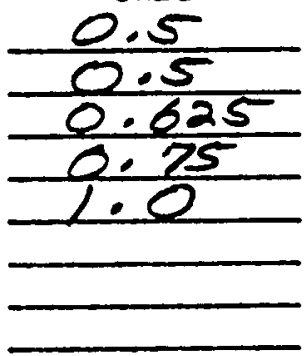

Web center zone thickness GWCT

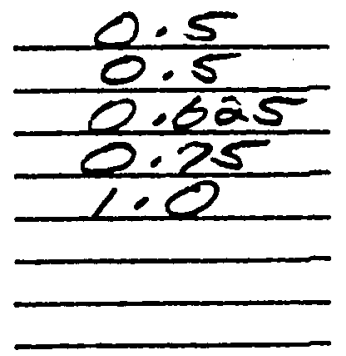

GIRDBR PLANGBS, UPSTRBAM (IN.) -- (FIG. 15.) Groups of similar girders Opstream flange widths Top Number Bottom Number NGIRDI
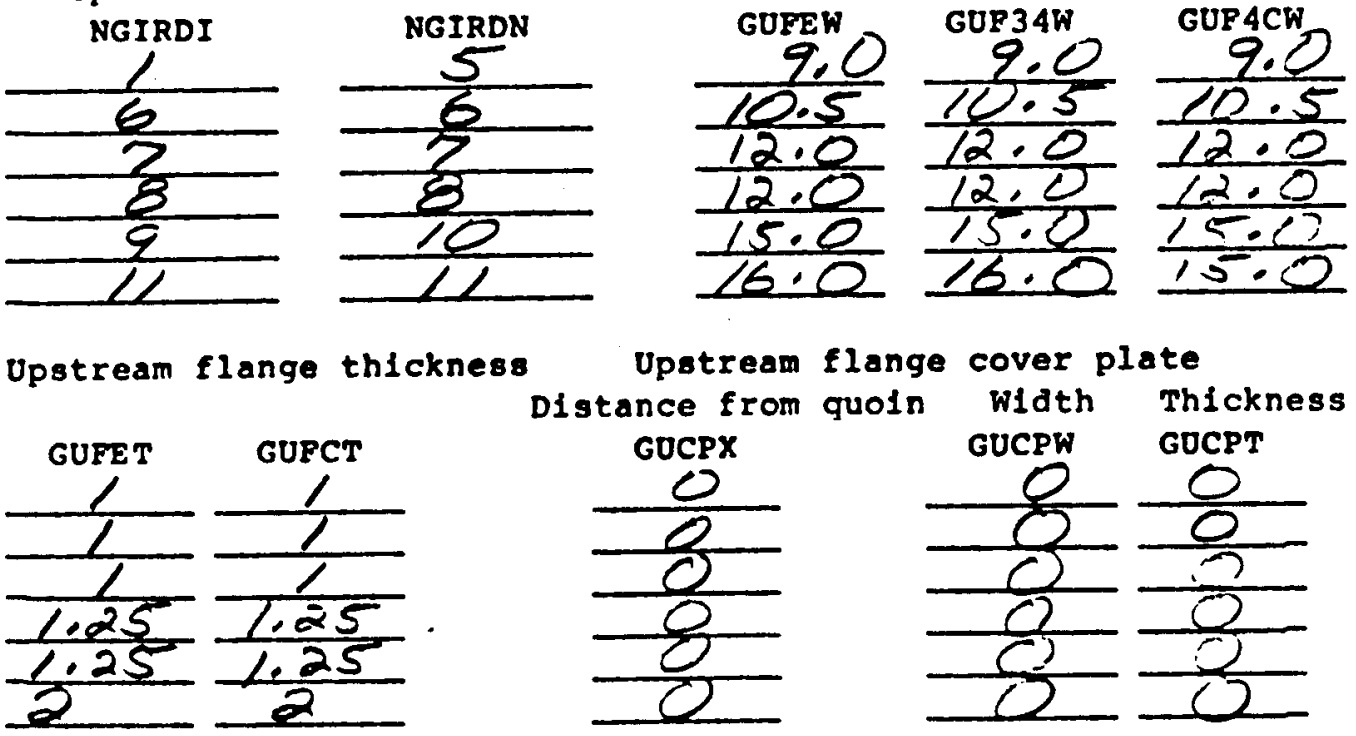

Elange cover plate quoin width Thickness GUCPW GOCPT

GIRder ptangs, domstrobah (IM.) -- (FIG. 15.) Groups of similar girders. Downstream flange widths

Top Number NGIRDI

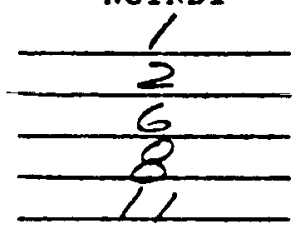

Bottom Number NGIRDN
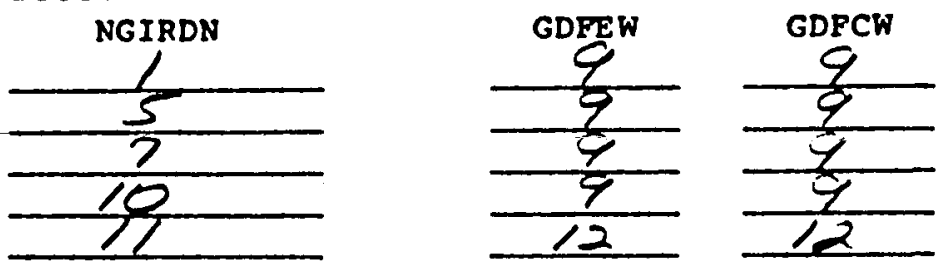

Downstream flange thickness

Downstream flange cover plate Distance from quoin

GDFET

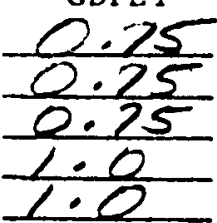

GDFCT

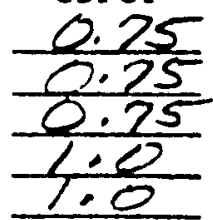
GDCPX

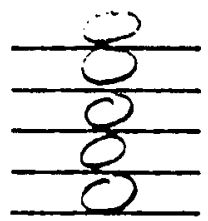

width Thickness GDCPW GDCPT

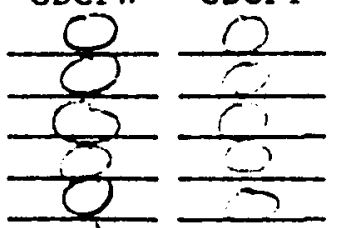

Figure 9. Inspection form (cont.) 
GIRDER WEB THICKNESSES: Provide the girder web thicknesses on the basis of the available design drawings. For each similar group of girder web thicknesses, record the top girder, NGIRDI, and the bottom girder, NGIRDN. In addition, the end zone web thickness, GWET, and the center zone web thickness, GWCT, must be recorded. See Figure 15 for illustration of girder web

thicknesses.

GIRDER FLANGES, UPSTREAM: Provide the upstream flange widths and thicknesses on the basis of the available drawings. For each similar group of upstream girder flanges, record the top girder, NGIRDI, and the bottom girder, NGIRDN, along with the end zone width, GUFEW, and thickness, GUFET, from the girder end to the corner splice. Also record the flange width from the corner splice point to the flange splice point, GUF34W, and the flange width from the flange splice point to the girder centerline, GUF4CW. The flange thickness, GUFCT, is usually the same in these two regions and must be recorded. In addition, the upstream flange, cover-plate distance from the quoin, GUCPX, width, GUCPW, and thickness, GUCPT, must be recorded. A zero in the last three entries indicates that no cover plate is present. See Figure 15 for illustration.

GIRDER FLANGES, DOWNSTREAM: Provide the upstream and downstream flange widths and thicknesses based on the available drawings. For each similar group of upstream girder flanges, record the top girder, NPANLI, and bottom girder, NGIRDN, along with the end zone width, GDEEW, and thickness, GDFET, from the girder end to the splice point. Also record the width, GDFCW, and the thickness, GDFCT, from the splice point to the downstream cover plate location, GDCPX, width, GDCPW, and thickness, GDCPT, must be recorded. A zero in the latter three of these entries indicates no cover plate is present. See Figure 15 for illustration. 
D.s. ARMY CORPS OF EMGIMBERS

MITER LOCR GATE STROCTURE SARTY INSPBCTION

PAGE 9
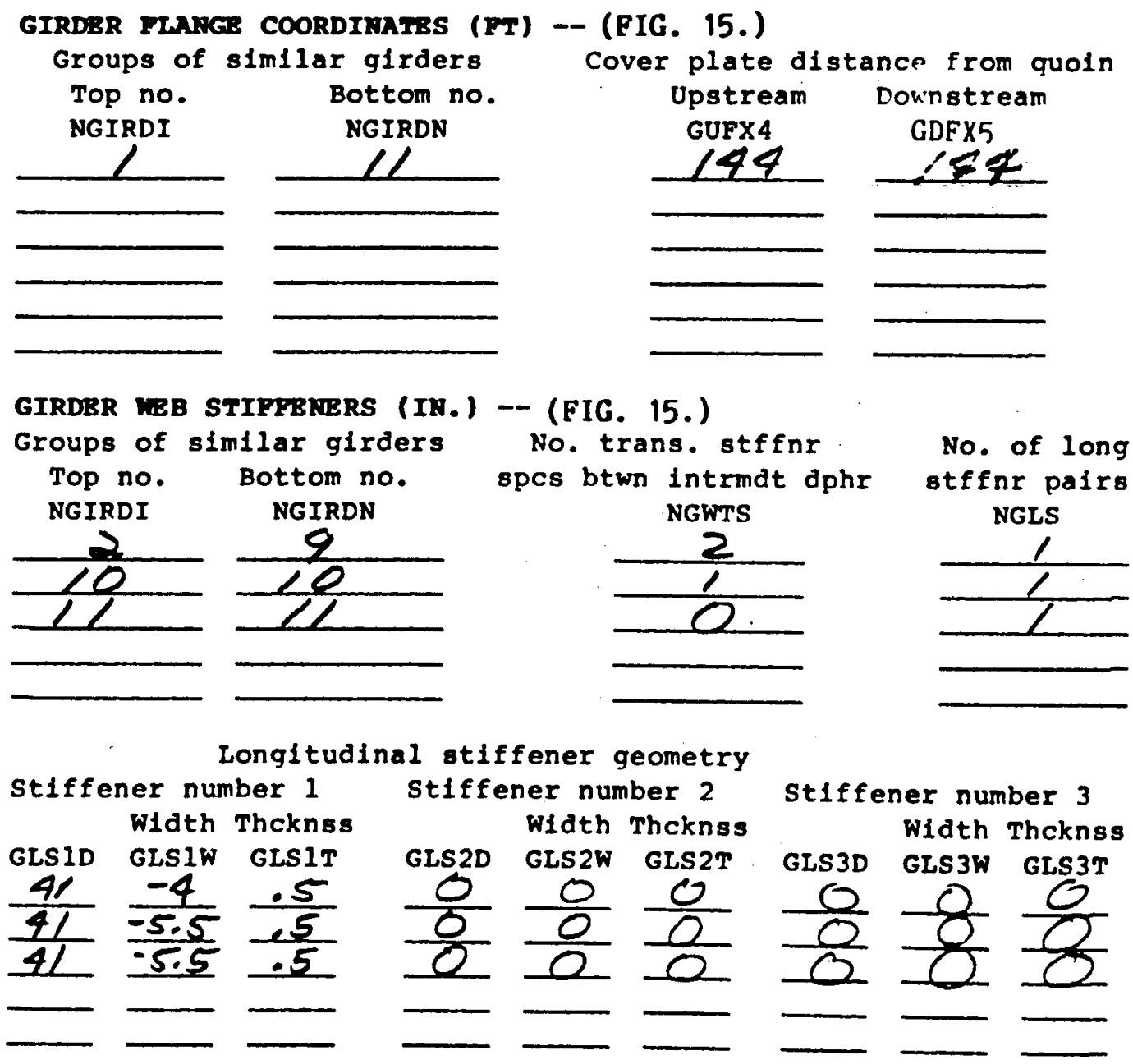

INTBRCOSTAL AND SKIn PLATB GEONBTRY (IR.) -- (FIG. 15.)
Groups of similar intercostals

Top girder no. Bottom firder no.
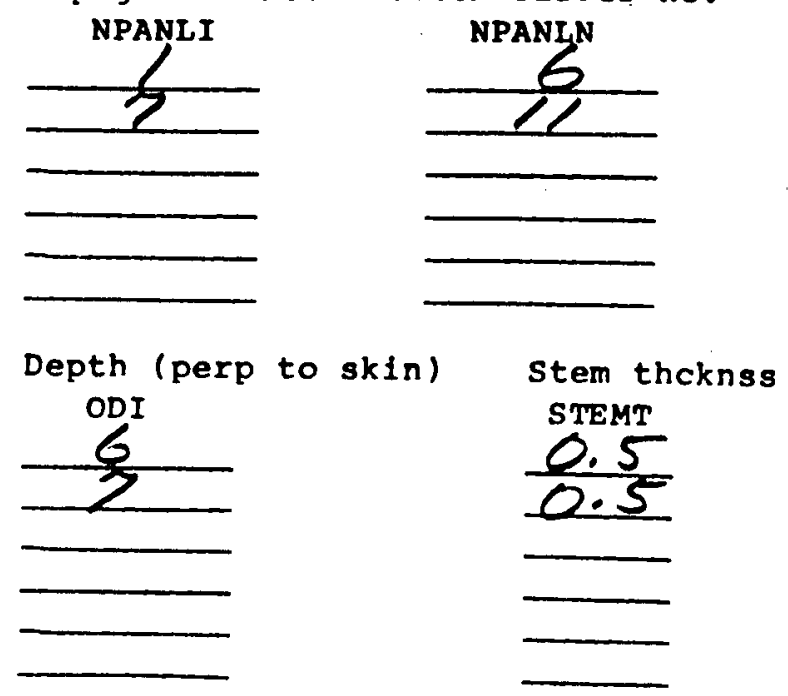

Skin plate thickness

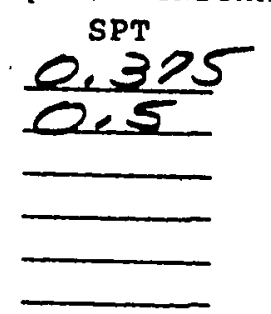

Figure 9. Inspection form (cont.) 
Page 9 Comments: Structural Components Data.

GIRDER FLANGE COORDINATES: Provide the girder flange splice coordinates on the basis of available design drawings. For each similar group of girder flange splice coordinates, record the top girder, NGIRDI, and the bottom girder, NGIRDN, along with the upstream flange splice coordinates, GUFX4, and the downstream flange splice coordinates, GDFX5. The coordinate is measured from the quoin contact point as illustrated in Figure 15.

GIRDER WEB STIFFENERS: Provide the girder web stiffener information on the basis of the available design drawings. For each similar group of girder web stiffeners, record the top girder number, NGIRDI, and the bottom girder number, NGIRDN. Also, record the number of girder web transverse (vertical) stiffener spaces, NGWTS, between adjacent intermediate diaphragms, and the number of longitudinal stiffeners, NGLS, between girder flanges. In addition, indicate for each of the longitudinal web stiffeners (1) the distance from the downstream web edge, GLS1D, (2) the width, GLS1W, and (3) the thickness, GLS1T. A zero entry indicates no stiffener present, and a negative entry for a longitudinal web stiffener width indicates stiffeners on only one side of the web. See Figure 15 for illustration.

INTERCOSTAL AND SKIN PLATE GEOMETRY: Provide the intercostal and skin plate geometry on the basis of the available design drawings. For each similar group of panels, record the top girder, NPANLI, and the bottom girder, NPANLN, and the corresponding skin plate thickness, SPT, within this region. In addition, record (1) the overall depth of the intercostal, ODI (including the flange thickness), (2) the thickness of the perpendicular leg touching the skin plate, STEMT, (3), the width of the angle parallel to the skin plate (flange), FWI, and (4) the flange thickness of the intercostal, FTI. See Figure 15 for illustration. 


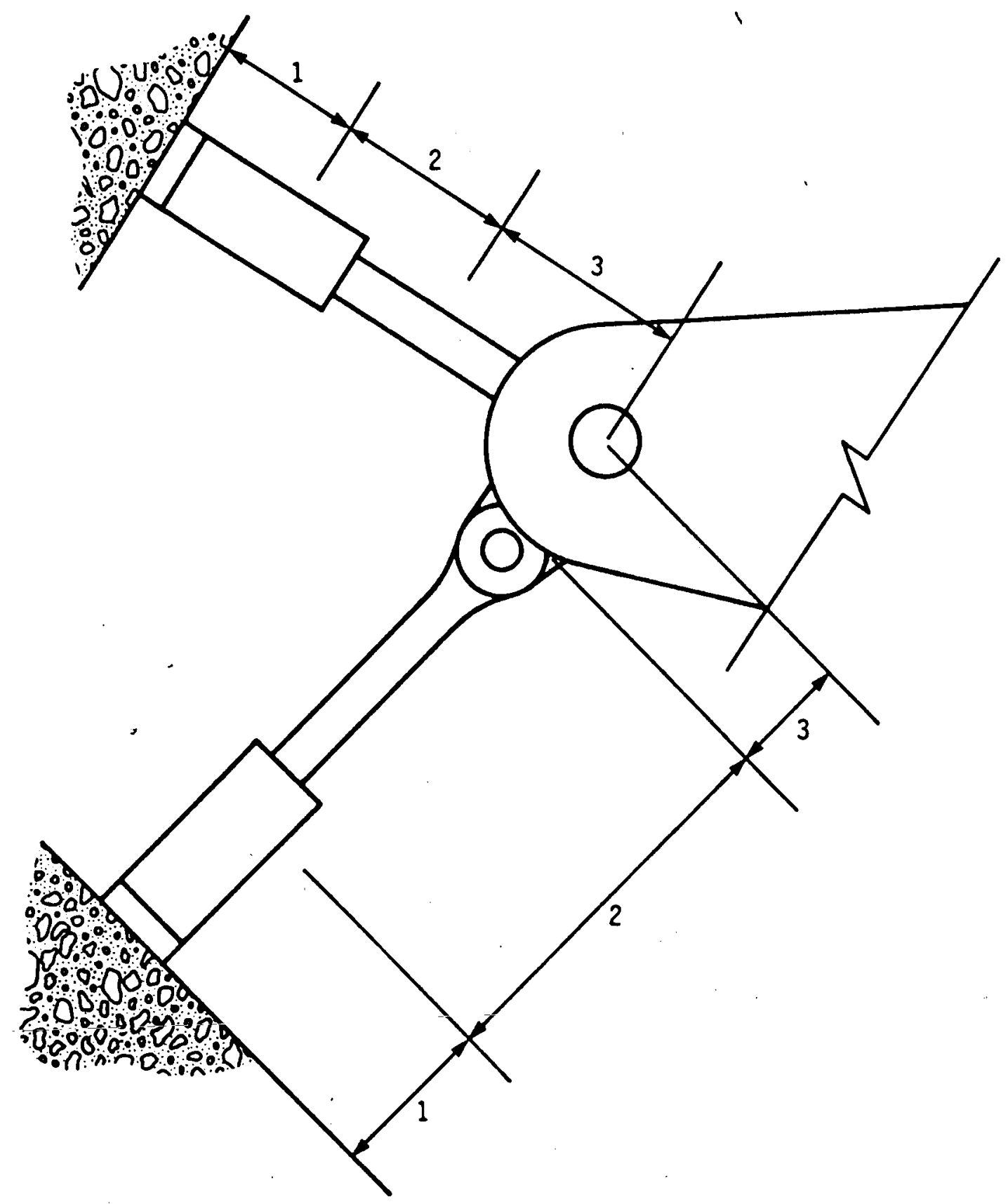

Figure 10. Double linkage pin assembly (dimensions) 

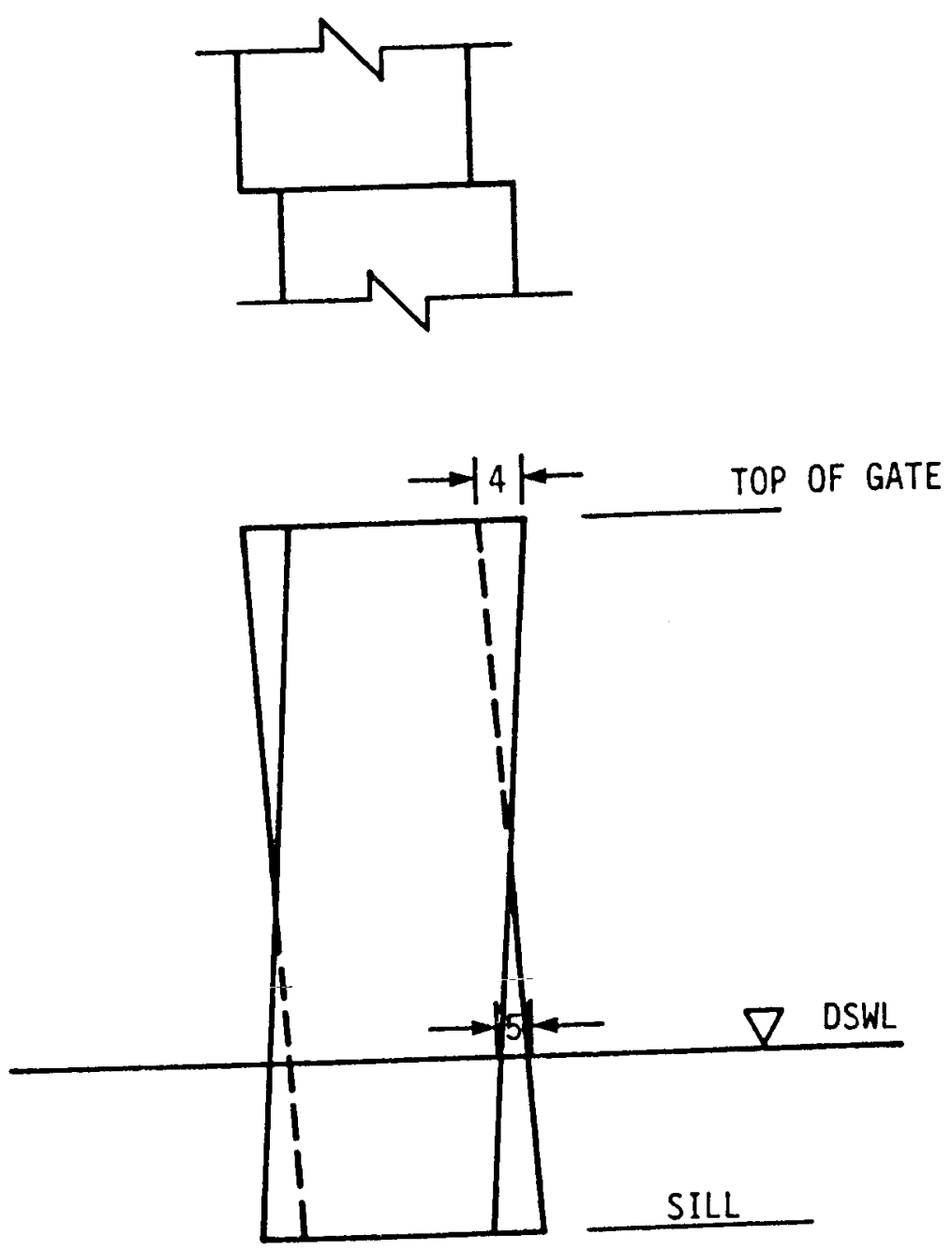

Figure 11. Miter block offset 


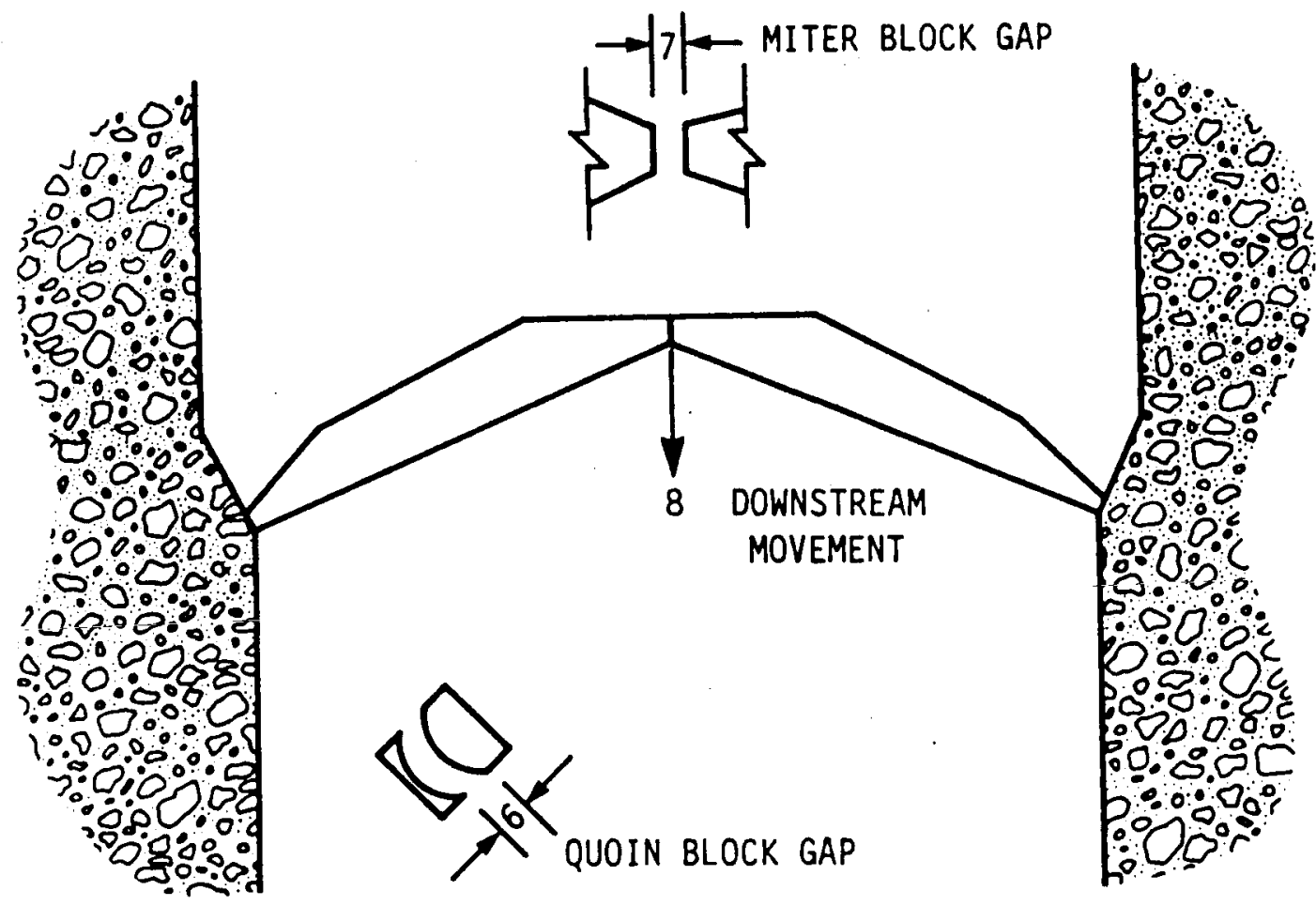

Figure 12. Gaps, downstream movement

40 


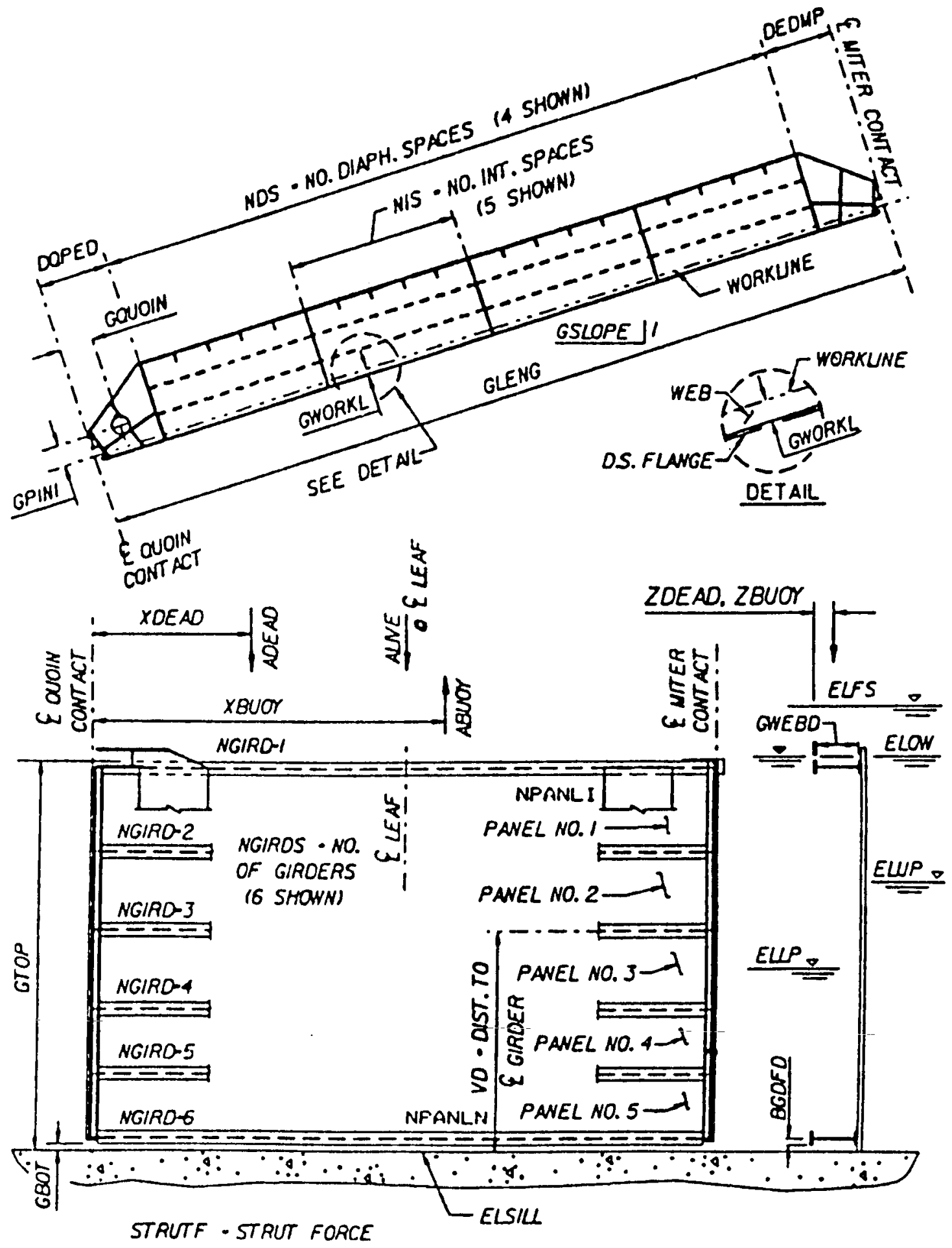

Eigure 13. Leaf geometry 


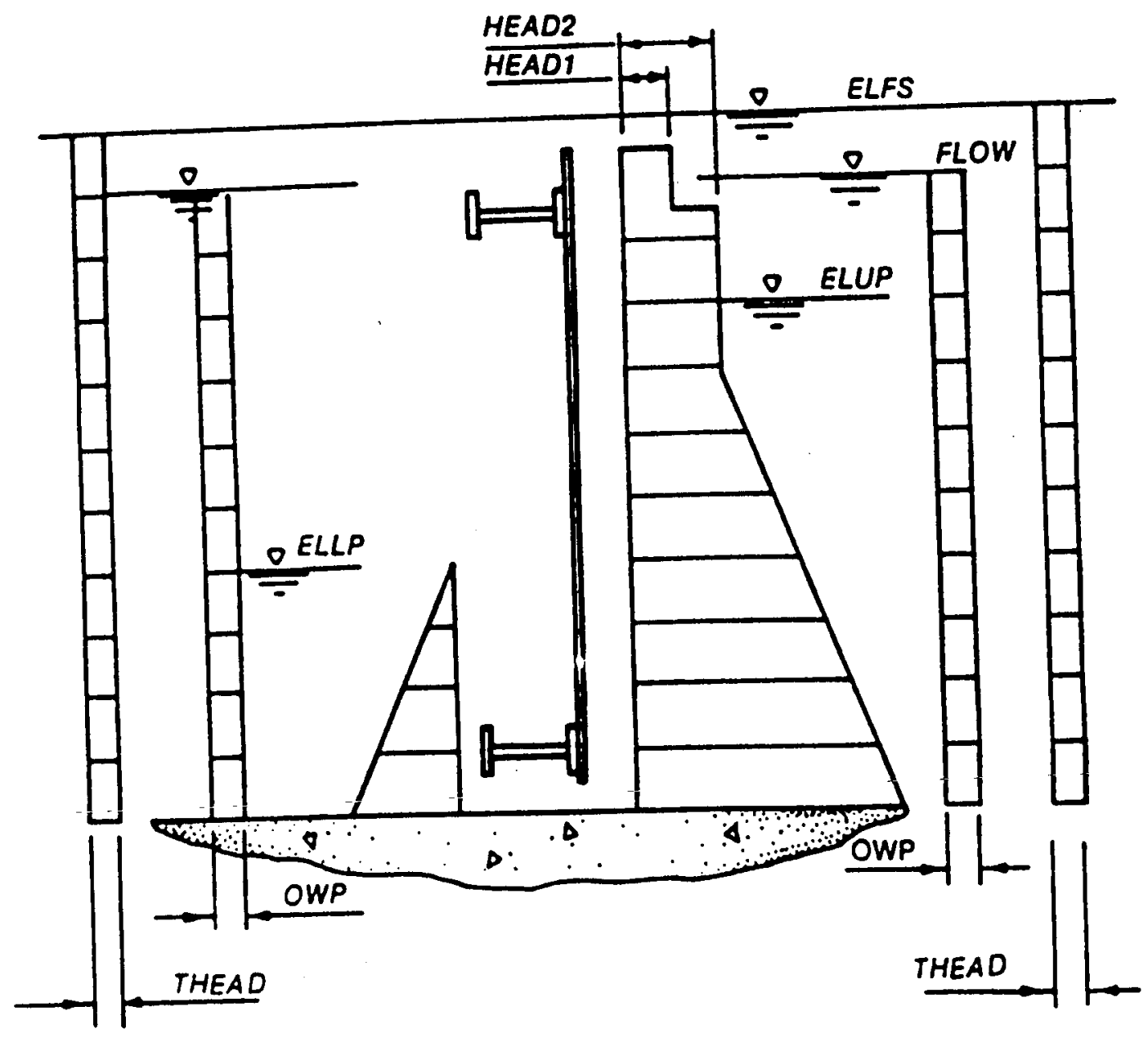

Figure 14. Water elevations (computer input) 


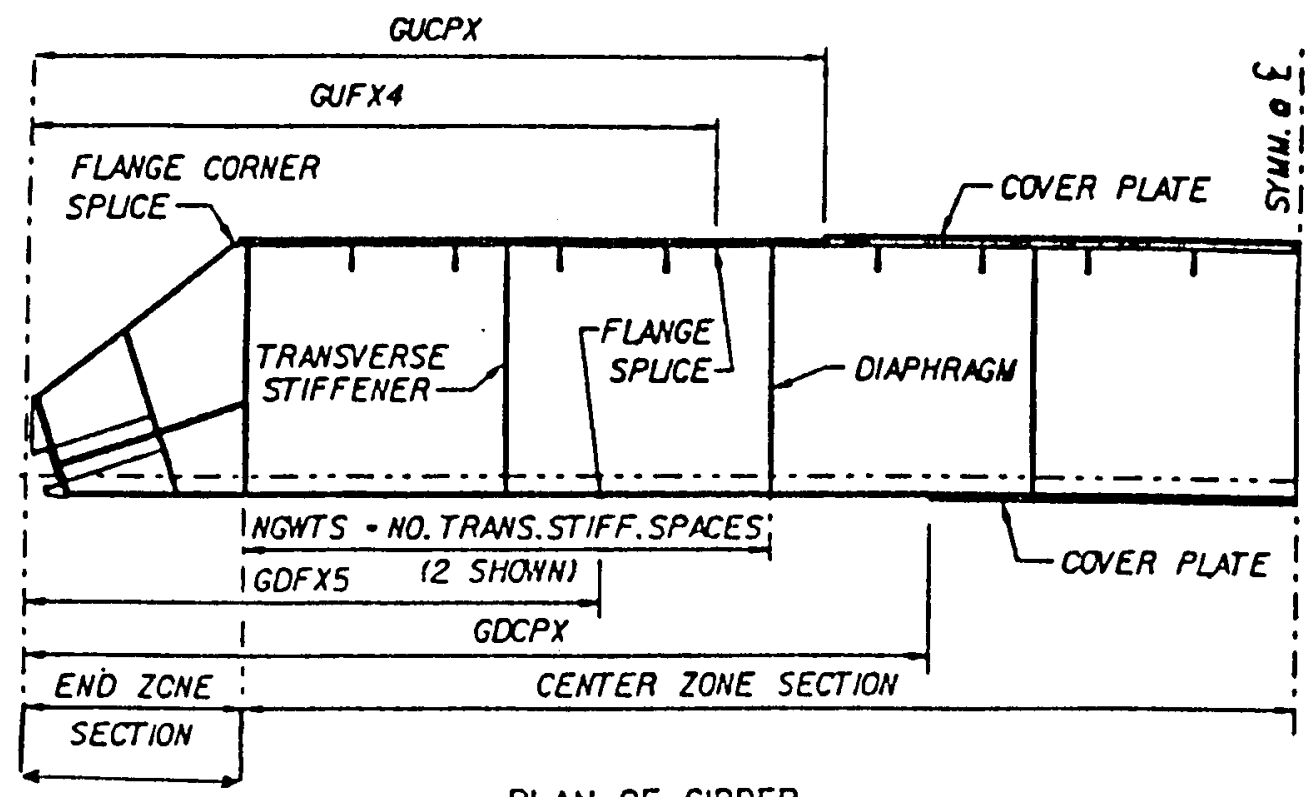

us

as

PLAN OF GIRDER

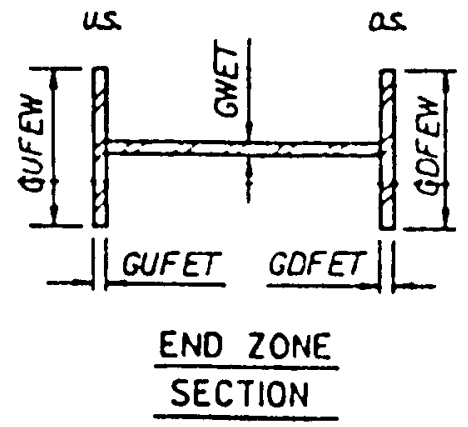

NGLS - NO. LONGTUUONAL
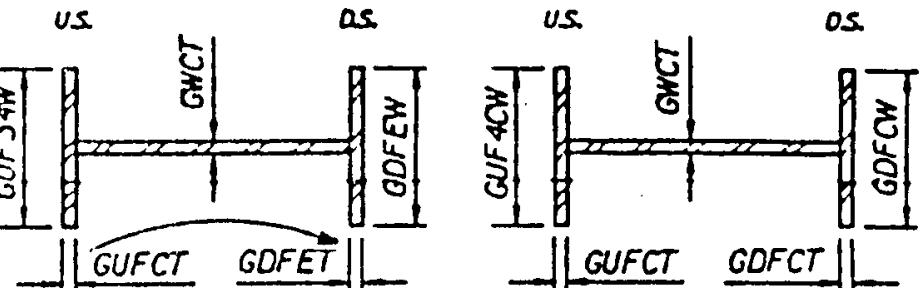

STIFFENERS (3 SHOWN)

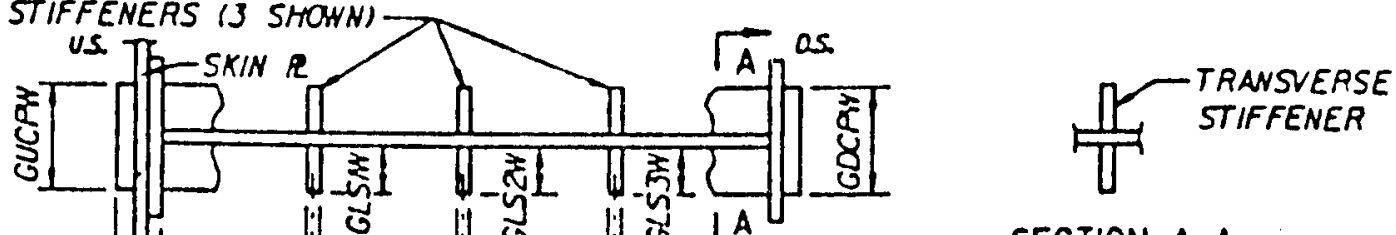

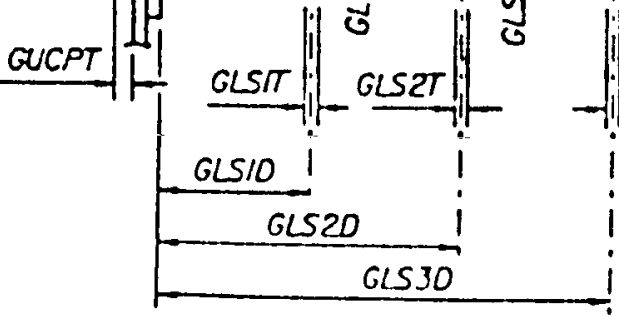

COVER PLATE \& STIFFENERS
CENTER ZONE

SECTION

(LEFT OF SPLICE)
CENTER ZONE

SECTION

(?IGHT OF SPLICE) 
40. Structural safety often refers to potential loss of life or significant property damage. If a structure is unsafe, it is in danger of collapse. Structural safety has traditionally been measured by a factor of safety. Hence, uncertainties in loading and structural strength (i.e., emergency conditions) are accounted for by selecting an appropriately high factor of safety to ensure a sufficient margin between the applied loads and the structural resistance. For example, the design criteria for miter lock gates typically require a factor of safety of two.

41. In this project a structural condition index is defined as a measure of the safety of the structure or risk of failure of the structure. It is based directly upon the calculation of a factor of safety of the structure. The factor of safety calculation is often perceived as a fairly rational, objective process. However, many simplifying assumptions must be made. In fact, the structural analysis of a miter lock gate involves many subjective decisions. Fortunately, many of the assumptions have been standardized and published by the US Army Corps of Engineers. Therefore, the factor of safety and hence the structural condition index are at least reasonably repeatable (relative to the functional condition index in the following chapter).

\section{Structural Analysis}

42. A basic part of the structural safety evaluation is a structural analysis. As with all structural analyses, several assumptions must be made. In this work, the basic assumption is that miter lock gates behave in the manner for which they were designed. With this assumption, the US Army Corps of Engineers design manuals, 1963 and 1984, are used for the structural analysis. These sources are supplemented by a US Army Corps of Engineers computer program, CMITER (US Army Corps of Engineers, 1987), that implements these rules for the horizontally framed gate.

43. Horizontaliy framed gates generally provide a more rigid structure than vertically framed gates. For shallow gate leaves up to a height-to-width ratio of 1 , the vertically framed gate requires less material and weighs less. The horizontally framed gate is used on higher lift locks. Horizontally framed gates are used most frequently, with the exception of the Mississippi River system. Approximately 95 percent of miter lock gates in service and all new construction are horizontally framed. Moreover, CMITER analyzes only 
horizontally framed gates; thus, the structural analysis in this study is concerned with horizontally framed gates only.

44. The structural analysis module of CMITER, called CMINV, interfaces with the inspection forms to perform a structural analysis of several components on the horizontally framed gate leaf. The completed inspection forms, pages 6 to 9, which serve as the input to CMINV, are described in Part II. Because the input and output of CMINV is long and detailed, the structural analysis in this project has been limited to three significant components: girders, intercostals, and skin plate.

45. A computer program (MTR) has been written by project personnel to postprocess the CMINV output file by calculating the factors of safety of the three selected components. The computer selects the worst case in terms of the lowest Condition Index of the three components for each of five load cases.

\section{Loads}

46. The loads normally applied to miter lock gates consist of water pressure, operating loads (opening and closing), boat impact, and dead and live loads. Water pressure is produced by pool differential on the sides of the gate as the lock is filled or emptied. Operating loads are the result of the strut arm force and water resistance to the moving leaf as it is opened and closed. Boat impact load is the force produced by barge and vessel collisions with the gate. Dead load includes ice, mud, and the like, and live load includes loads acting on the bridgeway and walkway. Abnormal or emergency loads include any of the normal loads in addition to earthquake loads, increased water loads (dewatering for maintenance), and temporal hydraulic loads (temporal head) below the full submergence elevation (a pulse load or a wave) (Figure 16).

47. The load types described above are grouped into six load cases. Load Case 1

48. Load Case 1 is a normal operating condition in which the gate leaves are in the mitered position and subjected to both upper and lower pools (Figure 16). The Corps permits the use of $10 \mathrm{ft}$ of head for girders and $6 \mathrm{ft}$ of head for skin plate to act as equivalent impact loads. The equivalent boat. impact load represents a minimum load to which the girders and skin plate are subjected (Figure 17). Hence, it only loads the girders and skin plate in the upper part of the gate.

49. Since Load Case 1 is a normal operating condition the allowable stresses specified in the design manual (US Army Corps of Engineers, 1963) are applicable. The design factor of safety, FS $\mathrm{d}$ is 2.0 . 
FULL SUBMERGENCE

WATER ELEVATION

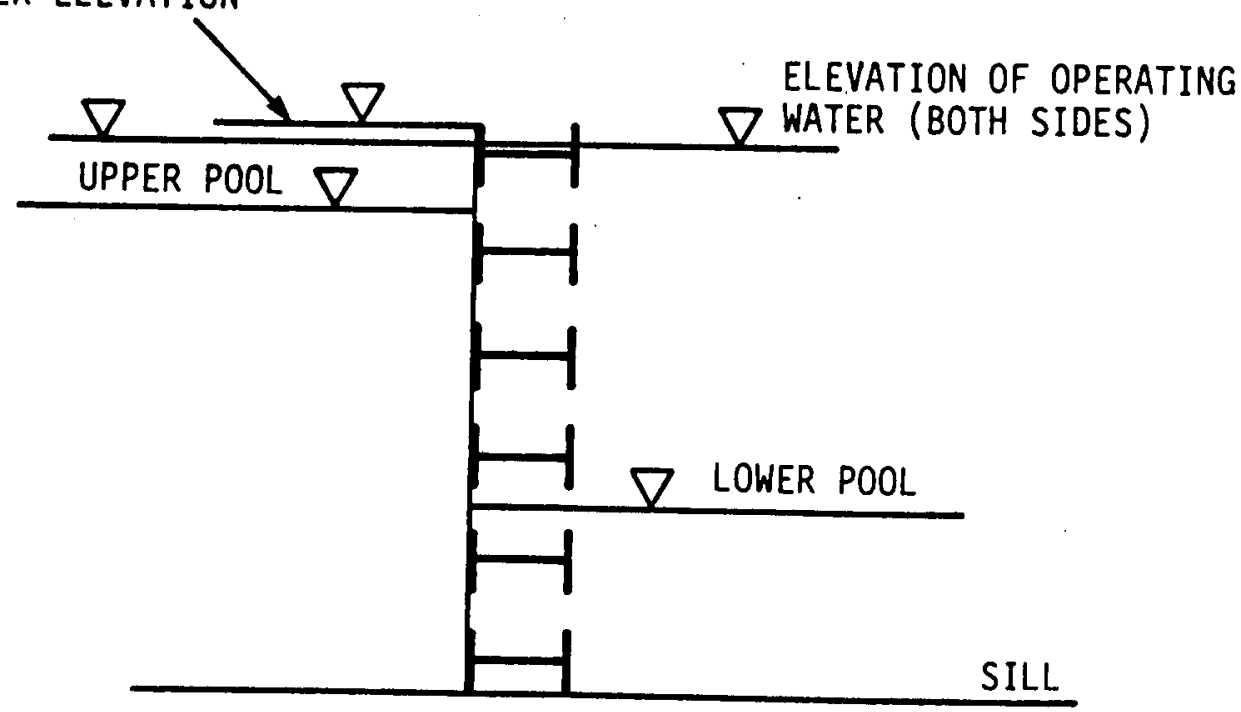

Figure 16. Water elevations
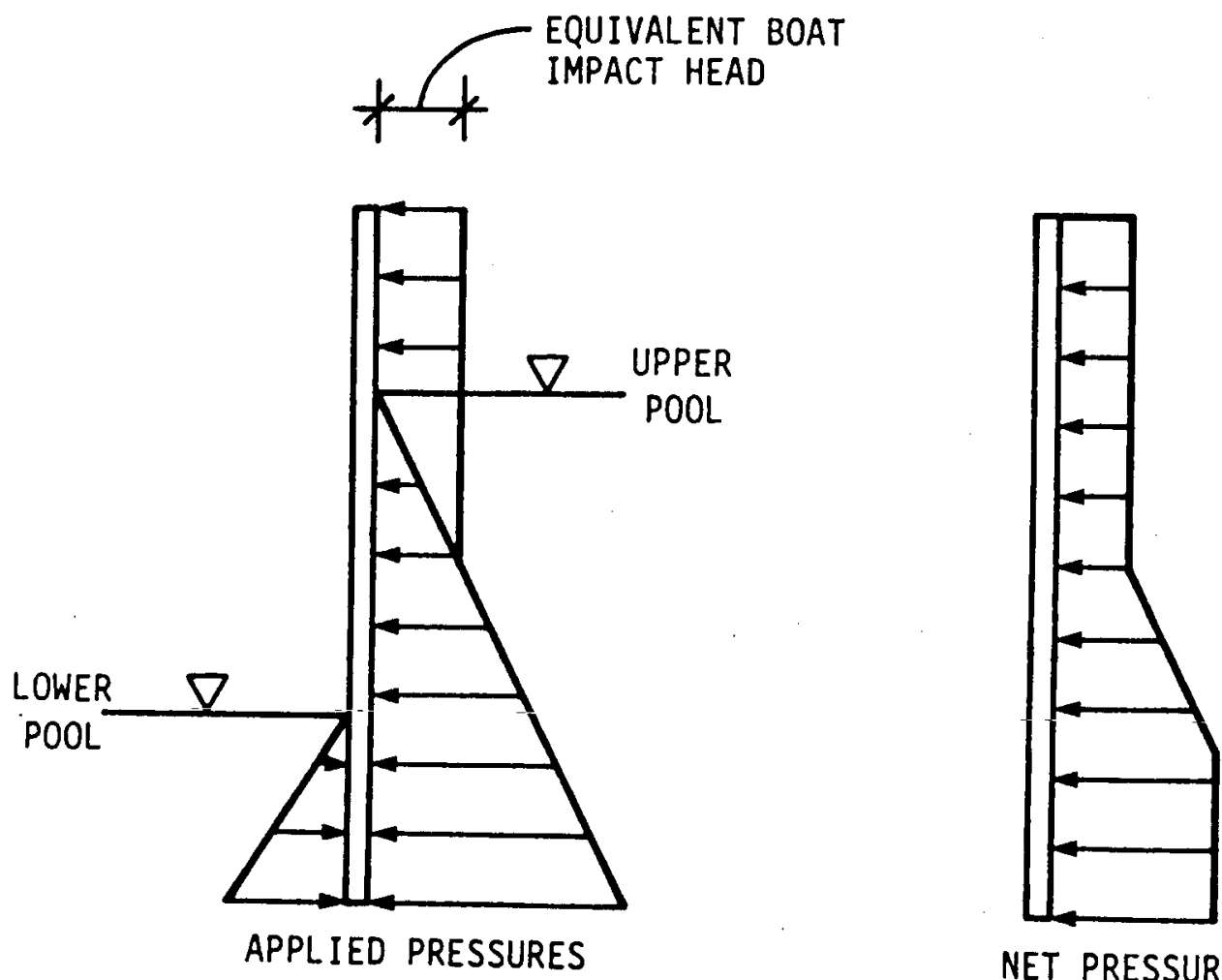

NET PRESSURE

Figure 17. Load case 1 
50. Load Case 2 consists of the gate leaves in the mitered position with water pressure due to the full upper pool only. This is the dewatered condition (Eigure 16).

51. Load Case 2 is an abnormal condition so that a 33-percent increase in the allowable stresses is permitted. The design factor of safety, $\mathrm{FS}_{\mathrm{d}}$, is 1.5 .

Load Case 3

52. Load Case 3 consists of dead load (ice and mud) and the water drag when the gate is opening or closing (Figure 16). Load Case 3 does not include static water head.

53. Load Case 3 is an unmitered operating condition which permits the normal allowable stresses. The design factor of safety, FS , is 2.0 .

\section{Load Case 4}

54. Load Case 4 is an unmitered operating condition consisting of the gate weight, live load on the walkway and bridgeway, dead load of ice and mud, and the temporal head (Figure 16). CMINV defaults to $1.25 \mathrm{ft}$ head to represent the temporal load (pulse load or wave resulting from overfill or overemptying).

55. Load Case 4 has no static head and allows a 33-percent increase in the allowable stress. The design factor of safety, $F S_{d}$, is 1.5 .

Load Case 5

56. Load Case 5, unmitered obstruction, usually controls the design of the strut and pintle. The structural analysis in this project has been limited to three components: girders, skin plate, and intercostals. Load Case 5 does not stress these components and has been omitted.

\section{Load Case 6}

57. Load Case 6 consists of Load Case 1 (without boat impact) plus the earthquake condition, which is represented by a constant gate acceleration (default equal $0.05 \mathrm{~g}$ in CMINV).

58. Load Case 6 is the mitered earthquake condition resulting in a 33 percent increase in the allowable stress. The design factor of safety, FS $_{d}$, is 1.5 .

\section{Component Condition Index for Each Load Case}

59. The minimum factor of safety for each of the three components for each load case is determined. It is related directly to the structural condition index by using the condition index zones in Table 2. If the factor of safety is equal to the design value, the condition index is 100 . If the factor of safety falls below 1.0, a zone 3 (condition index less than 40) is 
indicated. Figure 18 illustrates the two straight lines that are used to relate the factor of safety and the structural condition index.

$$
C I= \begin{cases}40 x \text { FS } & \text { FS }<1 \\ 40+60\left(\frac{F S-1}{F S_{d}-1}\right) & \text { FS }>1\end{cases}
$$

where $F S_{d}$ is the design factor of safety.

Girders

60. The main girders of horizontally framed gates in the full mitered position of Figure 19 form a series of three hinged arches symmetrical about the centerline of the lock chamber. The forces and reactions acting on one gate leaf along with the corresponding moment diagram are shown schematically in Figure 20. The determination of the internal forces and moments within the girders is adequately described in "Lock Gates and Operating Equipment" (US Army Corps of Engineers, 1984).

61. The girder design procedure states that an effective girder section includes an effective width of skin plate, $b^{\prime}$, acting as a cover plate. The Corps follows American Institute of Steel Construction (AISC 1980, Section 1.9.1.1), which suggests that

$$
b^{\prime}=\frac{95}{\sqrt{F_{y}}} t
$$

where $t$ is the plate thickness and $F_{y}$ is the yield stress in kips per square in.

62. One of the program authors revealed in a telephone conversation that the investigation module, CMINV, differs somewhat from the theory given in the Corps Engineering Manual for the effective webs of girders. CMNIV follows AISC, Section 1.9.2.2 (AISC 1980), which suggests that an effective web depth is

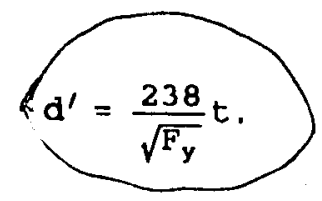

If the actual web area is greater than the effective web area, the effective area is used; otherwise, the actual web area is used. This is a conservative assumption. 


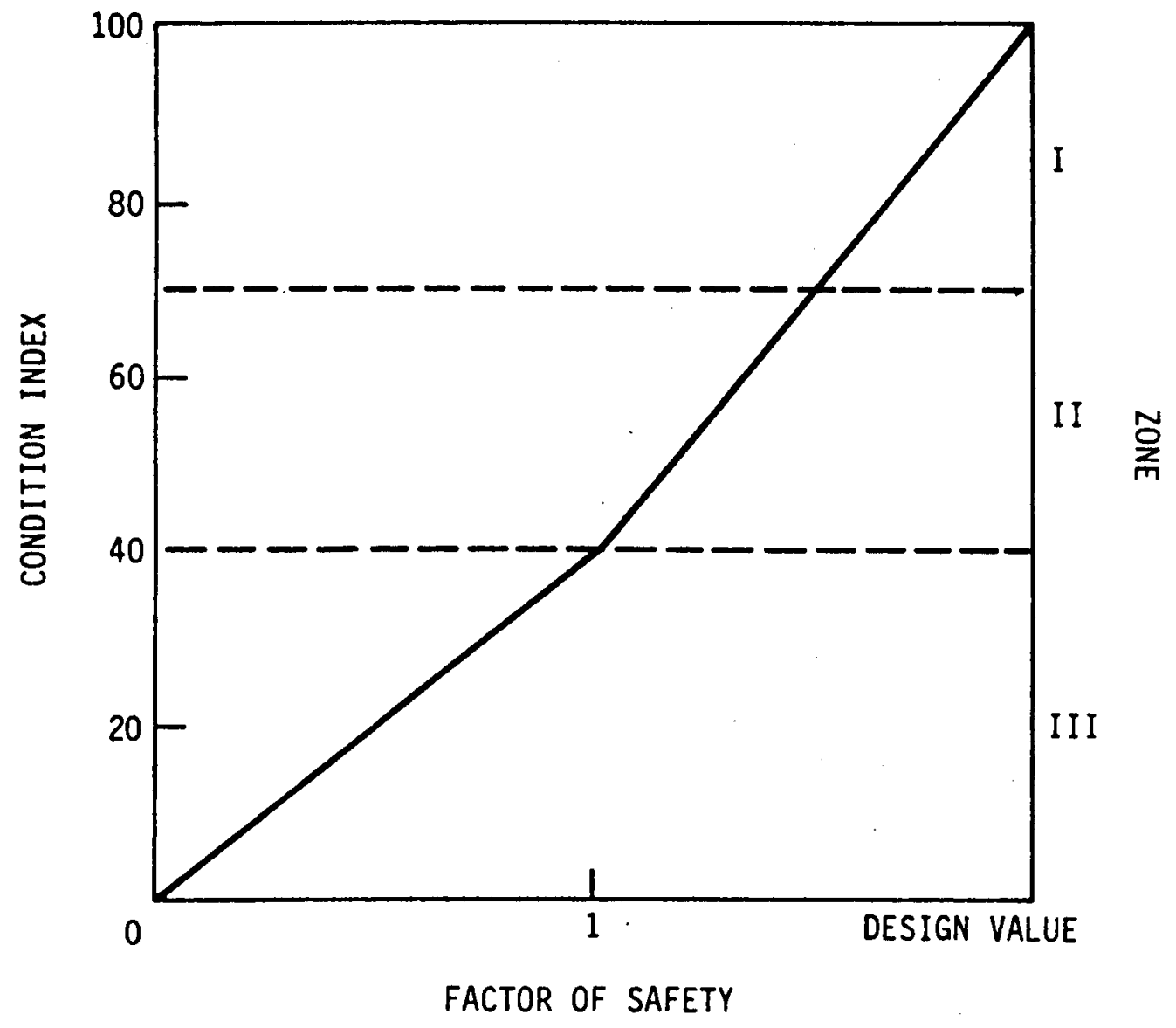

Figure 18. Relationship between factor of safety and structural condition index (Eq 1 ).

FULL MITERED POSITION-- PLAN VIEW

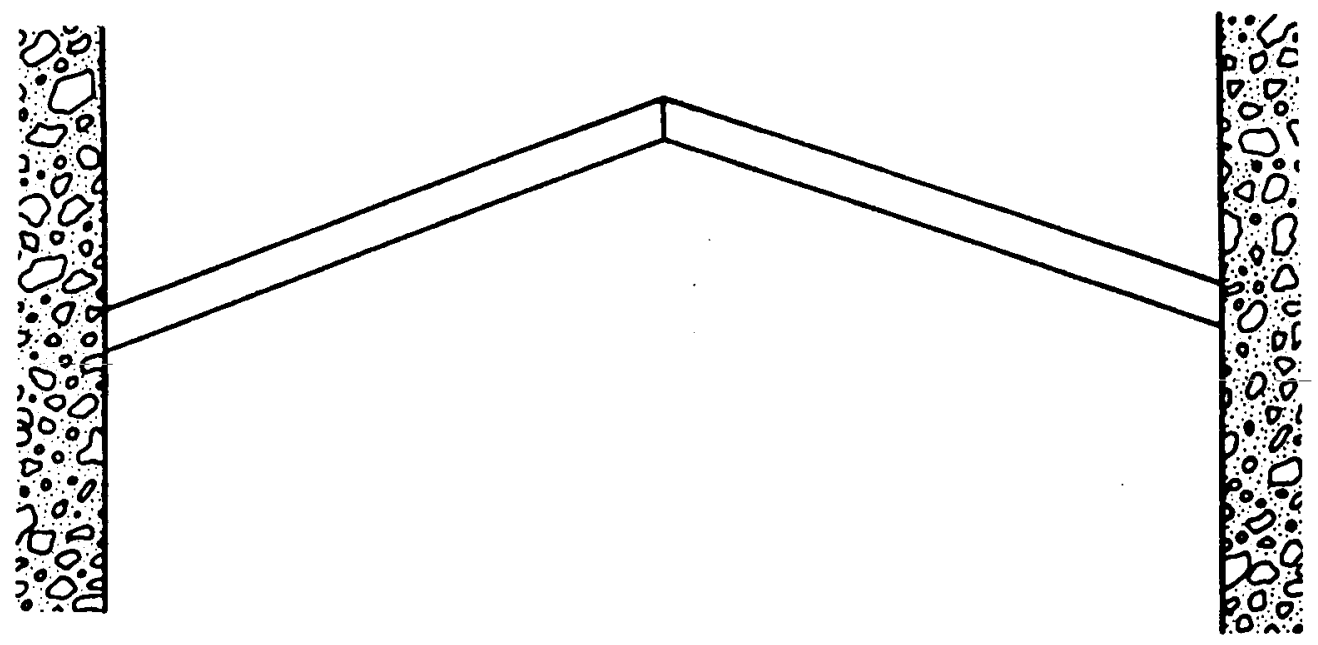

Figure 19. Three-hinged arch 


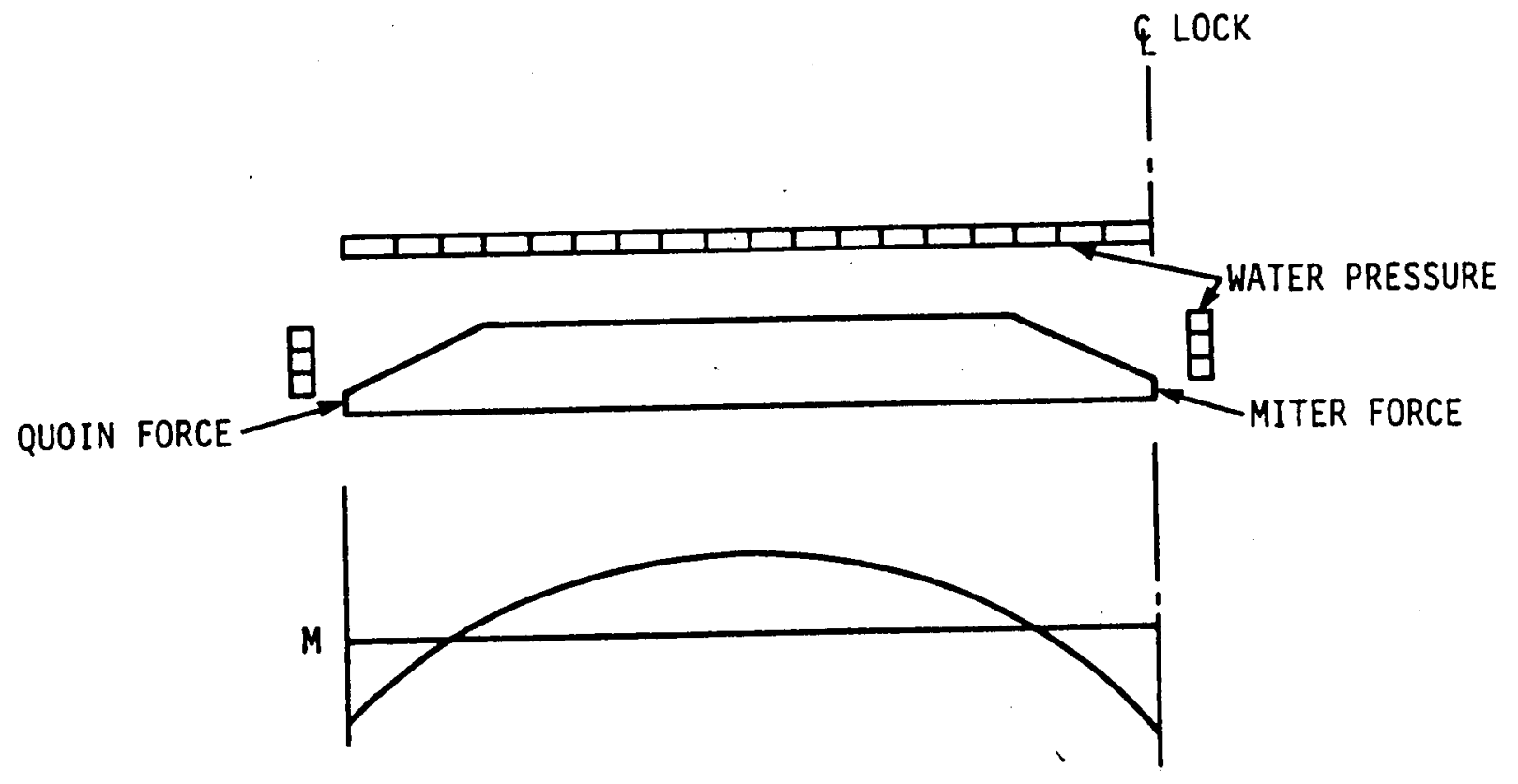

Figure 20. Forces and reactions on miter lock gate

63. When a stress analysis is performed, the calculated bending and axial stresses are compared to the allowable stress. The allowable values of axial and bending stress are determined by the US Army Corps of Engineers (1963) or AISC specifications. The girder effective length for buckling is taken as the distance between end diaphragms, and the radius of gyration is taken around the major axis. As a check for weak axis buckling, the girder effective length is taken as the distance between intermediate diaphragms with a minor axis radius of gyration. The bending factor (BF) is defined as the ratio of actual stress to the allowable stress. For girders, the bending factor is the following.

64. If $\mathrm{f}_{\mathrm{a}} / \mathrm{F}_{\mathrm{a}} \leq 0.15$,

$$
B F=\frac{f_{a}}{F_{a}}+\frac{f_{b}}{F_{b}} .
$$

65. If $\mathrm{f}_{\mathrm{a}} / \mathrm{F}_{\mathrm{a}}>0.15$,

$$
B F=\frac{f_{a}}{F_{a}}+\frac{C_{m b}^{f_{b}}}{\left(1-\frac{F_{a}}{F_{e}^{\prime}}\right) F_{b}} .
$$


where

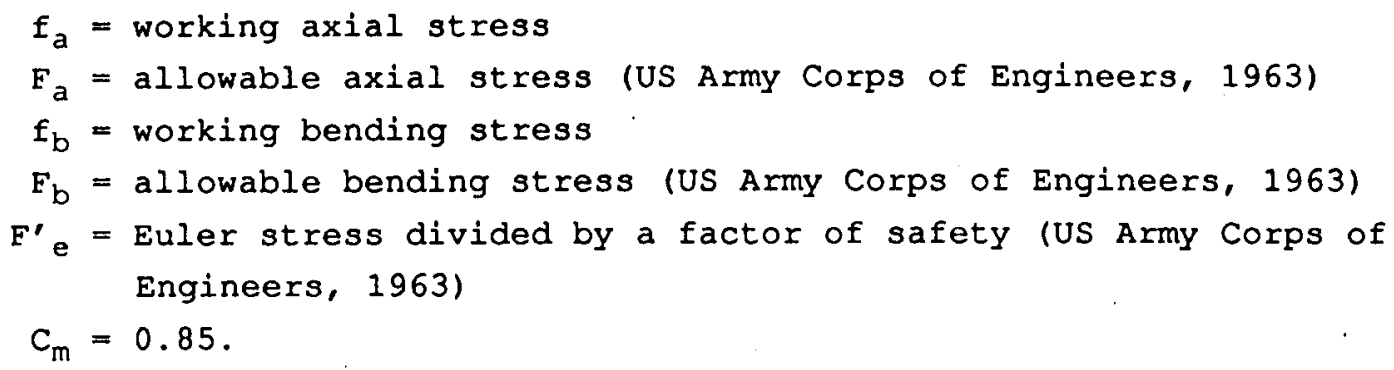

For design, the BF must be less than one.

66. For each load case $i$ described above:

a. The stress investigation module, CMINV, calculates the bending factors, $\mathrm{BF}_{j}$, according to $\mathrm{Eq} 4$ or $\mathrm{Eq} 5$ for up to 10 locations along length of girder, $f$. The number of locations depends upon the number of changes in the cross-sectional properties. For example, CMINV calculates the stresses at all changes in cross section, at the center, and at the ends.

b. A computer program, which interfaces with the CMINV output file, calculates the safety factors for each girder, FS $j$, as the least factor of safety for all 10 locations, or

$$
F S_{j}=\frac{F S_{d}}{\operatorname{maximum}\left(\mathrm{BF}_{j}\right)},
$$

and the condition index, $\mathrm{CI}_{\mathrm{Gj}}$, from $\mathrm{Eq} 1$.

c. The program calculates the overall condition index for all girders for the load case $i, C_{G 1}$, as the minimum of all girder condition indexes,

\section{Skin plate}

$$
C I_{G i}=\operatorname{minimum}\left(C I_{G j} \text { for all girders }\right) \text {. }
$$

67. The skin plate is located on the upstream side of most horizontally framed miter lock gates and is designed for plate action. For the structural analysis, the edges of the panels are assumed to be fixed at the centerline of the vertical intercostals and at the edges of the horizontal girder flanges. Plate theory is used to determine the stress in the skin plate (US Army Corps of Engineers 1984).

68. The Huber-Mises yield criteria, which combines the two perpendicular stresses in the plate, $f_{x}$ and $f_{y}$, into an effective stress, $f_{\text {, at. a }}$ particular point is used to evaluate the combined stress.

$$
f^{2}=f_{x}^{2}+f_{y}^{2}-f_{x} f_{y} \text {. }
$$

The effective skin plate stress is determined at two locations: (a) At the intercostal, where $f_{x}$ is the plate analysis stress at the fixed edge and $f_{y}$ is the intercostal bending stress from the following section, and (b) at the girder, where $f_{x}$ is the girder bending stress from the previous section and $f_{y}$ 
is the plate analysis stress. For design, the effective stress, f, must be less than $0.75 \mathrm{~F}_{\mathrm{y}}$.

69. For each Load Case $i$ described above:

a. The stress investigation module, CMINV, calculates the biaxial skin plate stress, $f$, according to Eq 8 for two locations per panel.

b. A computer program interfaces with the CMINV output file and calculates the bending factor, $\mathrm{BF}_{j}$, for each panel, if by dividing the effective stress $f$ by the allowable biaxial stress. The program then calculates the safety factor for each panel, FS $j$, as the least factor of safety for the two locations according to Eq 6 , and the condition index, $\mathrm{CI}_{\mathrm{Sj}}$, from Eq 1 .

c. The program calculates the overall condition index for all skin plate panels for the Load Case $i, \mathrm{CI}_{\mathrm{Si}}$, according to

$$
\mathrm{CI}_{S I}=\operatorname{minimum}\left(\mathrm{CI} \mathrm{Sj}_{\mathrm{f}}\right. \text { for all skin panels). }
$$

\section{Intercostals}

70. Intercostals provide stiffness to the skin plate between vertical diaphragms. An effective width of the skin plate is assumed to act with an intercostal (Eq 2). Intercostals are assumed fixed at the girder centerline with the average water pressure at the center of the panel acting on a contributing area as shown in Figure 21. The intercostal stress is determined at the midspan and ends of the intercostal.

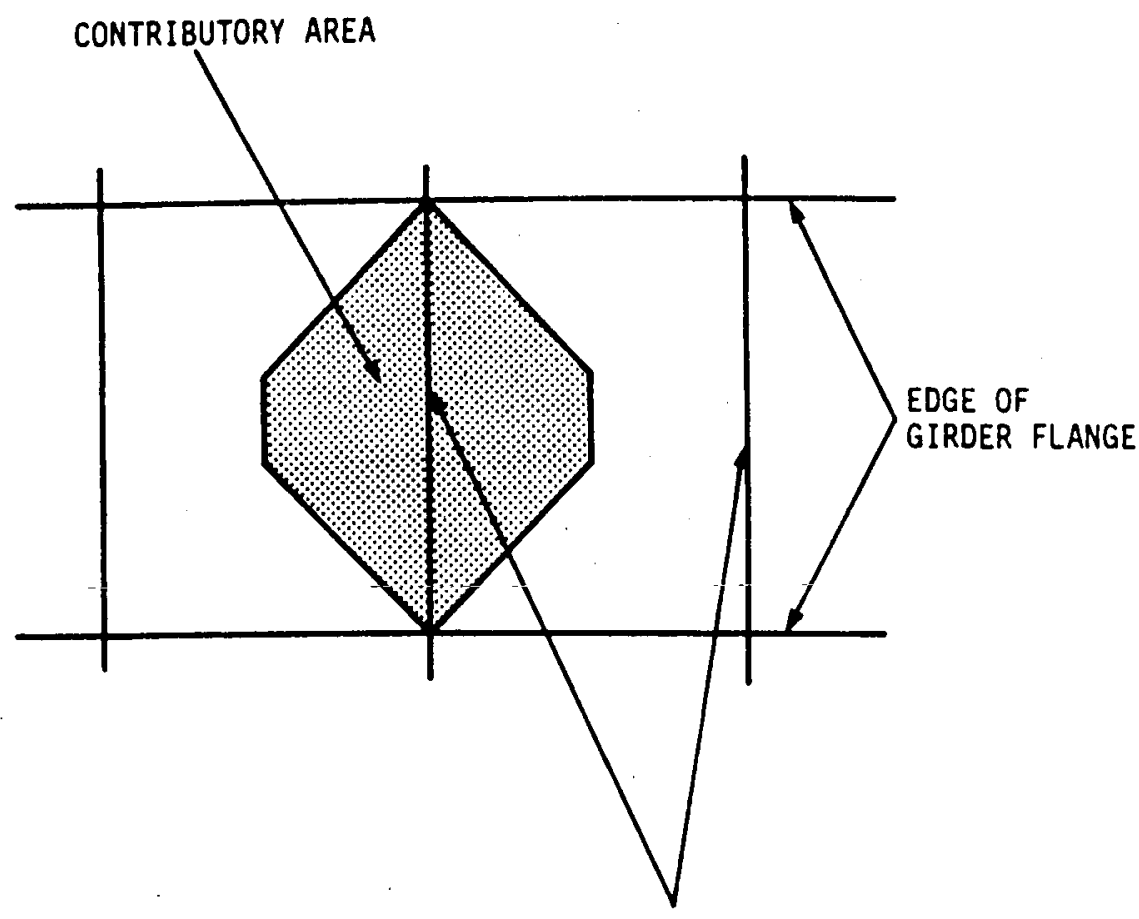

\section{INTERCOSTALS}

Figure 21. Contributory area for intercostal 
71. For each load case $i$ described above:

a. The stress investigation module, CMINV, calculates the end and midspan intercostal stress for each panel $j$.

b. A computer program interfaces with the CMINV output file and calculates the bending factor, $\mathrm{BF}_{j}$, safety factor, FS , and condition index, $\mathrm{CI}_{I f}$, following the same procedure as in the skin plate analysis.

c. The program calculates the overall condition index for all intercostals for the load case $i, C_{I 1}$, according to

$$
C I_{I i}=\text { minimum }\left(C I_{I j}\right. \text { for all intercostals). }
$$

\section{Leaf condition index for all load cases}

72. The structural condition index for an entire leaf for each individual load case, $\mathrm{CI}_{1}$, is the minimum condition index of the three component condition indexes, Eq 7, 9 and 10. Thus, for each Load Case $i$

$$
\mathrm{CI}_{i}=\operatorname{minimum}\left(\mathrm{CI}_{\mathrm{Gi}}, \mathrm{CI}_{\mathrm{Si}}, \mathrm{CI}_{\mathrm{Ii}}\right)
$$

The final leaf structural condition index for all load cases is calculated by taking the minimum of the condition indexes for each load case,

$$
\mathrm{CI}=\text { minimum }\left(\mathrm{CI}_{1}, \mathrm{CI}_{2}, \mathrm{CI}_{3}, \mathrm{CI}_{4}, \mathrm{CI}_{6}\right)
$$

\section{Corrosion-Modified Structural Condition Index}

73. Corrosion is the loss of steel due to interaction with its environment. The US Army Corps of Engineers recognizes this material loss and adds $1 / 16$ in. to the design thicknesses of the structural components for lock gates. Structural components subjected to corrosion detract from the safety or structural soundness of a miter lock gate. If a structural component has a low structural condition index, the presence of corrosion introduces an additional risk. The material loss from corrosion on a gate is seldom uniform. To account accurately for corrosion losses, locations with reduced thicknesses would have to be carefully mapped during the inspection. A sophisticated analysis technique that allowed for localized thickness reductions would follow. A less tedious and more conservative technique is to apply a corrosion factor, representing the worst corrosion level for a component, to the structural condition index of the same component

Corrosion-modified structural condition index

$=$ (structural condition index) (corrosion condition index). 
The corrosion condition index is the functional condition index (Distress Code 10 in Chapter 4) expressed as a fraction for each specific component (girder, skin, and intercostal). The structural condition index is defined earlier for the girders (Eq 7), skin (Eq 9), and intercostals (Eq 10). The corrosionmodified structural condition index in Eq 13 is not intended to be a sophisticated correction that reflects all the aspects of corrosion thickness reduction. Such sophistication is beyond the inspection level and analysis level of this project. The equation does, however, recognize that the safety of a structure is compromised by corrosion. As such, if both a reduced structural condition (low factor of safety) and corrosion condition index (high corrosion) occur, it will be reflected by Eq 13. This should alert an engineer to indicate further investigation may be necessary (zone 3 condition).

74. The corrosion-modified structural condition index for an entire leaf is found as in the previous section. For each load case, Eq 11 is used to find the minimum of each component. The minimum of all load cases is the final corrosion-modified structural condition index, Eq 12. 
75. The second set of criteria that evolved during this project was much more subjective than the structural evaluation described in Part III. This set of criteria involves "engineering judgment" and depends on the experience of the person making the evaluation. These aspects of the condition index were much more difficult to capture. Experts in this field were interviewed, and discussion continued over 1 year until a consensus began to develop. Preliminary field visits of engineers with lock and dam personnel were conducted at Mississippi Lock and Dam 14 and 15, Wilson and Fort Louden on the Tennessee River, and at old Hickory on the Cumberland River. After progressively indepth discussions, field tests were conducted at Lock and Dam 15 and 19 on the Mississippi, Kentucky Dam on the Tennessee, and Barkley Dam on the Cumberland. The authors have attempted to blend all the opinions expressed at these meetings into a set of "expert opinion" rules that are embedded in the evaluation that constitutes the functional condition index. The rules have been designed to interpret straightforward visual observation data in much the same manner that a seasoned engineer would interpret field observations.

76. The experts took many factors into account as they evaluated the functional condition index. One aspect was the serviceability of the structure, that is, its performance at normal and below-normal service conditions on a day-to-day basis. For example, if a miter lock gate is leaking excessively, it is not performing at its intended level of service. Extreme leaks would prevent operation of the lock. Excessive gudgeon pin wear, for instance, will eventually prevent gate operation. The appearance of the gate in its particular location is a factor. Operational noises are indications of problems.

77. Probably a more important factor in the functional condition index is, for lack of a better term, subjective safety. Subjective safety refers to the idea that an engineer, using his or her judgment, may decide that a safety problem is likely. A single observation or series of inspection observations may indicate that a potential problem exists or, on the basis of the engineer's experience, that a safety problem is developing and may soon become 
critical. These types of observations are difficult to quantify. They cannot, for example, be incorporated into a simple structural analysis, such as those described in Part III. Only a visual indication of the problem is present.

78. As another example, excessive movement of the anchorage embedment may Indicate a potential safety problem. The embedded anchorage may have corroded and be approaching a failure condition. The only visual observation may be movement at the steel and concrete interface. Only a more detailed inspection, which may require concrete removal, will reveal the true cause. However, for the purposes of this study, it is certainly appropriate to reduce the condition index of the gate because of the potential safety problem. Cracks, dents, leaks, downstream movement of the gate during filling, and gaps between the bearing blocks may also indicate safety problems.

79. A series of critical measurements are made on each gate to quantify the functional condition index. Experts were asked to interpret these measurements in light of the serviceability and safety of the gate and assign limiting values to the measurements. Specifically, a series of distresses is identified. Each distress is quantified by a measurement, $x$. For example, anchorage movement is a distress quantified by three quantities, one of which is the relative motion between the steel and the concrete at the steel and concrete interface. Typically, each distress could be either a problem in itself or an indication of a problem. For example, corrosion distress is itself a problem. Anchorage movement is a problem in itself if it is sufficiently large to impede gate operation, or it could indicate a safety problem, as discussed in the previous paragraph.

80. The functional condition index is quantified by

$$
\text { Functional } C I=100(0.4)^{X / X_{\max }}
$$

where $x_{\max }$ is some limiting value of $x$. According to the previous description of action zones (Table 2), $x_{\max }$ is defined as the point at which the functional condition index is 40 , that is, the dividing point between zones 2 and 3. Figure 22 illustrates the equation and zones from Table 2 . If $x$ is 0 , that is, no distress, the condition index is 100. Note that the functional 
condition index never quite reaches 0 . Following the discussion in the paragraphs above, $x_{\max }$ for each distress has been selected by experts to be the point at which the gate requires immediate repair or, at a minimum, mandates a more detailed inspection and condition index evaluation. In other words, it is a potentially hazardous situation. The experts have made the judgment for $x_{\max }$ based on serviceability or subjective safety considerations. The mix and weight of serviceability versus safety are incorporated into the experts' judgment. Tables of $\mathrm{x}_{\max }$ are given in this chapter for several distresses.

81. If a miter lock gate structure is designed and constructed properly, it has an initial condition index of 100. As time passes and the structure is exposed to varying environmental and operational situations, its condition will deteriorate. The condition index will degrade as various distresses are incurred. Ten distresses have been identified for

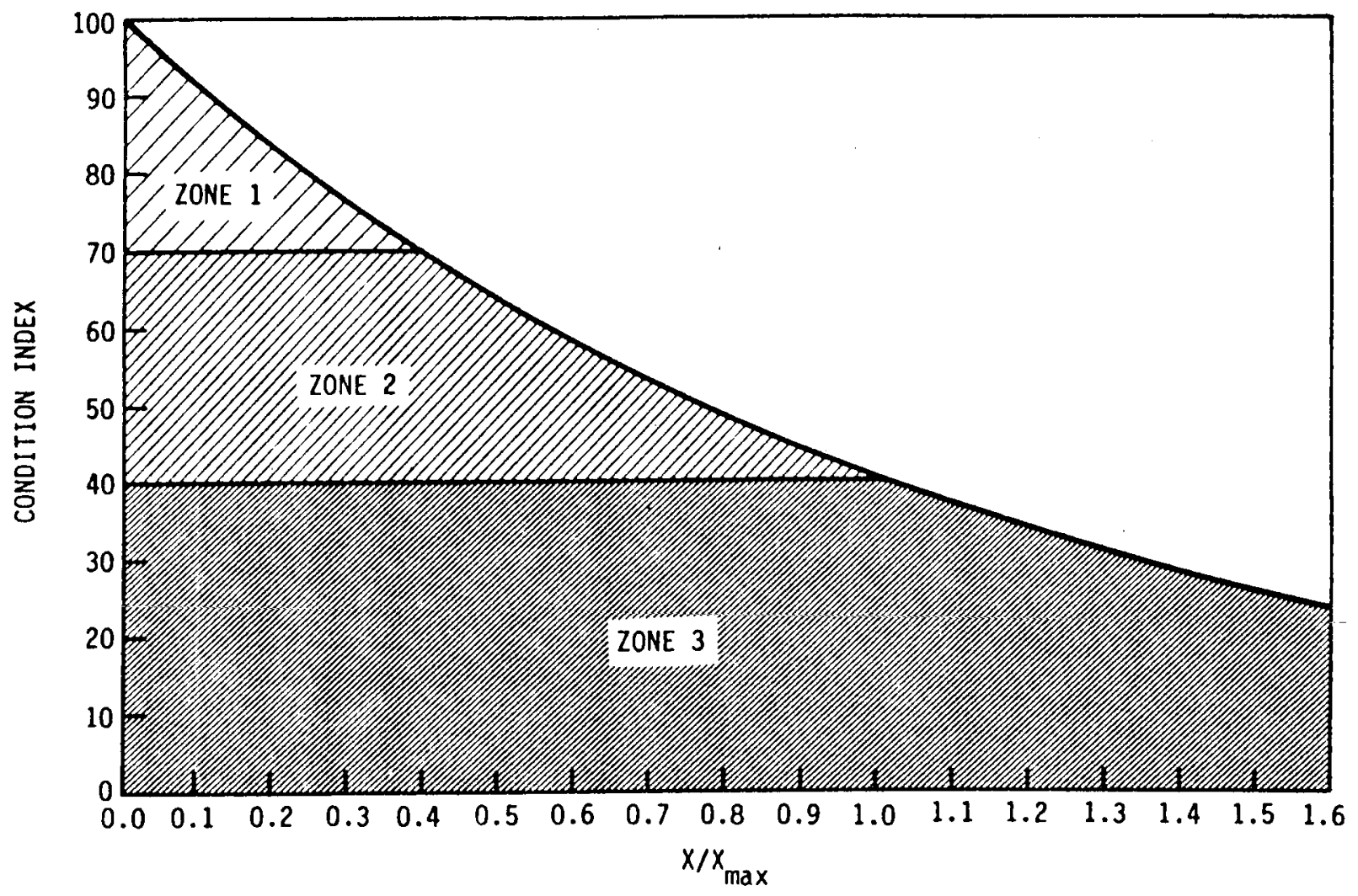

Figure 22. Functional condition index related to $\mathrm{X} / \mathrm{X}_{\max }$ (Eq 14) 
Table 3

Distresses in Miter Lock Gates

\begin{tabular}{|c|c|c|}
\hline $\begin{array}{l}\text { Distress } \\
\text { Code }\end{array}$ & Distress & Brief Description \\
\hline 1 & $\begin{array}{l}\text { Top anchorage } \\
\text { movement }\end{array}$ & $\begin{array}{l}\text { Motion of the upper anchorage system } \\
\text { during gate operation }\end{array}$ \\
\hline 2 & Elevation change & $\begin{array}{l}\text { Vertical displacement of the gate during } \\
\text { operation }\end{array}$ \\
\hline 3 & Miter offset & $\begin{array}{l}\text { Misalignment of the bearing blocks at the } \\
\text { mitex point }\end{array}$ \\
\hline 4 & Bearing gaps & $\begin{array}{l}\text { Gaps between the bearing blocks at the } \\
\text { quoin and miter }\end{array}$ \\
\hline 5 & Downst ream movement & $\begin{array}{l}\text { Downstream displacement of the miter } \\
\text { point as the head is applied }\end{array}$ \\
\hline 6 & Cracks & Breaks in the structural steel components \\
\hline 7 & Leaks/boils & Water passing through or around the gate \\
\hline 8 & Dents & Disfiguration of the steel components \\
\hline 9 & Noise/Vibration & $\begin{array}{l}\text { Abnormal noise, vibration, or jumping } \\
\text { during gate operation }\end{array}$ \\
\hline 10 & Corrosion & $\begin{array}{l}\text { Loss of steel due to interaction with the } \\
\text { environment }\end{array}$ \\
\hline
\end{tabular}

categorization in this project. Each is described briefly in Table 3 . Each of these distresses can detract from the safety and serviceability of miter lock gates.

\section{Distress Descriptions and $x_{\max }$}

82. The functional condition index for each distress depends on the ratio of a field measurement $x$ to some limit, $x_{\max }$ as in Eq 1 . In the following sections, the definition, measurement of $x$, and $x_{\max }$ values for each distress will be described. Values are presented here for consideration by the initial users of this work.

83. Potential causes of each distress are also listed and discussed. These causes are the problems that must be addressed in the maintenance and 
repair of the gate. The diagnosis of causes for each distress is a complex issue. Many times, a distress may have several possible causes. Or, often, a combination of distresses must be present before a certain cause can be identified.

\section{Distress Code 1: Top Anchorage Movement}

\section{Definition and causes}

84. Anchorage movement is a horizontal, translational displacement of the components that make up the top anchorage system. This movement is in addition to the normal rotation that occurs at the gudgeon $p$ in as the gates open and close. Typically each gate leaf has two anchorage arms, one parallel and one approximately perpendicular to the lock chamber. Movement can occur at three locations on each anchor arm (Figure 10). It can occur during opening or closing the gates and during filling or emptying the lock chamber. Anchorage movement can be caused by several factors:

a. Location 1: Interface of embedded steel with concrete.

(1) Corrosion of steel within embedment.

(2) Failure of concrete at embedment.

(3) Movement of steel within concrete.

b. Location 2: Embedded steel to eyebar connection.

(1) Wedge pin wear.

(2) Linkage pin or bolt wear.

c. Location 3: Eyebar to gate leaf connection.

(1) Gudgeon pin wear.

(2) Gudgeon pin bushing wear.

The top anchorage system is the only mechanism that connects the top of the lock gate to the lock wall. Hence, the presence of anchorage movement may indicate a significant structural problem, or it could eventually introduce structural problems into other gate components.

Measurement and limits

85. The anchorage dimensions will be measured at the three locations on each anchor bar (parallel and perpendicular) (Figure 10). At Location 2, some anchorage configurations have an additional linkage pin. The measurement of 
movement at Location 2 will be made across both pin connections. Dimensions will be recorded on the inspection form when the gate leaves are in four positions: recessed (fully open), near mitered, mitered with 1 -ft head, and mitered with full head (fully closed). The maximum motion that occurs at Location $1, x_{1}$, is found by subtracting the smallest of the measurements at the four gate positions from the largest. Locations 2 and 3 are done similarly. Although the position at which the maximum motion occurs is not explicitly contained in the condition index, an experienced engineer may wish to know it to aid in diagnosis of the particular cause. The presence of any concrete cracking or spalling in the vicinity of the embedded anchorage at Location 1 is also recorded.

86. A displacement of $0.03 \mathrm{in}$. has been selected as the limiting motion at Location 1 for all gate sizes.

$$
\mathrm{x}_{\max 1}=0.03 \mathrm{in} .
$$

The experts judged that motion greater than this could indicate a significant structural problem. Any spalling or cracking of the concrete in this area will reduce its functional condition index by a factor of 0.85 .

87. Location 2 is often a pin connection or a wedge pin connection. The linkagebar usually includes a length adjustment device such as a turn buckle or wedge plates. The limiting $x_{\max 2}$ at this location was judged to depend on the leaf height, which is critical for the operation of high gates. A limiting value of $0.50 \mathrm{in}$. was chosen for low gates (width divided by height equal to 2) and $0.125 \mathrm{in.} \mathrm{for} \mathrm{high} \mathrm{gates} \mathrm{(width/height} \mathrm{equal} \mathrm{to} \mathrm{1/2).} \mathrm{For}$ other heights, a linear equation that fits these two cases is used:

$$
x_{\max 2}=0.25 \text { (width/height)(in.). }
$$

88. Location 3 is the relative movement of the gudgeon pin with respect to the linkage arm. The maximum displacement at this location was again judged to depend on leaf height. The linear equation

$$
x_{\max 3}=0.18(\text { width/height })(\text { in. })
$$


gives a value of $0.36 \mathrm{in}$. for low gates (width and height equal to 2) and 0.09 in. for high gates (width/height equal to $1 / 2$ ).

89. The functional condition index for an individual anchor arm is taken as the minimum of the condition indexes of its components:

$$
\mathrm{CI}=\operatorname{minimum}\left(\mathrm{CI} I_{1}, \mathrm{CI}_{2}, \mathrm{CI}_{3}\right)
$$

The functional condition index for the anchorage movement distress for an individual leaf is the minimum of the condition index for the perpendicular or parallel anchor bars.

\section{Example}

90. From measurements at the four leaf positions, a miter lock gate leaf $62 \mathrm{ft}$ wide and $100 \mathrm{ft}$ tall has the following maximum movements in the perpendicular anchor arm:

$$
\begin{aligned}
& x_{1}=0.004 \mathrm{in} . \\
& x_{2}=0.02 \mathrm{in} . \\
& x_{3}=0.04 \mathrm{in} .
\end{aligned}
$$

The concrete around the embedded anchorage (Location 1) is spalled and cracked. From Eq 16 and 17

$$
\begin{aligned}
& x_{\max 2}=0.25(62 / 100)=0.16 \mathrm{in} . \\
& x_{\max 3}=0.18(62 / 100)=0.11 \mathrm{in} .
\end{aligned}
$$

The functional condition indexes for the perpendicular anchor arm are

$$
\begin{aligned}
& C I_{1}=\left[100(0.4)^{0.0004 / 0.03}\right] 0.85=75 \\
& C I_{2}=100(0.4)^{0.02 / 0.16}=89 \\
& C I_{3}=100(0.4)^{0.04 / 0.11}=72
\end{aligned}
$$

where the 0.85 factor has been used in $\mathrm{CI}_{1}$ because the concrete is cracked. By Eq 18 the functional condition index for the perpendicular anchor arm is 


$$
C I_{\text {perp }}=\text { minimum }(75,89,72)=72 .
$$

This puts the CI in very good condition: function, not impaired. To continue, the functional condition index for the parallel anchor arm for this example could be

$$
C I_{\text {para }}=82 \text {. }
$$

The functional condition index for the top anchorage movement for this leaf is the minimum of the perpendicular and parallel condition indexes,

$$
C I=\operatorname{minimum}(72,82)=72 \text {. }
$$

If the concrete had not been cracked near the perpendicular arm, $\mathrm{CI}_{1}$ would be 88 and $\mathrm{CI}_{\text {perp }}$ would still be' 72 , which would still control the functional condition index for the top anchorage movement distress and thus give it a very good rating.

\section{Distress Code 2: Elevation Change}

\section{Definition and causes}

91. The elevation change distress represents vertical displacement of the gate leaves as they are brought from the recessed position to a mitered, full-head position. Elevation change can be caused by several factors.

a. Quoin bearing failure if the elevation change occurs at the quoin as the head is applied.

b. Premature quoin contact if the elevation change occurs at the miter as the gate is brought into miter.

c. Blocking out a floating pintle if the elevation change occurs at the quoin as the gate is brought to miter and head is applied.

Excessive elevation changes indicate that additional stresses may exist in the gate components, for example, pintle, anchorage, or girders, depending on which of the above causes is identified. 


\section{Measurement and limits}

92. Measurement of elevation changes will be made at the miter and quoin of each gate leaf with the leaves in four positions: recessed, near miter, mitered with 1 -ft head, and mitered with full head. From the above causes, the important changes in quoin elevation occur between leaf positions 2 and 4 and between positions 3 and 4 . Hence, the $x$ value for the change in quoin elevation is chosen as

$$
\begin{array}{r}
x_{Q}=\operatorname{maximum}[(\text { elevation e } 4 \text { - elevation e 2), } \\
\text { (elevation e } 4 \text { - elevation ( 3)]. }
\end{array}
$$

The limiting $x_{\max }$ value for the change in quoin elevation has been judged to be

$$
x_{\operatorname{maxQ}}=0.05 \mathrm{ft} .
$$

Foot units are used because elevation changes are recorded by a surveying instrument with a level rod graduated in feet. Elevation changes beyond $x_{\max }$ would be judged severe and indicate a problem requiring further consideration. 93. The miter elevation change between positions 1 and 3 and positions 2 and 3 is considered important by the experts:

$$
\begin{array}{r}
x_{M}=\operatorname{maximum}[\text { (elevation e } 3 \text { - elevation e 1), } \\
\text { (elevation \& } 3 \text { - elevation ( 2)]. }
\end{array}
$$

The limiting value for the change in miter elevation was judged to be more critical for high leaves. Values of $0.04 \mathrm{ft}$ for high leaves (width/height equal $1 / 2$ ) and $0.16 \mathrm{ft}$ for low leaves (width/height equal 2) were judged to be appropriate. An equation that gives these values as well as values for intermediate heights is

$$
x_{\max M}=0.08(\text { width/height })(f t) .
$$




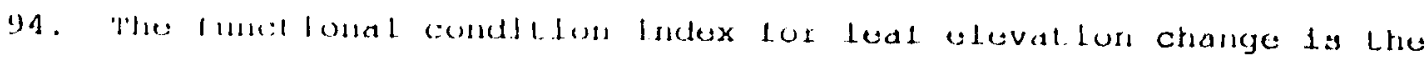
minimum of the quoin and miter values:

$$
\mathrm{CI}=\operatorname{minimum}\left(\mathrm{CI} \mathrm{Q}^{\prime} \mathrm{CI_{M }}\right)
$$

Example

95. The following elevation readings have been recorded in feet for a miter lock gate $70 \mathrm{ft}$ wide and $100 \mathrm{ft}$ tall.

\begin{tabular}{|c|c|c|c|c|}
\hline & Position 1 & Position 2 & Position 3 & Position 4 \\
\hline \hline Miter & 3.82 & 3.81 & 3.80 & 3.81 \\
\hline Quoin & 3.75 & 3.74 & 3.75 & 3.75 \\
\hline
\end{tabular}

Taken from Eq 19, the appropriate $x$ value for the elevation change at the quoin is

$$
\begin{aligned}
x_{Q} & =\operatorname{maximum}[(3.75-3.74),(3.75-3.75)] \\
& =0.01 \mathrm{ft} .
\end{aligned}
$$

From Eq 20,

$$
\mathrm{X}_{\operatorname{maxQ}}=0.05 \mathrm{ft}
$$

The functional condition index for the elevation change at the quoin is

$$
C I=100(0.4)^{0.01 / 0.05}=83
$$

From Eq 21, the $x$ value for the change in elevation at the miter is

$$
\begin{aligned}
X_{M} & =\text { maximum }[(3.80-3.82),(3.80-3.81)] \\
& =0.02 \mathrm{ft} .
\end{aligned}
$$


From Eq 22

$$
\mathrm{x}_{\max M}=0.056 \mathrm{ft} .
$$

The functional condition index for the elevation change at the miter is

$$
C I_{M}=100(0.4)^{0.02 / 0.056}=72 \text {. }
$$

From Eq 23, the final CI for elevation change for this leaf is

$$
C I=\operatorname{minimum}(83,72)=72 \text {. }
$$

\section{Distress Code 3: Miter offset}

\section{Definition and causes}

96. The miter offset distress represents gate leaves longitudinally misaligned with respect to each other at the miter blocks as illustrated in Figure 11. In this distress, the bearing blocks at the miter do not meet exactly. Such a condition can introduce eccentricities at the bearing surfaces which, in turn, introduce additional stresses into the structural components of the gate, especially the horizontal girders, as head is applied. Diagonals may also be overstressed.

Miter offsets can be caused by several factors:

a. Improper diagonal prestress.

b. Blockage of sill.

c. Improper closure.

d. Improper gate alignment.

e. Deformed gate.

f. Malfunctioning mitering device.

Safety could be compromised if the condition is severe.

Measurement and limits

97. For a horizontally framed leaf, the miter offset will be measured at the top of the gate, $O_{1}$ (Dimension 4, Figure 11) and at the water level, $O_{2}$ (Dimension 5, Figure 11) with $1 \mathrm{ft}$ of head (Figure 23). The distance from the 

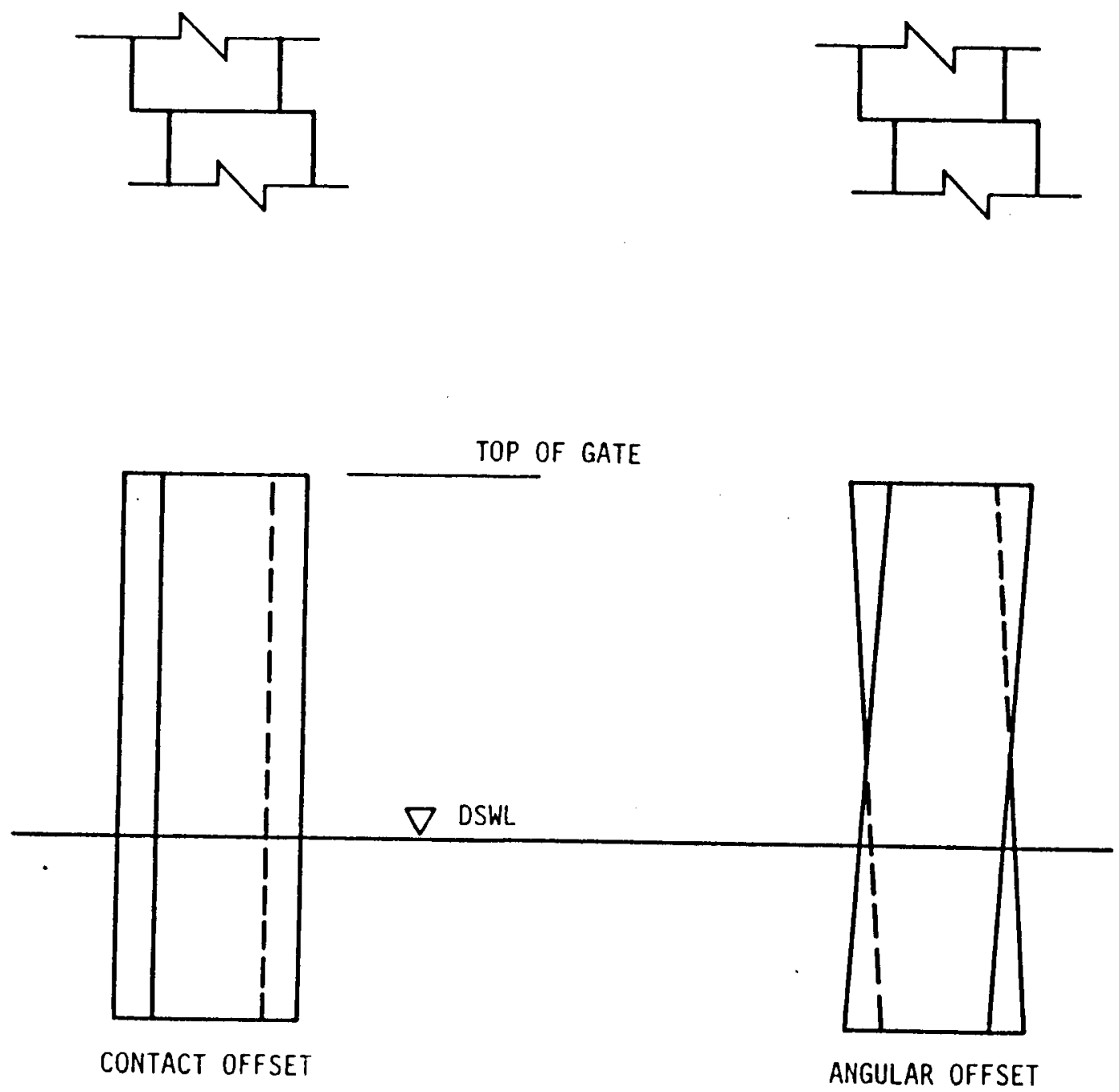

Figure 23. Miter block offsets (contact and angular)

walkway will be recorded at each measurement location, $Y_{1}$ and $Y_{2}$, respectively. The sign convention for miter offset is as follows: right gate farther downstream than the left gate is a positive offset. For the horizontally framed gate, the maximum offset is of concern because it will have the greatest eccentricity. The maximum could, of course, occur at any point along the miter bearing blocks. Since measurements are not made along the entire length, the miter blocks will be assumed to remain straight. The maximum offset will then occur at the top or at the sill. Since the bearing 
blocks are assumed to remain stralght, the recorded gaps and distances can be used to extrapolate to the offset at the sill,

$$
\left.O_{S}=\left[O_{1}\left(Y_{2}-H\right)+O_{2}\left(H-Y_{1}\right)\right] / Y_{2}-Y_{1}\right)
$$

98. Two types of miter offsets will be defined for horizontally framed leaves. The two types usually have different causes. The first type, contact offset, occurs when the miter bearing blocks are nominally parallel and plumb but do not meet properly (Figure 23). Contact offset is measured by the maximum offset distance

$$
x_{C}=\text { maximum of absolute value }\left(O_{1}, O_{S}\right)
$$

98. Two types of miter offsets will be defined for horizontally framed leaves. The two types usually have different causes. The first type, contact offset, occurs when the miter bearing blocks are nominally parallel and plumb but do not meet properly (Figure 23). Contact offset is measured by the maximum offset distance

$$
x_{C}=\text { maximum of absolute value }\left(O_{1}, O_{S}\right)
$$

If $\mathrm{x}_{\mathrm{C}}$ is too large, poor bearing conditions exist and eccentricity is introduced into the leaf girders. The experts judged the limiting case to be

$$
x_{\operatorname{maxC}}=2 \text { in. }
$$

99. The second type of offset, angular offset, is a measure of the relative angle between the two leaves. In this case the miter bearing blocks are not parallel. One or both blocks are misaligned with respect to the other in an X-like pattern (Figure 23). Angular offset is expressed as the difference between the sill and top offset:

$$
x_{A}=\text { absolute value of }\left(O_{S}-O_{1}\right)
$$


The misalignment represented by this angle is often caused by improper diagonal prestress. The limiting value for angular offset is also selected as

$$
x_{\max A}=2 \mathrm{in}
$$

but for reasons different from those for contact offset. The presence of flapping diagonals during gate operation will reduce the condition index of the angular offset by a factor of 0.85 .

100. The condition index for horizontally framed miter offsets is

$$
C I=\operatorname{minimum}\left(C I_{C^{\prime}} C I_{A}\right) \text {. }
$$

It is the same for both leaves.

101. For a vertically framed gate, only the offset at the top of the miter block, $o_{1}$, is

$$
x=0_{1}
$$

If $\mathrm{X}$ is too large, a poor bearing condition exists and eccentricity is introduced in the top girder as in the horizontally framed case. The limiting value for the vertically framed offset, which is not as critical as for horizontally framed, is

$$
\mathrm{x}_{\max }=4 \mathrm{in} .
$$

The miter offset condition index applies to both leaves.

\section{Example}

102. For a 60-ft-tall horizontally framed miter lock gate, the following miter offsets were recorded. The diagonals did not flap when either leaf was opened and closed.

$$
\begin{array}{ll}
o_{1}=+1 \mathrm{in} . & y_{1}=1 \mathrm{ft} \\
o_{2}=+1 / 8 \mathrm{in} . & y_{2}=26 \mathrm{ft} .
\end{array}
$$


From Eq 24

$$
o_{S}=[1(26-60)+1 / 8(60-1)] /(26-1)=-1.1 \mathrm{in} .
$$

The contact offset is (Eq 25)

$$
x_{C}=\text { maximum of absolute value }(1,1.1)=1.1 \mathrm{in} .
$$

The condition index for the contact offset is

$$
C I_{C}=100(0.4)^{1.1 / 2}=60 \text {. }
$$

The angular offset between the two leaves is

$$
x_{A}=\text { absolute value }(-1.1-(+1))=2.1 \mathrm{in}
$$

The condition index for angular offset is

$$
C I_{A}=100(0.4)^{2.1 / 2}=38
$$

The condition index for all miter offsets is

$$
C I=\operatorname{minimum}(50,38)=38,
$$

which is a poor rating, a zone 3 condition.

\section{Distress Code 4: Bearing Gaps}

\section{Definition and causes}

103. The bearing gap distress represents an opening or separation of the bearing blocks at the miter, quoin, or both (Figure 12). Vertically framed gates can have a gap at the top girder only, whereas on horizontally framed gates the bearing gaps can run anywhere along the continuous length of the bearing blocks. Bearing gaps introduce additional stresses into the gate 
leaves because the gaps are forced closed as head is applied. Safety can be compromised if the gaps are excessive. Gaps can be caused by several factors:

a. Anchorage system wear.

b. Bearing block wear (quoin or miter).

c. Shifting of a floating pintle.

d. Blockage at the sill.

e. Improper gate alignment.

f. Deformed gate.

g. Improper adjustment of anchorage system.

h. Improper adjustment of gate seals (on vertical frame gates).

\section{Measurement and limits}

104. For a horizontally framed gate, measurements of the miter block gap will be made at the top of the gate, $\mathrm{MG}_{1}$, and at the water level, $\mathrm{MG}_{2}$, under a 1-ft-head situation (Dimension 7, Figure 12). Since gaps will not be measured along the entire length, the miter blocks will be assumed to remain straight, as for the offset distress. The recorded gaps and the respective vertical locations, $Y_{1}$ and $Y_{2}$, can be used to extrapolate the bearing gap between miter blocks at the sill, $\mathbf{M G}_{S}$, by a straight-line equation,

$$
\left.M G_{-S}=\left[M G_{1}\left(Y_{2}-H\right)+M G_{2}\left(H-Y_{1}\right)\right] / Y_{2}-Y_{1}\right)
$$

The $\mathrm{x}_{\mathrm{M}}$ value for miter block gaps on a horizontally framed gate is the maximum gap

$$
\mathrm{X}_{\mathrm{M}}=\operatorname{maximum} \cdot\left(\mathrm{MG}_{1}, \mathrm{MG}_{\mathrm{S}}\right) \cdot
$$

The presence of a leak at the miter bearing blocks, which follow the rising (emptying) water level and close as the water level continues to rise (empty), will also be recorded. The presence of this type of leak suggests a bearing gap forced closed as head pressure is applied. Additional stresses are implied. The limiting value for miter block gaps in a horizontal framed gate has been selected as

$$
\mathrm{x}_{\operatorname{maxM}}=1 / 2 \text { in }
$$


This level is judged to give concern about stresses induced as the gap is forced closed. Any leaks following the rising (emptying) water level will reduce the functional condition index by a leak factor, LF:

$$
\begin{gathered}
L F=1 \text { (no leaks at changing water level). } \\
L F=0.85 \text { (leak present at changing wter level). }
\end{gathered}
$$

105. For a horizontally framed gate, measurements of the quoin block gap will also be made at the top of the gate, $Q G_{1}$, and at the water level, $\mathrm{QG}_{2}$, under a 1-ft-head situation (Dimension 6, Figure 12). If the quoin blocks are assumed to remain straight, the recorded gaps and respective vertical locations, $Y_{1}$ and $Y_{2}$, can be used to extrapolate the gap between quoin blocks at the sill, $Q_{S}$, by a straight-line equation,

$$
\left.Q G_{S}=\left[Q G_{1}\left(Y_{2}-H\right)+Q G_{2}\left(H-Y_{1}\right)\right] / Y_{2}-Y_{1}\right)
$$

The gap between the quoin blocks at the sill may be affected by the type of pintle. If the pintle is fixed, then the important value is

$$
x_{Q}=\operatorname{maximum}\left(Q G_{1}, Q G_{S}\right)
$$

If the pintle is floating, then

$$
\mathrm{X}_{Q}=\operatorname{maximum}\left(Q G_{1}, Q G_{2}\right)
$$

The $\mathrm{x}_{\max }$ value for quoin blocks on a horizontal framed gate has been selected in the same way as for the miter:

$$
\mathrm{x}_{\max Q}=1 / 2 \text { in }
$$

Any leaks at the quoin that follow the rising (emptying) water level will reduce the condition index of the quoin by the leak factor (Eq 35).

106. For a vertically framed gate, measurements of the miter block gap and the quoin block gap will be made at the top girder bearing block, under a 
1-ft-head situation. Because this is the only bearing contact point between the gate leaves, the measurement could normally be expected to be 0 when the 1-ft gate leaves achieve a stable mitered position with head. The exception would probably be leaf blockage by foreign material or improper adjustment of miter seals. The $x_{M}$ and $x_{Q}$ values for the miter and quoin block gap on a vertically framed gate is the measurement $\mathrm{MG}_{1}$ and $\mathrm{QG}_{1}$, respectively. Leaks at the seals are not a factor. The $x_{\max }$ value for bearing block gaps on a vertically framed gate has been selected as

$$
\mathrm{x}_{\max M}=\mathrm{x}_{\max Q}=1 / 2 \text { in. }
$$

Gaps in the bearing blocks of vertically framed gates would normally not introduce additional stress into the top girder as the gap is forced closed. However, distortion must occur somewhere within the leaf to permit gap closure.

107. The condition index for all gaps is the minimum of the condition indexes of the miter or quoin bearing gaps.

$$
C I=\operatorname{minimum}\left(C I_{M^{\prime}} C I_{Q}\right)
$$

\section{Example}

108. For a 78-ft-tall horizontally framed miter lock gate having a fixed pintle, the following gaps were recorded at the miter and quoin.

$$
\begin{aligned}
\mathrm{MG}_{1} & =1 / 8 \mathrm{in} . & \mathrm{Y}_{1} & =1.5 \mathrm{ft} \\
\mathrm{MG}_{2} & =3 / 16 \mathrm{in} . & \mathrm{Y}_{2} & =40 \mathrm{ft} \\
\mathrm{QG}_{1} & =1 / 4 \mathrm{in} . & \mathrm{Y}_{1} & =2 \mathrm{ft} \\
\mathrm{QC}_{2} & =3 / 8 \mathrm{in} . & \mathrm{Y}_{2} & =42.5 \mathrm{ft} .
\end{aligned}
$$

By Eq 32

$$
M G_{S}=[1 / 8(40-78)+3 / 16(78-1.5)] /(40-1.5)=0.25 \mathrm{in} .
$$

and by Eq 33

$$
x_{M}=\operatorname{maximum}(0.25,1 / 8)=0.25 \text { in }
$$


For the quoin, by Eq 36

$$
\left.Q G_{S}=[1 / 4(42.5-78)+3 / 8(78-2)] / 42.5-2\right)=0.48 \mathrm{in} .
$$

and Eq 37

$$
\mathrm{x}_{\mathrm{Q}}=\operatorname{maximum}(0.25,0.48)=0.48 \mathrm{in}
$$

A leak followed the rising water level only at the quoin. The condition index for the miter gap, Eq 1 , is

$$
C I_{M}=100(0.4)^{0.25 / 0.5}=63 .
$$

The condition index for the quoin gap is

$$
C I_{Q}=\left[100(0.4)^{0.48 / 0.5}\right] 0.85=35
$$

The condition index for all gaps is

$$
C I=\operatorname{minimum}(63,35)=35 \text {. }
$$

If the same leak pattern would have occurred at the miter instead of the quoin, the condition index for the miter gap would have been 54 , and the condition index for the quoin gap would have been 41 , resulting in a condition index of 41 for all gaps.

\section{Distress Code 5: Downst ream Movement}

\section{Definition and causes}

109. Downstream movement is a displacement of the miter point in the downstream direction as head is applied. This displacement occurs between the 1-ft-head and full-head positions. Downstream movement can be caused by several factors:

a. Shifting of floating pintle. 
b. Failed pintle anchorage (fixed pintle).

c. Bearing block wear (quoin or miter blocks).

d. Sill wear (vertically framed gate).

e. Blockage at sill.

f. Improper gate alignment at miter.

Excessive downstream movement can indicate that a structural failure has occurred or that additional stresses have been introduced.

Measurement and limits

110. Measurements of the horizontal movement of the miter point will be taken at two locations on the downstream face of the miter point in the mitered position. Longitudinal location will be measured near the top of the gate and as close to the downstream water surface as possible. A downstream displacement is considered positive. The displacement and distance from the walkway $\left(Y_{1}\right.$ and $Y_{2}$, respectively) will be recorded at the 1-ft-head and full-head positions. The downstream movements at the two locations, $L_{1}$ and $L_{2}$, respectively, are found by subtracting the measurements at the 1 -ft head and full-head positions (Dimension 8, Figure 12). If the mitered ends of the gates are assumed to remain straight, as before, the recorded displacements can be used to extrapolate the longitudinal movement of the gate at the sill, $L_{S}$, by a straight line equation,

$$
\left.L_{S}=\left[L_{1}\left(Y_{2}-H\right)+L_{2}\left(H-Y_{1}\right)\right] / Y_{2}-Y_{1}\right)
$$

The controlling measurement is taken as

$$
x=L_{S}
$$

The limiting displacement at the sill is

$$
\mathrm{x}_{\max }=4.0 \text { in. }
$$

for all types and heights of gates. The experts' reasoning for the different gates was somewhat different but the numerical values were similar. 
Example

111. For a 62-ft-tall miter lock gate the following net downstream horizontal movements were recorded.

$$
\begin{array}{rlrl}
L_{1} & =1.0 \mathrm{in} . & Y_{1} & =1.1 \mathrm{ft} \\
L_{2}=1.3 \mathrm{in} . & Y_{2}=45 \mathrm{ft}
\end{array}
$$

By Eq 42 the extrapolated net displacement at the sill is

$$
x=[1.0(45-62)+1.3(62-1.1)] /(45-1.1)=1.4 \text { in. }
$$

The condition index for the downstream movement is

$$
C I=100(0.4)^{1.4 / 4}=73 \text {. }
$$

\section{Distress Code 6: Cracks}

\section{Definition and causes}

112. Cracks usually represent a narrow opening, break, or discontinuity in the structural steel members. Cracks are caused by fatigue, brittle fracture, or overstressed structural steel components. Often barge or vessel impact is responsible. Obviously cracks have significant structural implications. Cracks can continue to grow if the cause of the overstress still exists or if the remaining steel cross section cannot carry the normal loads.

\section{Measurements and limits}

113. The number of occurrences of cracks in the girders (G), skin (S), or intercostals. (I) will be recorded on both the upstream and downstream faces of the gate leaf. Size and location of cracks are also recorded but are not used in the calculation of the condition index. It is implicitly assumed that very large cracks do not occur at the time of the inspection. Such cracks would be recognized and repaired immediately because of possibly severe consequences. The limiting value for girder cracks is

$$
\mathrm{X}_{\operatorname{maxG}}=1 \text {. }
$$


That is, one crack in a girder is considered critical. The limiting value for skin plate and intercostal cracks is

$$
\begin{aligned}
& \mathrm{x}_{\text {maxS }}=10 \\
& \mathrm{x}_{\operatorname{maxI}}=10 .
\end{aligned}
$$

The skin and intercostals are highly redundant and can tolerate more cracks with less severe consequences. Failure of an entire skin plate panel would be a big problem but not disastrous. The condition index for all cracks is taken as the minimum of girder, skin, and intercostal values.

$$
C I=\operatorname{minimum}\left(C I_{G^{\prime}} C_{S^{\prime}} C I_{I}\right)
$$

\section{Example}

114. The following numbers of cracks were counted for a miter lock gate leaf.

$$
\begin{aligned}
& x_{G}=0 \\
& x_{S}=3 \\
& x_{I}=1 .
\end{aligned}
$$

The condition index for girder cracks is

$$
C I_{G}=100(0.4)^{0 / 1}=100
$$

The condition index for skin plate cracks is

$$
C I_{S}=100(0.4)^{3 / 10}=76
$$

The condition index for intercostal cracks is

$$
C I_{I}=100(0.4)^{1 / 10}=91
$$


The condition index for all cracks is

$$
C I=\text { minimum }(100,76,91)=76 \text {. }
$$

\section{Distress Code 7: Leaks and Boils}

\section{Definition and causes}

115. The leak distress represents water passing through or around the gate leaves. Several kinds of skin and seal leaks or boils can be tolerated because they usually do not present a significant structural problem. For example, leaks along the vertical edges at a vertically framed gate may indicate seal wear or deterioration. Although the leak may be troublesome, it does not necessarily indicate a safety risk. On the other hand, leaks or boils on load-bearing surfaces quite probably indicate structural problems because such leaks indicate incomplete bearing. They would be interpreted similarly to bearing gaps (Distress Code 4). Skin leaks have an interpretation similar to skin cracks. Leaks and boils are caused by several factors:

a. Corrosion.

b. Structural cracks.

c. Vessel impact.

d. Bearing block wear.

e. Shifting of a floating pintle.

f. Blockage at the sill.

g. Improper gate alignment.

h. Improper adjustment at anchorage system.

i. Quoin-bearing material failure.

i. Seal wear.

k. Concrete failure behind quoin-bearing plate.

Measurement and limits

116. The location and length ( $f t), L_{S}$, of skin plate leaks are recorded. Point or very short leaks are recorded with a length equal to zero. The $x_{S}$ value for skin plate leaks is

$$
x_{S}=\text { sum of } L_{S} \text {. }
$$


Point leaks and leaks shorter than $1 \mathrm{ft}$ are added as 1 -ft leaks. The $\mathrm{X}_{\operatorname{maxs}}$ value for skin leaks is

$$
\mathrm{x}_{\operatorname{maxS}}=15 \mathrm{ft}
$$

117. The location and total length of quoin block, $\mathrm{L}_{Q}$, and miter block, $\mathrm{L}_{\mathrm{M}}$, leaks are also recorded. Quoin and miter leaks are visible leaks above the water surface. The $\mathrm{X}_{\mathrm{QM}}(\mathrm{ft})$ value for quoin and miter leaks is

$$
\mathrm{x}_{\mathrm{QM}}=\mathrm{L}_{\mathrm{Q}}+\mathrm{L}_{\mathrm{M}}
$$

The entire quoin and miter areas on a horizontally framed gate are load bearing. Leaks through these surfaces indicate incomplete bearing; that is, the structure is not performing as designed. The limiting value is expressed as a fraction of gate height $H$ (feet) as

$$
x_{\max Q M}=\text { height/10 (ft) }
$$

The limiting length of leaks on an 80-ft horizontally framed leaf would be $8 \mathrm{ft}$.

118. The quoin and miter areas of a vertically framed gate are covered by seals. The bearing surface is located only at the top of the miter and quoin. The limiting value is significantly larger than for a horizontally framed gate:

$$
X_{\operatorname{maxQM}}=(\text { height }) / 5(f t)
$$

The maximum length of leaks on a 40-ft, vertically framed leaf would then be 8 et.

119. Boils are leaks that occur underwater. The occurrence of boils in the quoin and miter areas and along the sill is recorded. The $\mathrm{X}$ value for boils is

$$
x_{B}=\text { Total number of boils. }
$$


Only ono boll should be permltted on a bearing surface and two could be allowed on sealing surfaces. The corresponding limiting value for both horizontally and vertically framed leaves has been judged to be

$$
x_{\operatorname{maxB}}=3
$$

If the leaf vibrates when the chamber is filling, $\mathrm{CI}_{B}$ is multiplied by 0.85 . 120. The condition index for all leaks and boils is

$$
C I=\operatorname{minimum}\left(\mathrm{CI}_{\mathrm{S}^{\prime}}, \mathrm{CI}_{\mathrm{QM}^{\prime}} \mathrm{CI}_{\mathrm{B}}\right)
$$

\section{Example}

121. A 40-ft-tall vertically framed gate has the following leak data:

$$
\begin{aligned}
& \text { Skin: } L_{S}=7 \mathrm{ft} \text { and } 4 \text { point leaks } \\
& \text { Quoin and Miter: } L_{M}=2 \mathrm{ft} .
\end{aligned}
$$

There was a boil at both the miter and quoin. From Eq 49

$$
x_{S}=7+4=11 \mathrm{ft}
$$

The condition index for skin leaks is

$$
C I_{S}=100(0.4)^{11 / 15}=51 \text {. }
$$

From Eq 51, the $\mathrm{x}_{\mathrm{QM}}$ value for bearing leaks is

$$
x_{Q M}=3+2=5 \mathrm{ft} .
$$

From Eq 53, the $x_{\max Q M}$ is

$$
x_{\max Q M}=40 / 5=8 \mathrm{ft} .
$$


The condition index for bearing leaks is then

$$
\mathrm{CI}_{\mathrm{QM}}=100(0.4)^{5 / 8}=56
$$

Because one boil occurred at both the miter and quoin,

$$
x_{B}=2 \text {. }
$$

From Eq 54, the condition index for boils is

$$
x_{B}=100(0.4)^{2.5}=69
$$

The condition index for all leaks and boils is

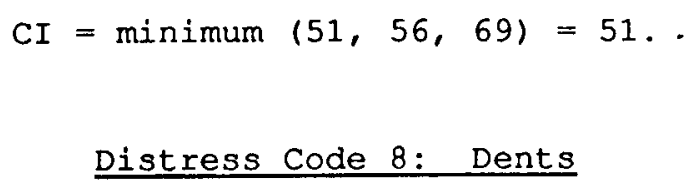

\section{Definition and causes}

122. Dents represent a disfiguration of the major components of miter lock gate leaves. Dents can be caused by several factors; most often, barge or vessel impact is responsible. Dents, particularly in girders, can cause structural distress and possibly a safety problem. A badly deformed girder cannot safely carry its design load.

\section{Measurements and limits}

123. The number of occurrences of dents on the girders, skin, or intercostals will be recorded on both upstream and downstream faces of the gate leaf. Size and location of dents are also recorded but are not used in the cI calculation. The limiting value for the number of girder dents is

$$
\mathrm{X}_{\operatorname{maxG}}=1
$$


The limiting value for the number of skin plate dents is

$$
x_{\max S}=10
$$

The limiting value for the number of intercostal dents is

$$
x_{\max I}=3
$$

124. As with cracks the condition index for all dents is the minimum:

$$
C I=\operatorname{minimum}\left(C I_{G^{\prime}} C_{S^{\prime}} C_{I}\right)
$$

\section{Example}

125. The following dent data were obtained for a miter lock gate leaf:

$$
\begin{aligned}
& x_{G}=0 \\
& x_{S}=4 \\
& X_{I}=1 .
\end{aligned}
$$

The condition index for girder dents is

$$
C I_{G}=100(0.4)^{0 / 1}=100
$$

The condition index for skin dents is

$$
C I_{S}=100(0.4)^{4 / 10}=69
$$

The condition index for intercostal dents is

$$
C I_{I}=100(0.4)^{1 / 3}=74
$$

The condition index for all dents is

$$
C I=\operatorname{minimum}(100,69,74)=69 .
$$




\section{Definition and causes}

126. The noise and vibration distress represents abnormal gate sounds and vibrations during the opening and closing of the gate. Gate noises and vibration are caused by several factors:

$$
\begin{aligned}
& \text { a. Load shift in the anchor bars. } \\
& \text { b. Seizing of pintle. } \\
& \text { c. Poorly lubricated pintle system. } \\
& \text { d. Loss of diagonal prestress. } \\
& \text { e. Obstructions at sills or quoins. }
\end{aligned}
$$

Abnormal noises commonly indicate a problem. Often a noise is difficult to isolate and diagnose, but if it is abnormal it should not be ignored.

\section{Measurement and limits}

127. Noise is recorded when it occurs at a specific location as the gate is opened or closed. The presence of vibration at any point in the gate swing is also recorded. Noises (other than flapping diagonals) occurring between the fully recessed (0-percent-mitered) and the 25-percent-mitered positions are not used in determining the condition index. A load shift from tension to compression occurs in the parallel anchorage in this interval. Any excessive anchorage movement will be recorded as an anchorage system distress and is covered under Distress Code 1. The noise from flapping diagonals is accounted for in the miter offsets (Distress Code 3). Noises occurring when the gate is over 90 percent closed are not recorded because several routine or normal noises occur at or near the fully mitered position. Between the 30- and 90percent-mitered positions, any abnormal noise will affect the condition index. Condition indexes for the possible noise and vibration combinations follow.

$\begin{array}{lr}\text { Noise, Vibration or Jumping } & \frac{\text { CI }}{\text { None }} \\ \text { Yes for either of the three } & 700 \\ \text { Yes for any two } & 40 \\ \text { Yes for all three } & 30\end{array}$


Obviously this distress is more subjective and less quantifiable than the other type; however, this should not minimize its importance because abnormal noises almost always indicate abnormal behavior, which should be investigated. Example

128. As a miter lock gate leaf was brought into the miter position, it made a popping noise at 75 percent closure. The condition index is

$$
C I=70 \text {. }
$$

If the gate had jumped in addition to the noise, the condition index would have been 40 .

\section{Distress Code 10: Corrosion}

\section{Definition and causes}

129. Corrosion is the loss of the steel material in a miter lock gate leaf due to interaction with its environment. The rate of corrosion is dependent on the concentration of moisture in contact with the steel. A miter lock gate structure is exposed to different areas of corrosion (Figure 24). While corrosion. is usually very evident and easily noticed in the exposed

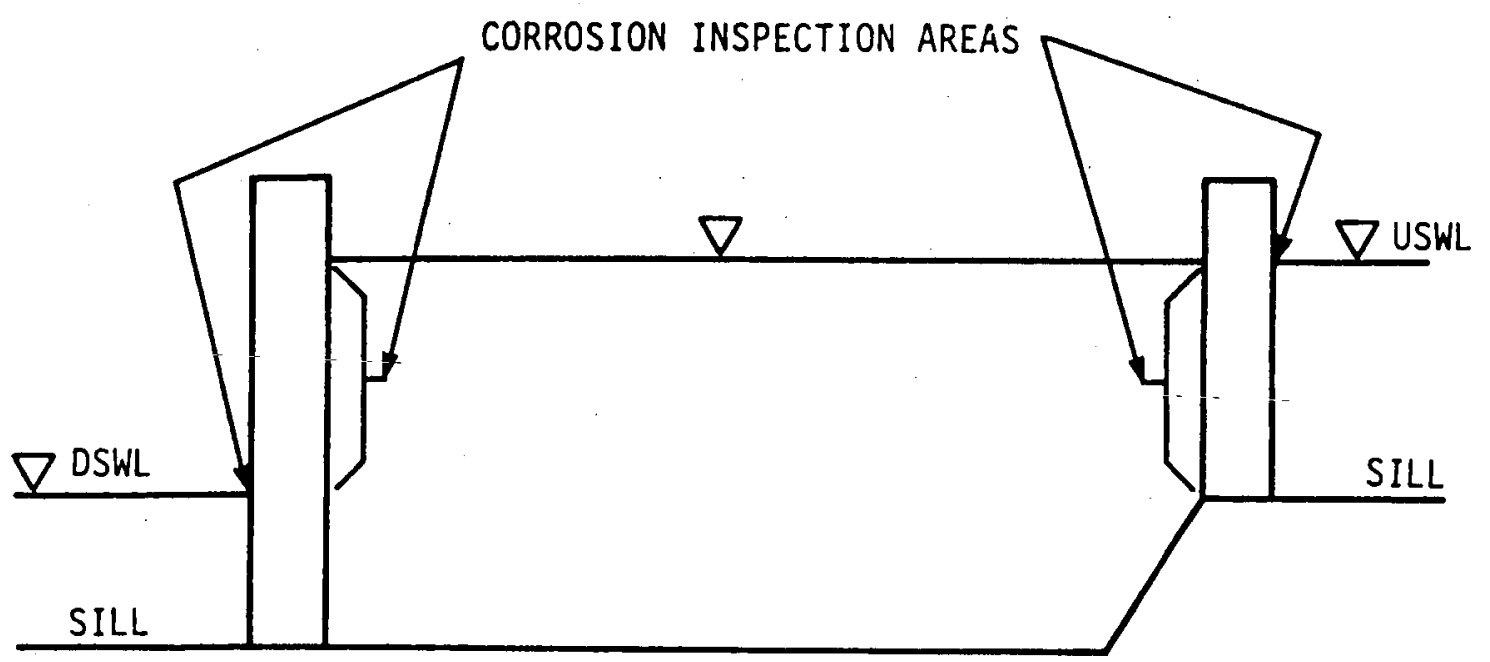

Figure 24. Corrosion inspection areas 
areas, often the concealed components, that is, those well below the water surtace, cause the most concorn fos safety. Most light corrosion has little structural significance. However, extensive corrosion can reduce the steel cross-sectional area enough to significantly increase stresses. Corrosion of a girder is more critical than skin corrosion, just as girder cracks are more important than skin cracks. Note that the corrosion condition index is also used in calculating the structural condition index (see Part III). Measurement and limits

130. The effect of corrosion in the atmospheric and splash zones is used to evaluate the corrosion condition index because it is visible there. A distress coefficient for corrosion must take into account that corrosion of a miter lock gate structure seldom impedes the operation of the structure. However, its safety has been reduced. The effect is a subjective evaluation of safety that is difficult to quantify by measurements or simple testing. One way to evaluate the corrosion of a structure is to set a series of standards, or levels of corrosion, having corresponding numeric distress coefficients. The base for such an evaluation standard would be new steel or clean and painted structural steel with no scale or pitting. Table 4 describes corrosion levels, and Figures 25 to 29 illustrate the various levels of corrosion used in the evaluation of the corrosion condition index. The corrosion levels of the girders (G), skin (S), and intercostals (I) will be recorded on both upstream and downstream faces of the gate leaf. The corrosion levels represent the $x$ values.

131. The limiting values for girder corrosion, $x_{\text {maxG }}$ skin corrosion, $\mathrm{x}_{\max }$, and intercostal corrosion, $\mathrm{x}_{\max I}$, are

$$
\begin{aligned}
& x_{\max G}=3 \\
& x_{\operatorname{maxS}}=4 \\
& x_{\operatorname{maxI}}=4 .
\end{aligned}
$$

As noted above, girder corrosion has more significance than skin corrosion because of the critical structural nature of the girders.

132. The condition index for the girder, skin, and intercostal corrosion will be the minimum of the downstream (D) and the upstream (U) 
corrosion condition indexes; this is similarly true for the skin and intercostals.

$$
\begin{aligned}
& C I_{G}=\operatorname{minimum}\left(C I_{D G^{\prime}} C_{U G}\right) \\
& C I_{S}=\operatorname{minimum}\left(C I_{D S^{\prime}} C_{U S}\right) . \\
& C I_{I}=\operatorname{minimum}\left(C I_{D I}, C I_{U I}\right) .
\end{aligned}
$$

The corrosion condition index for a leaf is the minimum,

\section{Example}

$$
C I=\operatorname{minimum}\left(C I_{G^{\prime}}{ }^{C I} I_{S} C I_{I}\right)
$$

133. A miter lock gate leaf has the following corrosion levels recorded for the upstream and downstream surfaces of its major structural components.

$\begin{array}{rll}\text { Girder: } & \mathrm{X}_{D G}=2 & \mathrm{x}_{U G}=1 \\ \text { Skin: } & \mathrm{X}_{D S}=1 & \mathrm{x}_{\mathrm{US}}=2 \\ \text { Intercostals: } & \mathrm{X}_{\mathrm{DI}}=1 & \mathrm{x}_{\mathrm{UI}}=2\end{array}$

Table 4

Levels of Corrosion (Refer Also to Fiqure 25)

\begin{tabular}{|c|l|}
\hline Level & Description \\
\hline \hline 0 & New condition \\
\hline 1 & Minor surface scale or widely scattered small pits \\
\hline 2 & Considerable surface scale and/or moderate pitting \\
\hline 3 & Severe pitting in dense pattern, thickness reduction in local areas \\
\hline 4 & Obvious uniform thickness reduction \\
\hline 5 & Holes due to thickness reduction and general thickness reduction \\
\hline
\end{tabular}




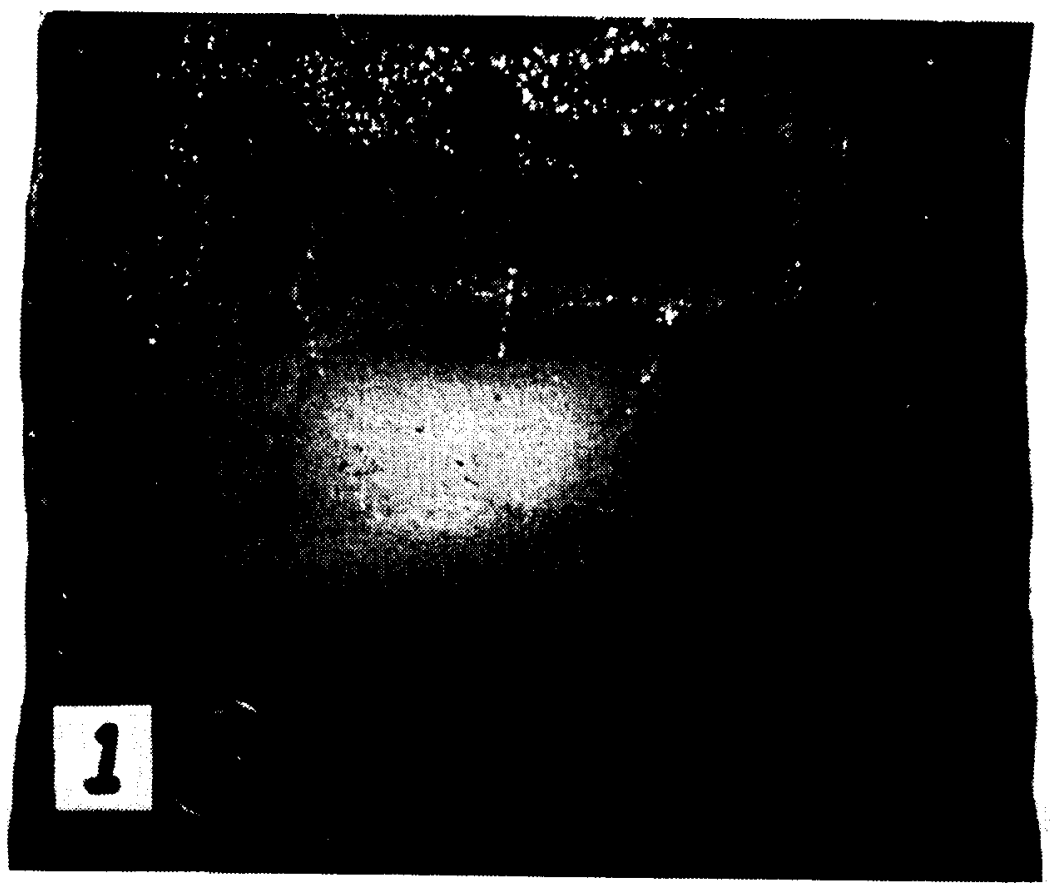

Figure 25. Level 1: Minor surface scale or widely scattered small pits

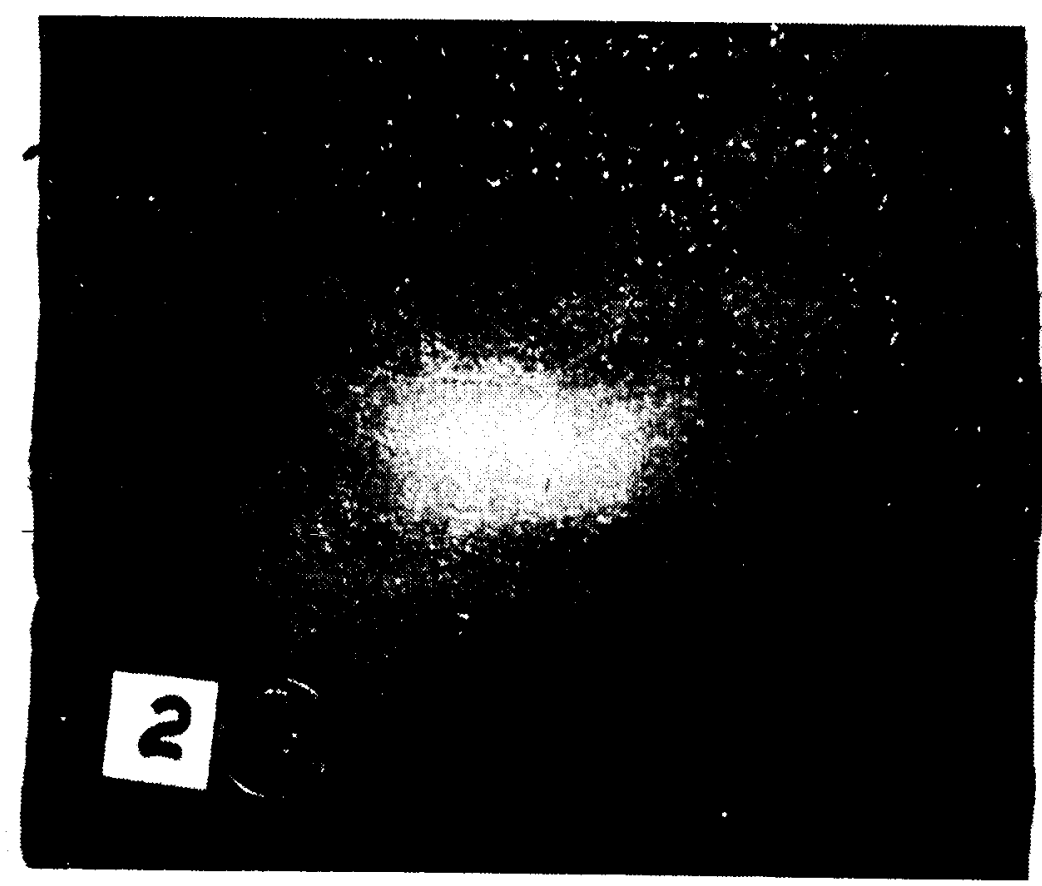

Figure 26. Level 2: Considerable surface scale and/or moderate pitting 


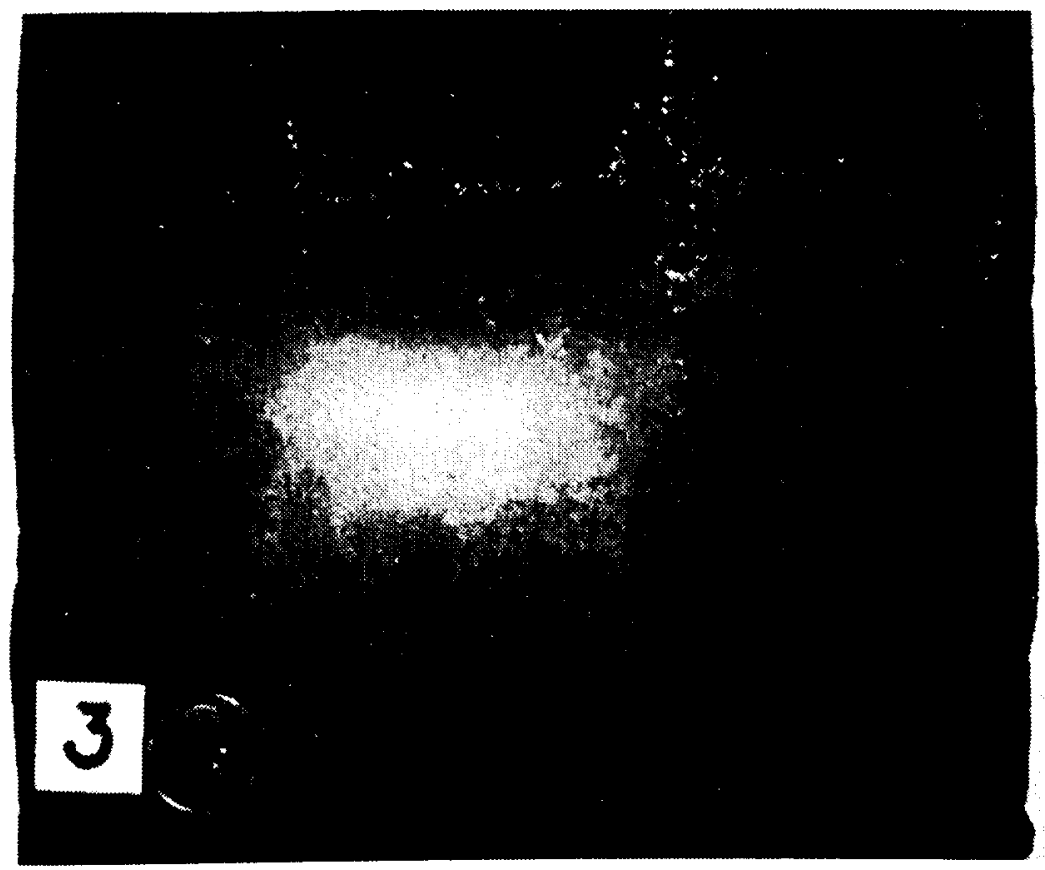

Figure 27. Level 3: Severe pitting in dense pattern, thickness reduction in local areas

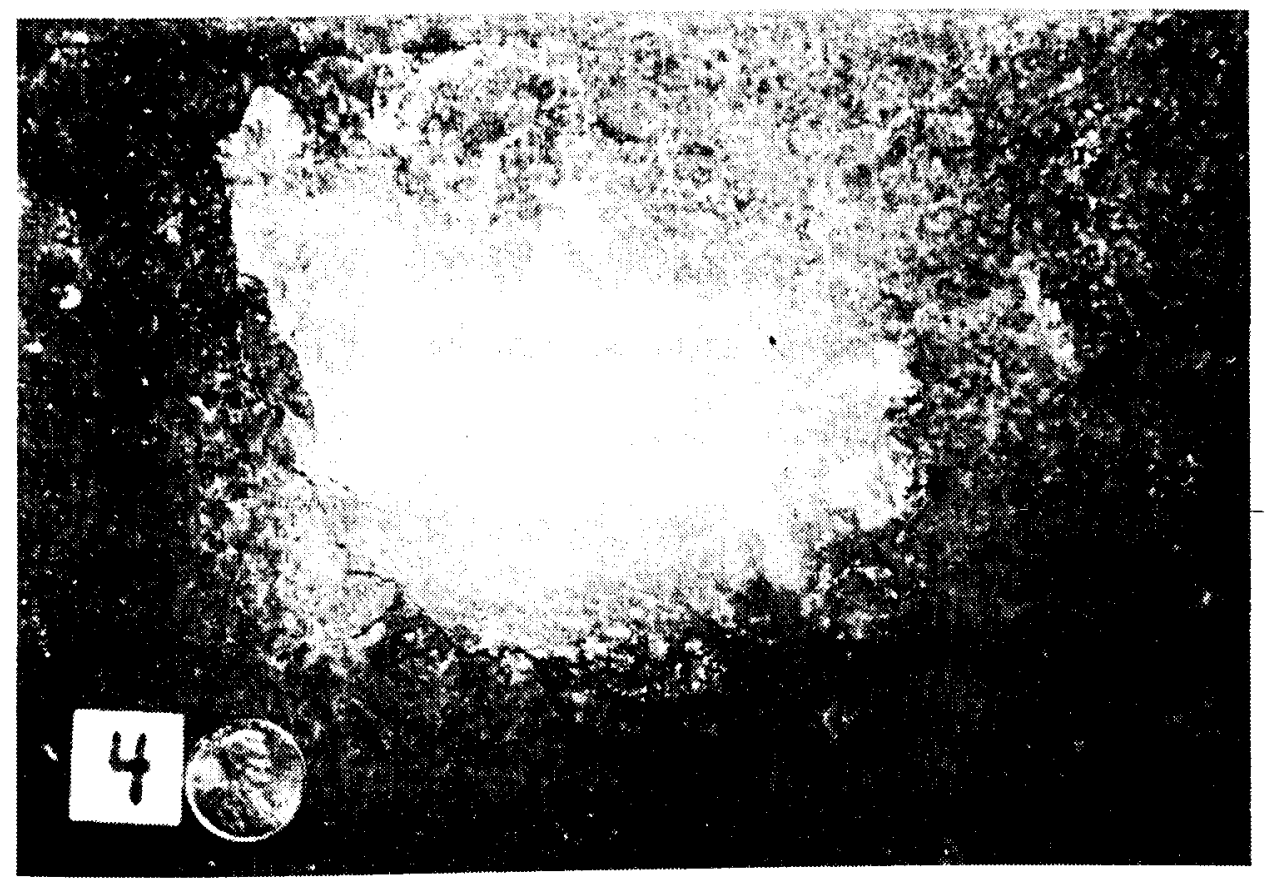

Figure 28. Level 4: Obvious uniform thickness reduction 


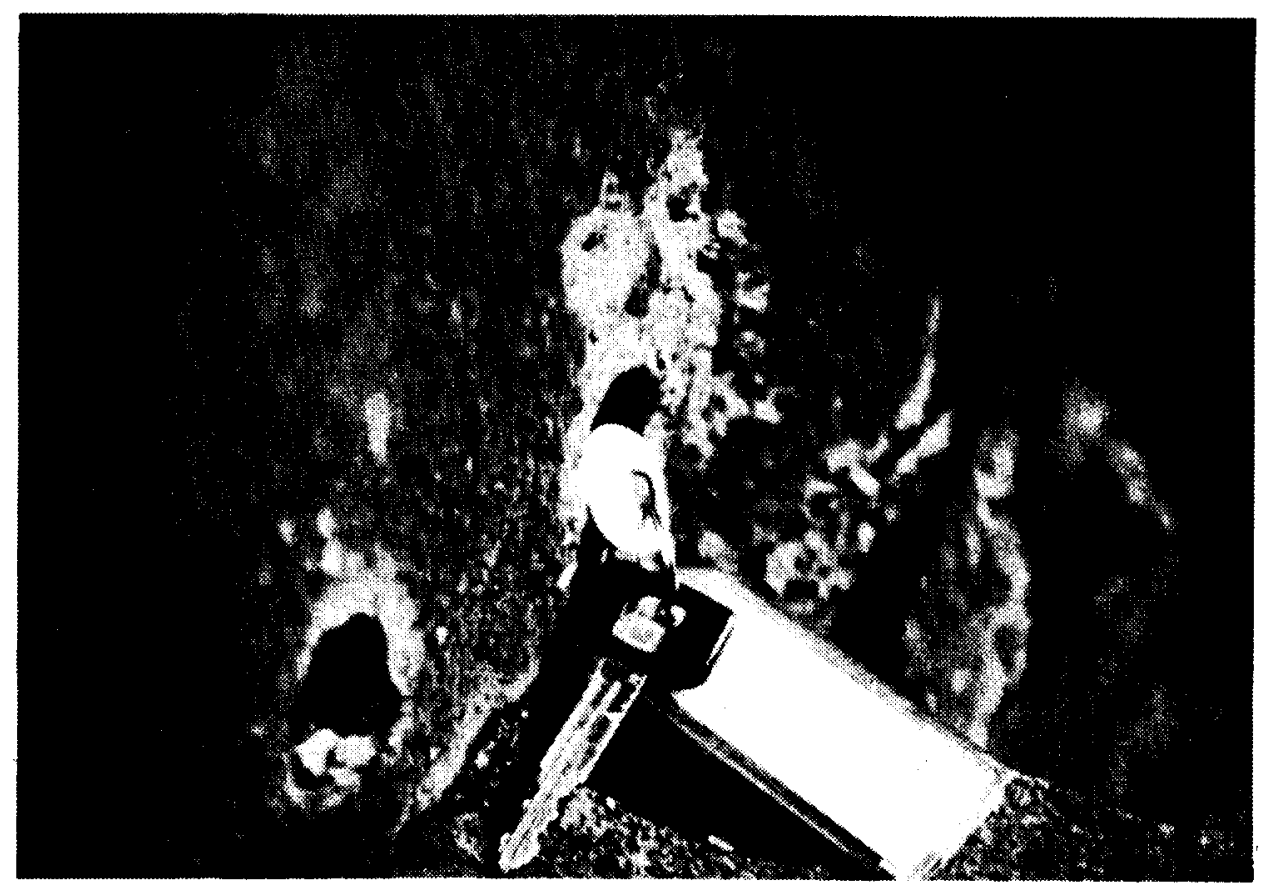

Figure 29. Level 5: Holes due to thickness reduction and general thickness reduction

From Eq 61 and 62, the condition index for girder corrosion is

$$
\begin{gathered}
C I_{D G}=100(0.4)^{2 / 3}=54 \\
C I_{U G}=100(0.4)^{1 / 3}=74 \\
C I_{G}=\text { minimum }(54,74)=54 .
\end{gathered}
$$

The condition index for skin corrosion is

$$
\begin{gathered}
C I_{D S}=100(0.4)^{1 / 4}=80 \\
C I_{U S}=100(0.4)^{2 / 4}=63 \\
C I_{S}=\text { minimum }(80,63)=63 .
\end{gathered}
$$

The condition index for intercostal corrosion is

$$
\begin{gathered}
C I_{D I}=100(0.4)^{1 / 4}=80 \\
C I_{U I}=100(0.4)^{2 / 4}=63 \\
C I_{I}=\text { minimum }(80,63)=63 .
\end{gathered}
$$


The condition index for entire corrosion over the gate leaf is

$$
\mathrm{ci}=\operatorname{MINIMUM}(54,63,63)=54 .
$$

\section{Multiple Distresses}

134. When several types of distress occur simultaneously, such as both anchorage movement and offset, the condition indexes are combined into a single value. Weighting factors are introduced to reflect the importance of the various distresses. Hence, let $w_{1}$ be the weighting factor for the functional condition index for Distress $i$. The weighting factors assign more value to the more significant distresses. Relative initial weights are listed in Table 5. They reflect, to some degree, the opinion of the corps experts. These factors also represent the opinion of the authors. The table illustrates that anchorage movement is the most important and dents the least important.

135. The normalized weighting factors are defined by

$$
w_{i}=w_{i} / w_{i}(100)
$$

Note that

$$
\Sigma w_{i}=100
$$

Values are listed in Table 5 (rounded to add up to 100). The combined functional condition index for all distresses is then given by

$$
\text { FunctionaI } C I=W_{1} C I_{1}+W_{2} C I_{2}+\ldots
$$

where the sum is for all 10 distresses. 
Table 5

Unadjusted Weighting Eactors for Distresses

\begin{tabular}{|c|l|c|c|}
\hline $\begin{array}{c}\text { Distress } \\
\text { Code }\end{array}$ & \multicolumn{1}{|c|}{ Distress } & $\mathbf{w}_{1}$ & $\mathrm{~W}_{1}\left(\frac{8}{8}\right)$ \\
\hline \hline 1 & Anchorage movement & 11 & 18 \\
\hline 2 & Elevation change & 9 & 14 \\
\hline 3 & Miter offset & 5 & 8 \\
\hline 4 & Gaps & 8 & 13 \\
\hline 5 & Downstream movement & 7 & 11 \\
\hline 6 & Cracks & 6 & 10 \\
\hline 7 & Leaks and boils & 1 & 5 \\
\hline 8 & Dents & 7 & 2 \\
\hline 9 & Noise, jumping, or vibration & 5 & 11 \\
\hline 10 & Corrosion & 8 \\
\hline
\end{tabular}

136. During the field testing of a preliminary version of the above rating procedure, it became clear that, as a distress became more severe, its relative importance became larger. Thus, a variable adjustment factor was introduced to increase the distress-weighting factor as its functional condition index approached zone 3 (Table 2). The adjustment factor, plotted in Figure 30; has a maximum value of 8; that is, if a distress has a condition index less than 40 , its importance increases 8 times.

\section{Field Testing}

137. The analysis of performance of the rating rules presented in this section is a study of the calculated functional condition index versus subjective index values determined by a group of miter lock gate expert engineers. The expert engineers provided the guidance for establishment and selection of distress rule values, as well as observation ratings of the field test miter 


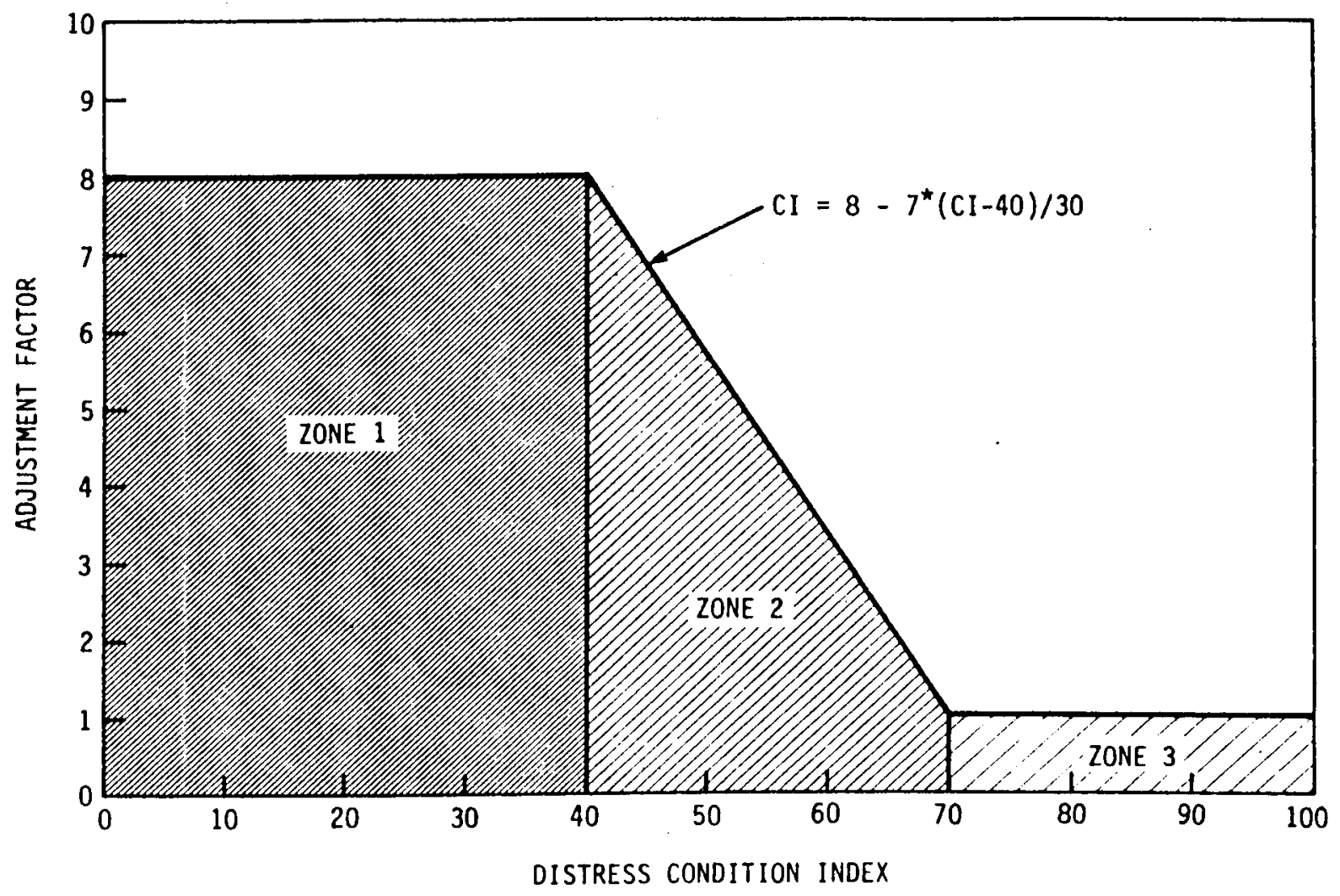

Figure 30. Weight adjustment factor for subjective condition index

lock gates. The miter lock gate experts who participated in the initial rule development were Mr. Jack Sirak and Mr. Eugene Ardine (Ohio River Division), Mr. Richard Atkinson (Rock Island District), Mr. D. Wayne Hickman, and Mr. Lynn Midget (Nashville District).

138. The inspection and rating procedure described in this report has been applied in three field tests. In August 1988 a preliminary procedure was applied to the lower lock gate at Lock and Dam 19 in Keokuk, Iowa. Four US Army Corps of Engineers experts were involved in this test: Ardine, Atkinson, Midget, and Hickman. Dr. Anthony Kao (USACERL project monitor) was an observer. Lock and Dam 19, located on the Mississippi River at Keokuk, IA, is a horizontally framed miter lock gate designed and built by the US Army Corps of Engineers in 1945. Each lower gate leaf is $51 \mathrm{ft}$ tall and $62 \mathrm{ft}$ wide. The lock chamber is $1,200 \mathrm{ft}$ long and $110 \mathrm{ft}$ wide. The results of that field 
test, although primarily qualitative, were used to make several modifications to the initial version of the rating procedure.

139. In October 1988 the second and third field tests were conducted in the Paducah, Kentucky, area by five Corps of Engineers experts:

Atkinson, Hickman, Midget, Mr. Steve Moneymaker (Barkley and Kentucky area lockmaster), and Mr. Tom Hood (Nashville District Office). Kao was also present. Two different locks and dams were inspected: Kentucky Lock and Dam (upper and lower gates) and Barkley Lock and Dam (upper and lower gates). Kentucky Lock and Dam, located on the Tennessee River by Kentucky Lake, Gilbertsville, Kentucky, is a double-skin-plate horizontally framed miter lock gate designed and built by the Tennessee Valley Authority (TVA) about 1955. The upper gates are $46.5 \mathrm{ft}$ tall and $62 \mathrm{ft}$ wide. The lower gates are $92.5 \mathrm{ft}$ tall and $62 \mathrm{ft}$ wide. The lock chamber is $600 \mathrm{ft}$ long and $110 \mathrm{ft}$ wide. Barkley Lock and Dam, located on the Cumberland River by Kentucky Lake, Paducah, Kentucky, is a horizontally framed, miter lock gate system designed and built by the US Army Corps of Engineers about 1958. The upper gates are $50 \mathrm{ft}$ tall and $62 \mathrm{ft}$ wide. The lower gates are $91 \mathrm{ft}$ tall and $62 \mathrm{ft}$ wide. The lock chamber is $800 \mathrm{ft}$ long and $110 \mathrm{ft}$ wide.

140. Each expert was asked to rate the individual distresses in each gate leaf, that is, assign a functional condition index to each distress. Additionally, the experts were asked to assess an overall leaf condition index. Many of the comments and suggestions made during that test have been incorporated into the current version of the procedure. Some adjustments to $\mathrm{x}_{\max }$ values and weighting values were made to better fit the experts' ratings. The previous portions of Part IV include these changes.

141. The following graphs present the expert subjective index versus the calculated functional condition index for the 10 gate leaves in the field test. One graph is presented for each of the 10 distresses. Each graph contains 10 groups of data, 1 group for each of the gate leaves:

ABBREVIATIONS FOR DISTRESS GRAPH COLUMNS

K'TKY $1=$ KENTUCKY LOCK: LOWER RIGHT GATE

KTKY $2=$ KENTUCKY LOCK: LOWER LEFT GATE 


KTKY 3 = KENTUCKY LOCK: UPPER RIGHT GATE
KTKY 4 = KENTUCKY LOCK: UPPER LEFT GATE
BRKY 1 = BARKLEY LOCK: LOWER RIGHT GATE
BRKY 2 = BARKLEY LOCK: LOWER LEFT GATE
BRKY $3=$ BARKLEY LOCK: UPPER RIGHT GATE
BRKY $4=$ BARKLEY LOCK: UPPER LEFT GATE
KEOK 1 = KEOKUK LOCK: LOWER RIGHT GATE
KEOK 2 = KEOKUK LOCK: LOWER LEFT GATE.

For example, KTKY 1 is the group of data for the right-gate. leaf of the lower set of gate leaves at the Kentucky Lock. Within each group of data are four columns of data that represent

a. the highest index assigned by an expert;

b. the lowest index assigned by an expert;

c. the three-expert average, which is the average of the three experts (Atkinson, Hickman, and Midget) who participated in all three field tests; and

d. the computer-model-calculated functional condition index. An analysis follows of the comparison of expert rating versus the computer model for each distress, and the overall gate leaf index. Anchor movement: Fiqure 31

142. The calculated functional condition indexes of 6 of the 10 gate leaves closely approximated the three-expert average. Of the other four gates, the calculated condition index values for three of the gate leaves (KTKY 2, KEOK 1, and KEOK 2) were questionable because of difficulties encountered in making specific and accurate measurements at the dimension points. At Lock 19, the first field test, inadequate apparatus prevented accurate location of the gudgeon pin centerline. Later procedures improved the measurements. The other calculated index value that had a wide variation from the experts was at BRKY 2, where excessive gudgeon pin wear was measured but the wear was not visually apparent.

Elevation changes: Figure 32

143. The calculated functional condition indexes of 8 of the 10 gate leaves closely approximated the three-expert average. In the other two cases, KTKY 2 and KEOK 1, measured elevation changes were observed, calculated, and 


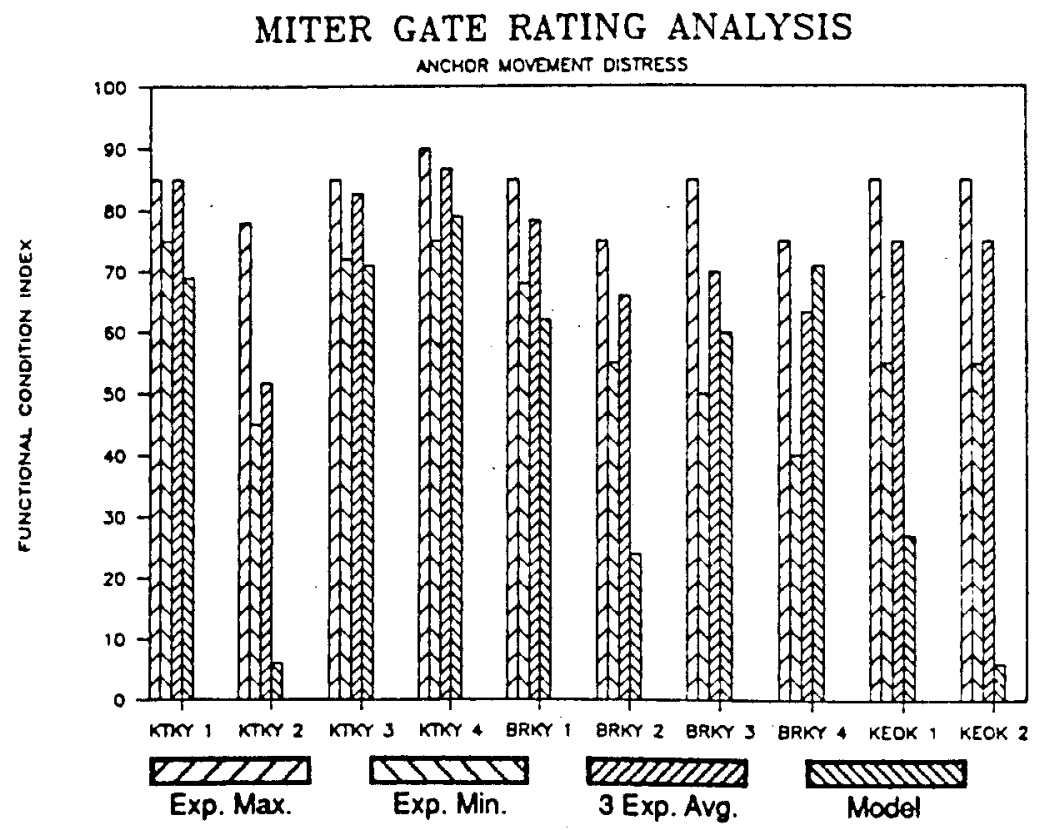

Figure 31. Anchor movement distress

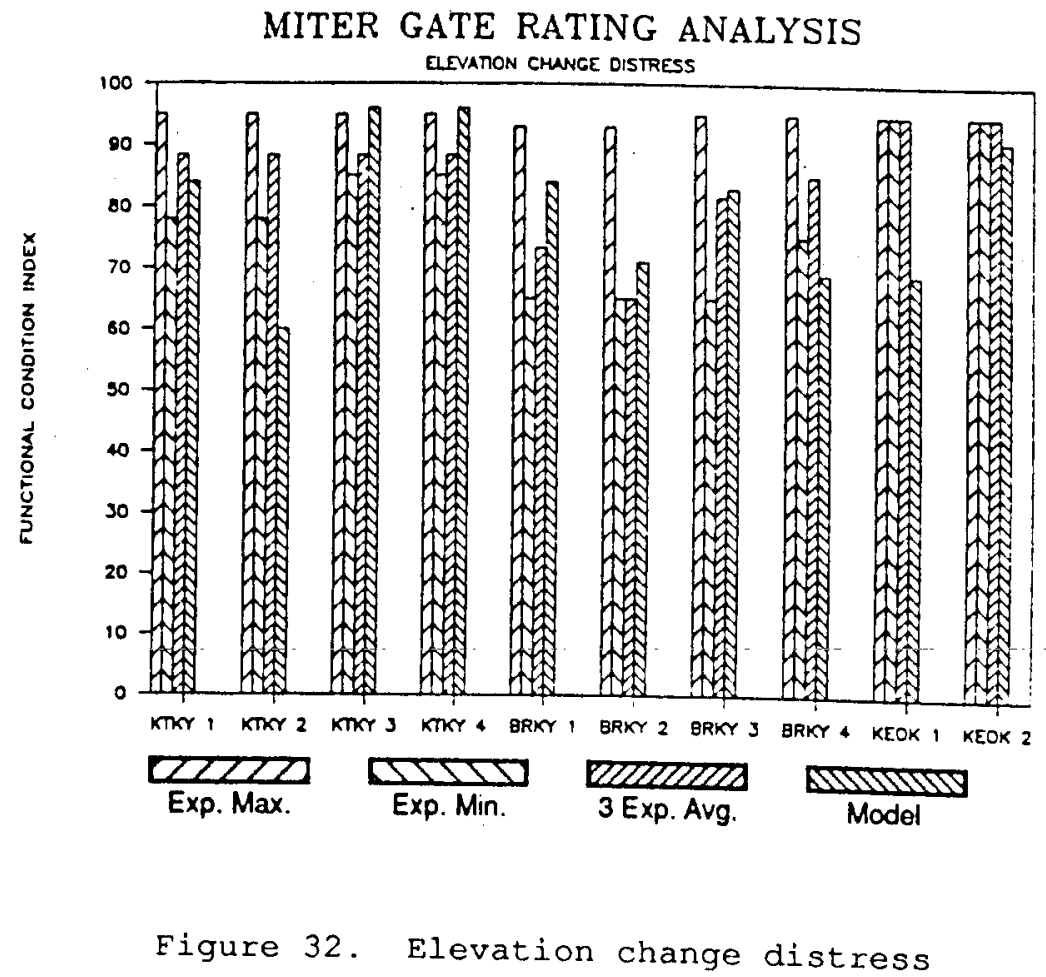


rated in the upper part of zone 2 by the computer model, whereas the experts rated the changes in the middle of zone 1 .

Miter offset: Figure 33

144. The calculated functional condition indexes for all 10 gate leaves closely approximated the three-expert average.

\section{Gaps: Fiqure 34}

145. The calculated functional condition indexes of 4 of the 10 gate leaves closely approximated the three-expert average. Four of the remaining index values were within 15 to 20 points of the three-expert average. In these four cases, the experts' averages, which were in the mid-90s, suggest that no significant gaps were present. However, the actual measurements with the expert rules gave condition indexes in the lower range of zone 1 . In the remaining two cases at KEOK 1 and KEOK 2, the measured gaps were partly the result of a preliminary procedure that was adjusted for later field tests. Longitudinal or Downstream Movement: Fiqure 35

146. The calculated functional condition indexes of all 10 gate leaves closely approximated the three-expert average.

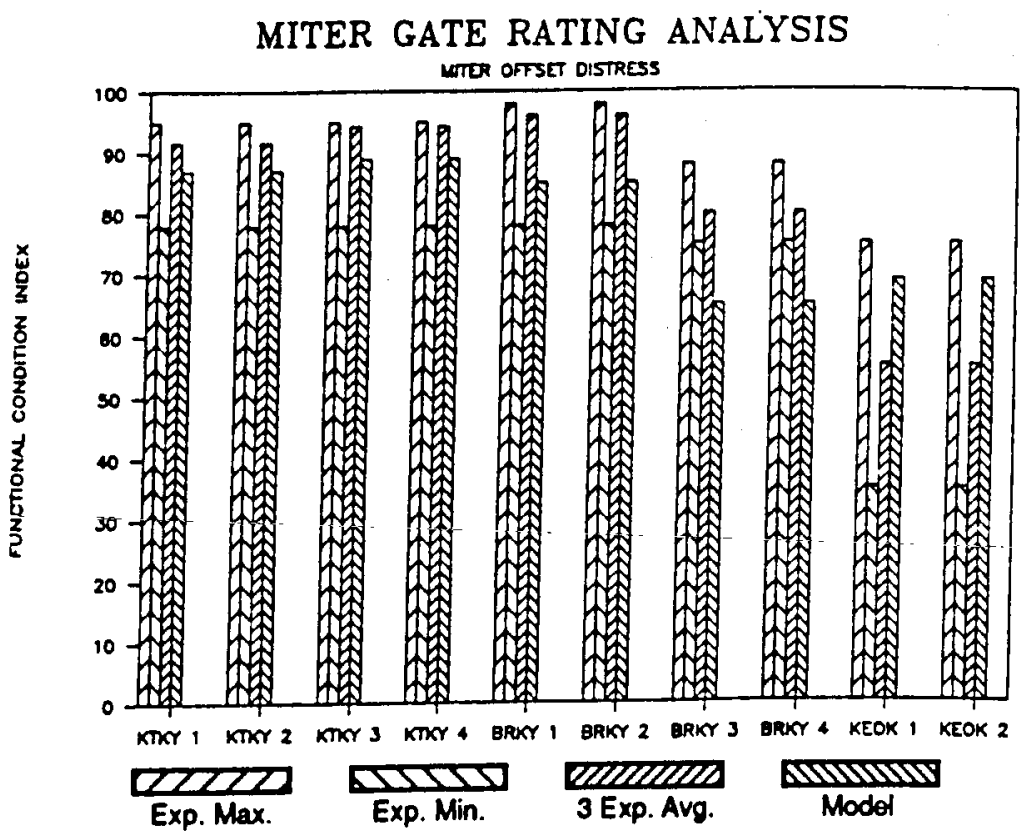

Figure 33. Miter offset distress 


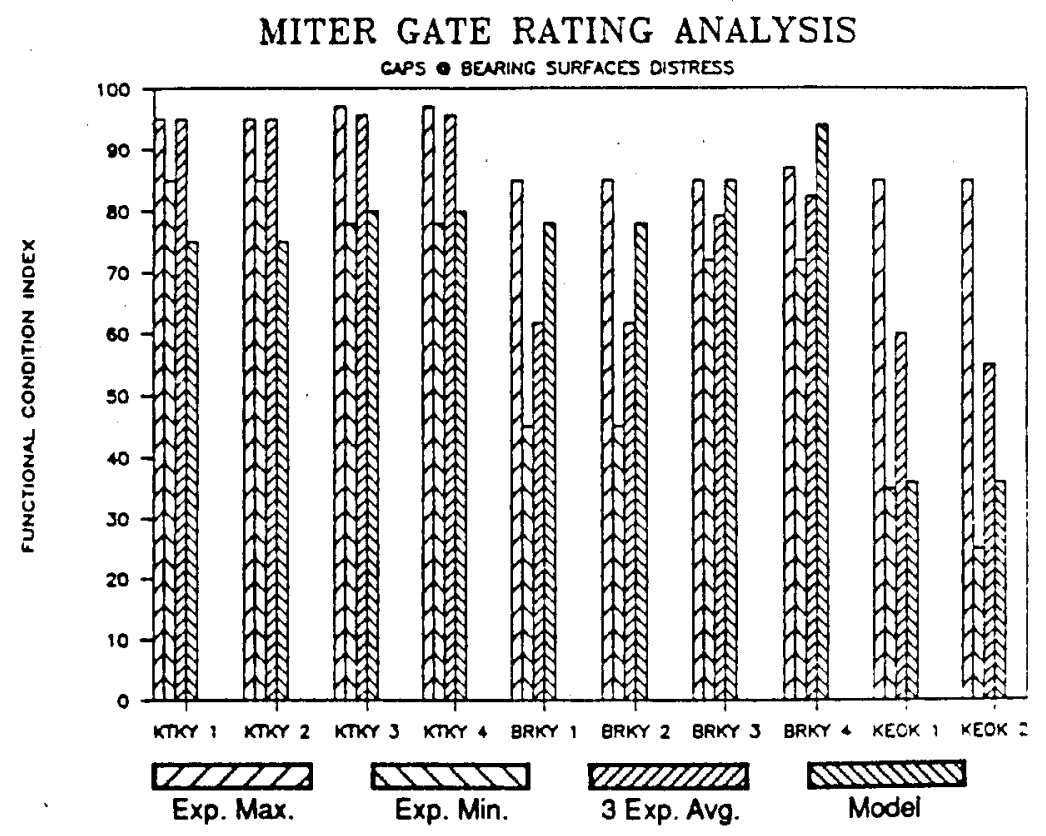

Figure 34. Gaps at bearing surface distress

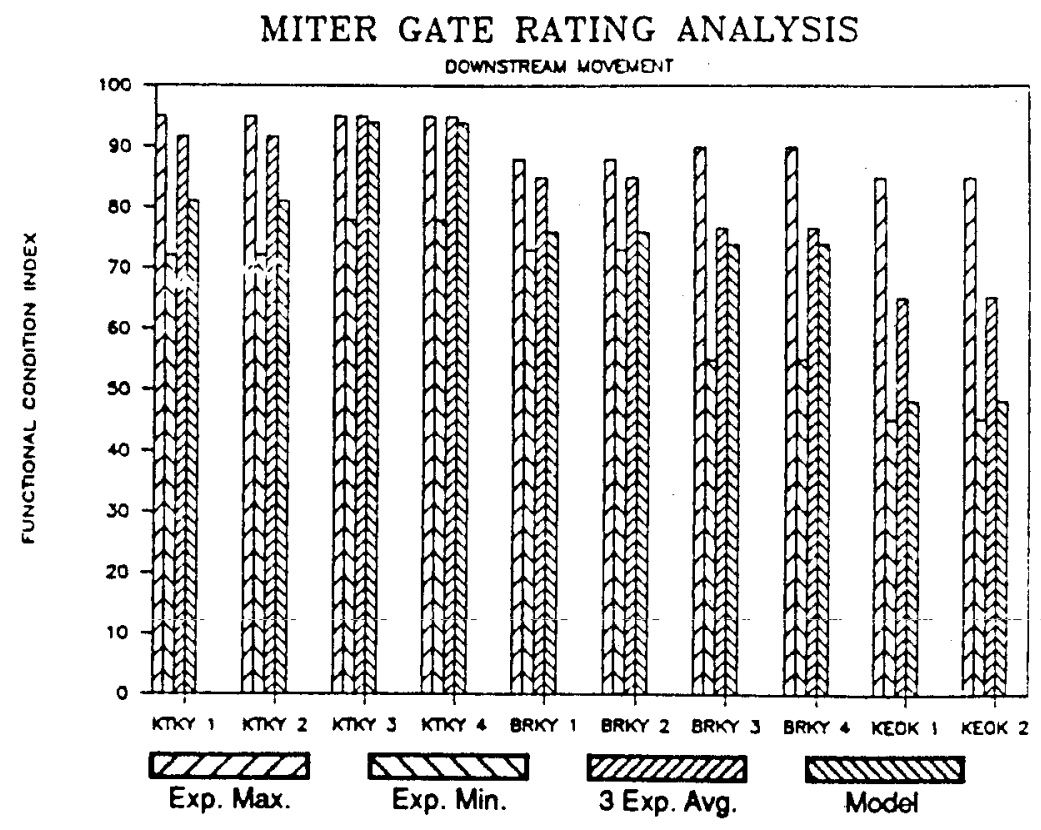

Figure 35. Downstream movement 


\section{Cracks: Eiqure 36}

147. The evaluation of cracks, which are another distress, was added to the model after the Lock 19 test. The experts rated cracks on only 4 of the 10 gate leaves; in those cases, the calculated functional condition index closely approximated the three-expert average. In the remaining six cases, the computer model calculated a 100 because no cracks were observed.

Leaks and Boils: Fiqure 37

148. The calculated functional condition index of 6 of the 10 gate leaves closely approximated the 3-expert average for 2 other cases, BRKY 3 and 4, minor leaks at the lower sill seal on the upper gate set were recorded as boils. These leaks became apparent as the chamber water level dropped below the upper miter sill. If the minor leaks had not been recorded as boils, the calculated index value would have been very close to the experts' rating. However, the authors think it appropriate and necessary to record the leak in this manner. The remaining two cases, KEOK 1 and 2, were very severe leakage conditions and the experts and the computer model both rated the condition severely, that is, in zone 3, but to a different degree.

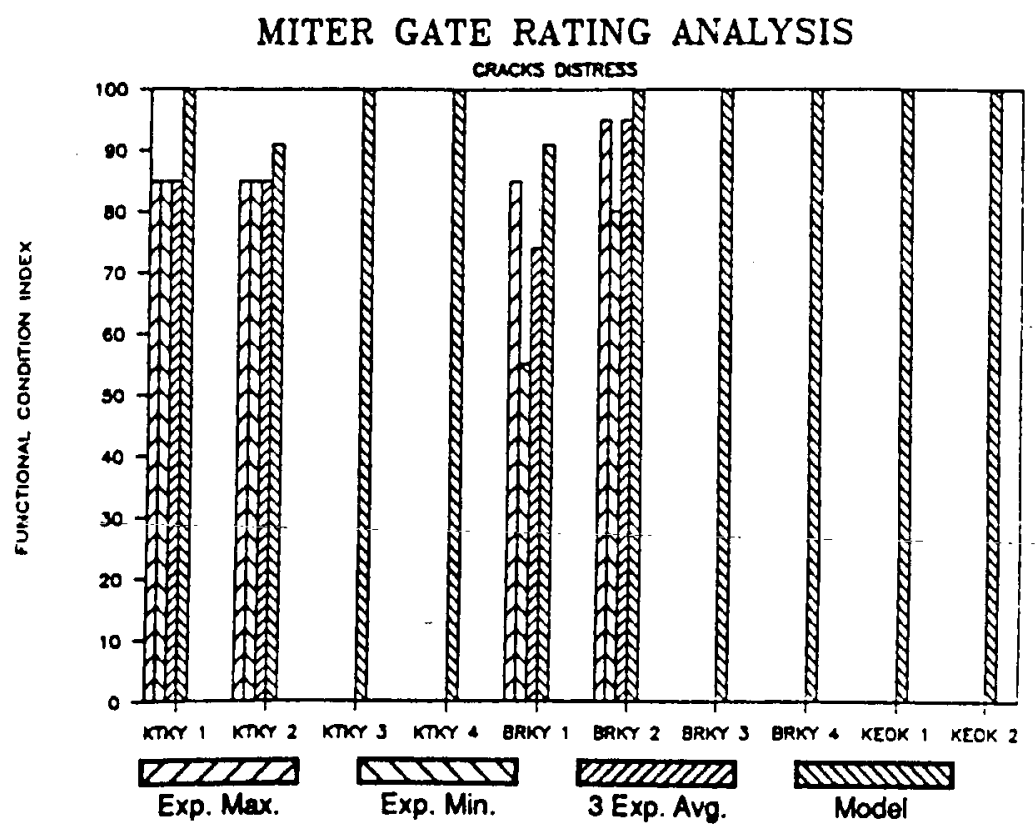

Figure 36. Crack distress 


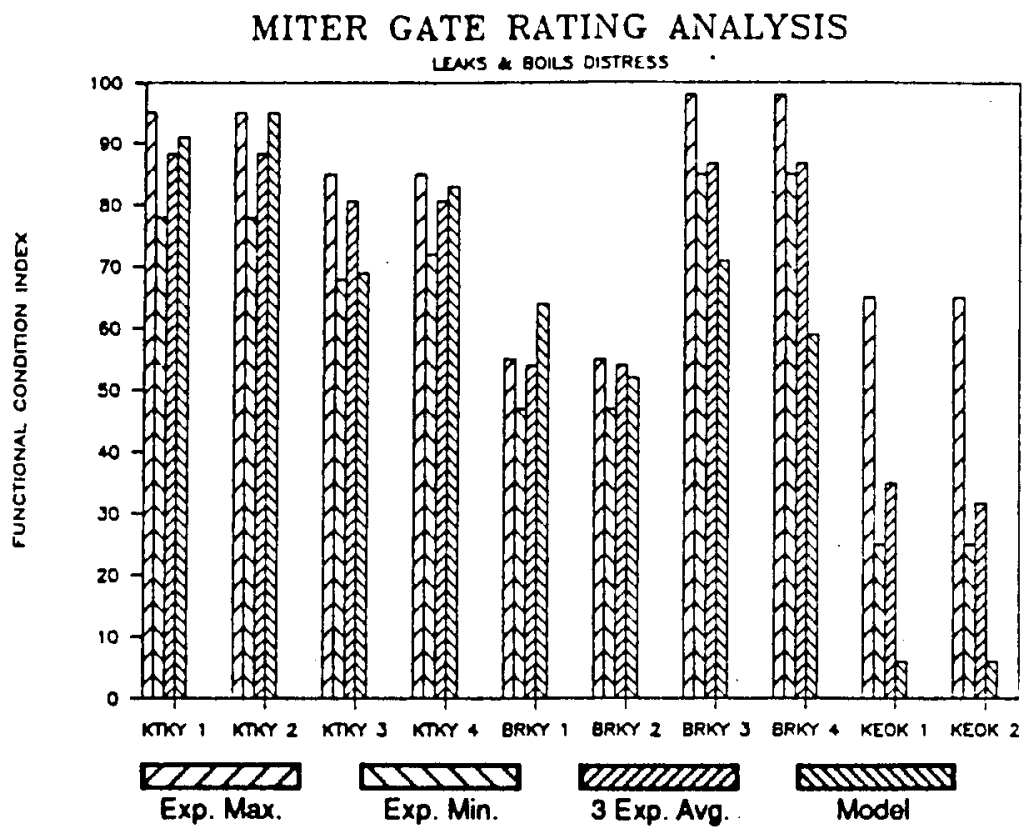

Figure 37. Leak and boil distress

\section{Dents: Figure 38}

149. The calculated functional condition indexes of 5 of the 10 gate leaves closely approximated the three-expert average. In two of the remaining cases, BRKY 1 and BRKY 2, the experts did not put a rating on dents, but the computer model calculated a 100 because no dents were observed. In one case, BRKY 3, one girder dent was observed, which, by the distress rules, resulted in a calculated condition index of 40 . However, the three experts did not rate the gate accordingly. In the last two cases, KEOK 1 and 2, no correlation can be made between the three-expert ratings that ranged from 95 to 25 and the computer model that calculated a 100 because no dents were observed. Noise, jump, and vibration: Fiqure 39

150. The calculated functional condition indexes of all 10 of the gate leaves closely approximated the three-expert average. It is noted the experts rated all the gate leaves in the 85 to 95 range, even though there were no identifiable occurrences of noise, jumps, or vibrations. The computer model will calculate a 100 index value under those circumstances. 


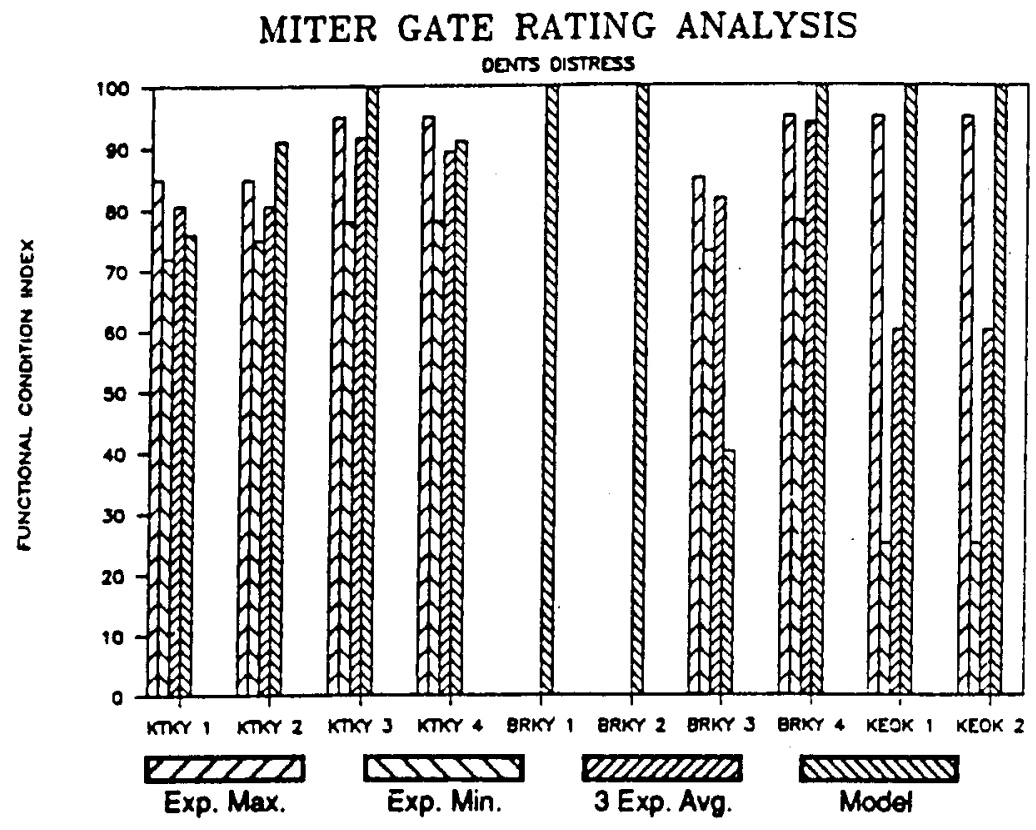

Figure 38. Dent distress.

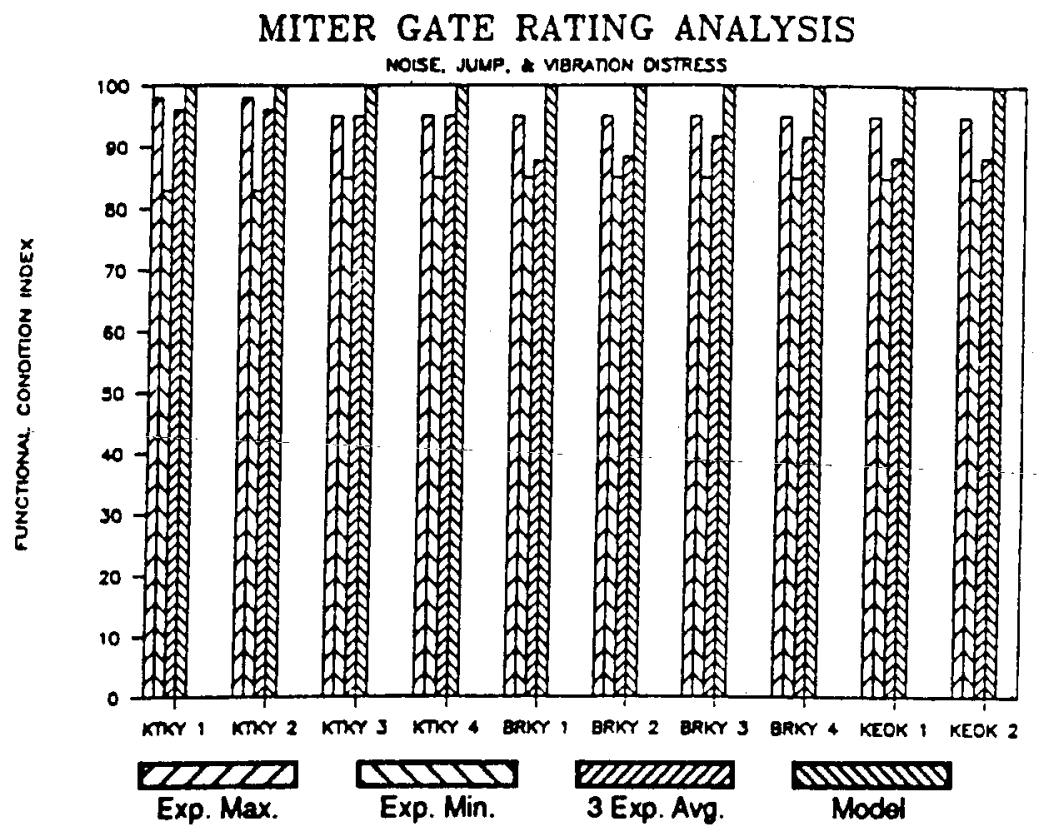

Figure 39. Noise, jump, and vibration distress 
Corrosion: Figure 40

151. The calculated functional condition indexes of 8 of the 10 gate leaves closely approximated the three-expert average. The remaining two calculated indexes at BRKY 1 and BRKY 2 are evaluated at the lowest value of zone 2 (40) because the downstream girders were judged to have a corrosion level of 3 ( $x_{\max }$ for girders). This conservative evaluation will highlight the corrosion problem, and a subsequent investigation may be in order. A Level 2 rating on the girder corrosion level would yield a condition index of 54, closely approximating the three-expert average. This case illustrates the subjective nature still inherent in the evaluation of corrosion.

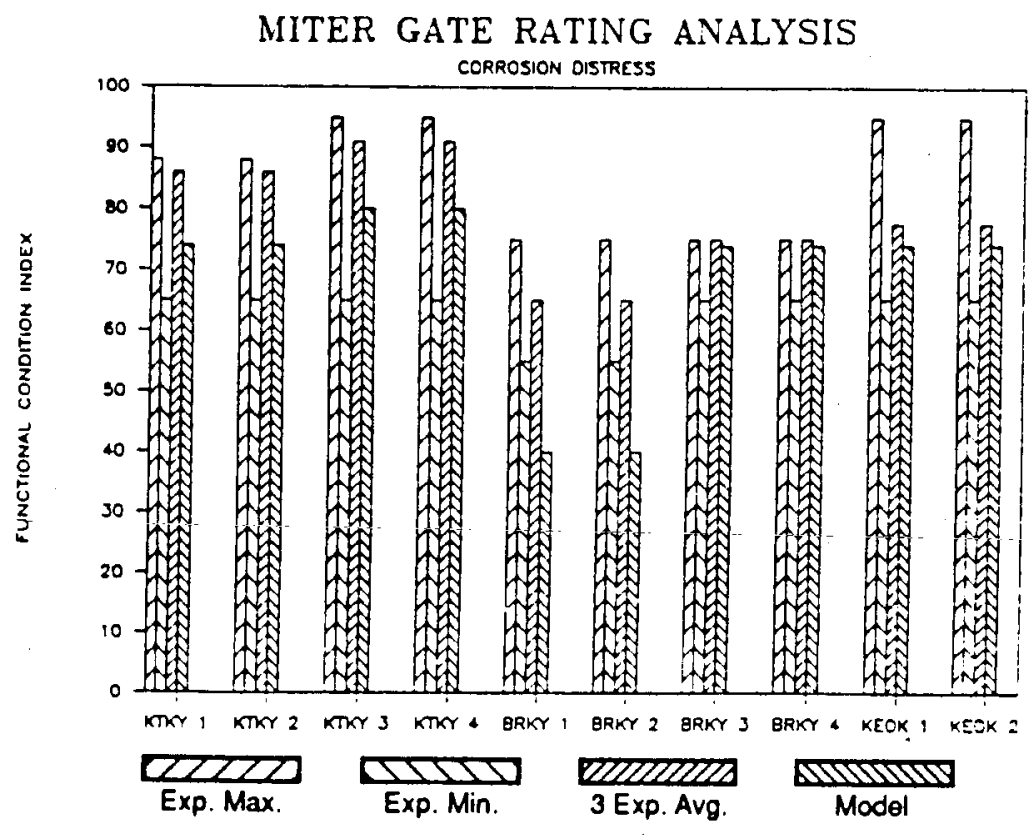

Figure 40. Corrosion distress 
Overall gate leaf ratings: Fiqure 41

152. The overall gate rating by the computer model tended to track very consistently with the three-expert average, and 9 of the 10 calculated combined functional condition indexes closely approximated the three-expert average. In one case, however, KTKY2, the difference was approximately 20 points. The lower rating by the computer model is directly attributable to the low rating on several individual distresses: anchor movement, gaps, and elevation change. These individual ratings lowered the combined index rating as well. While the 20-point differential is significant, the authors believe the computer model corresponds to a very reasonable degree with the experts' judgment on all 10 gate leaves.

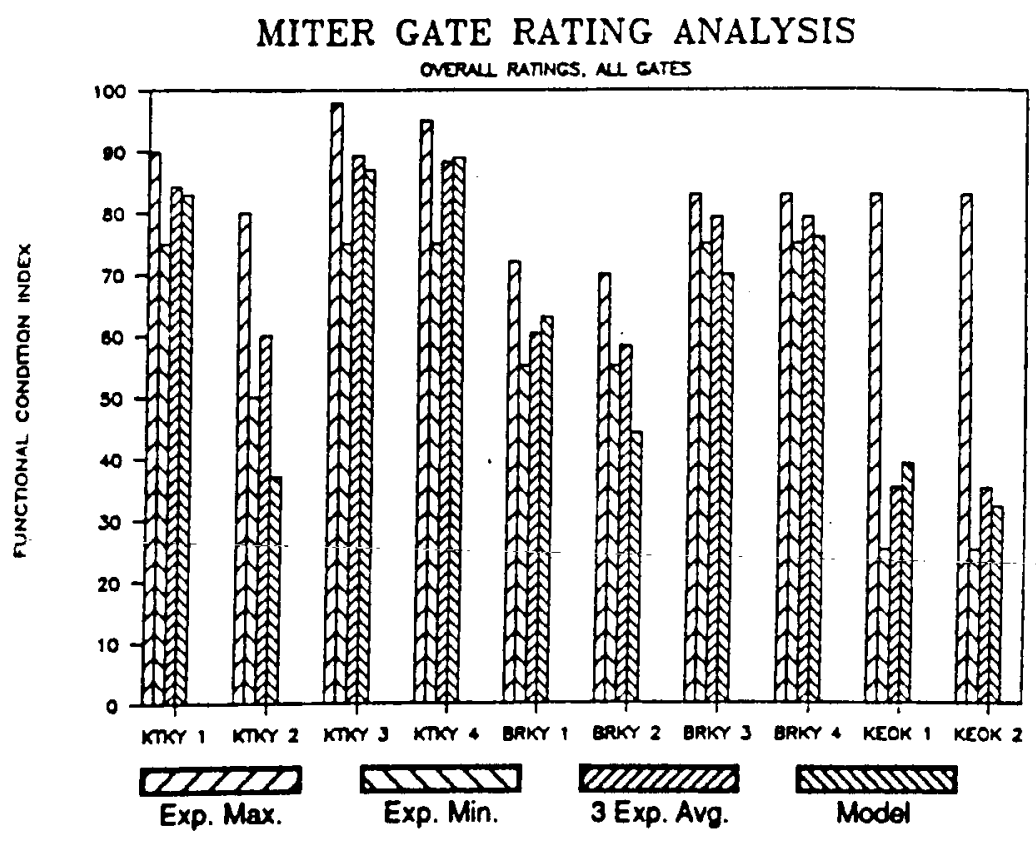

Figure 41. Overall ratings 


\section{PART V: SUMMARY AND CONCLUSIONS}

\section{Summary}

153. As part of the US Army Corps of Engineers REMR program, the project team at ISU developed an inspection and rating procedure for miter lock gates.

154. The inspection and rating procedure intentionally was kept as simple as possible. The inspection requires only simple hand tools such as a tape measure, level, dial gauge, and ruler. An inspection form was developed for recording historical information (location, previous inspections, repair history, etc.), structural information (cross sections, water depths, additional loadings, etc.), and distress documentation (offsets, elevation change, corrosion, etc.). Personal computer software was written for disk recording of inspection information.

155. A condition index is computed directly from the inspection records. The condition index is a number scale from 0 to 100 that indicates the current state of the structure. It is primarily a planning tool that indicates the relative need to perform REMR work. Condition indexes below 40 indicate that immediate repair is required or, possibly, that a more detailed inspection and reanalysis are required.

156. Two separate condition indexes make up the REMR condition index. The structural condition index is a reasonably objective measure of the structural safety. It is related directly to the safety factor, which is calculated by the PC software. A functional condition index, based on the subjective opinion of several experts from the Corps of Engineers, is also calculated. It involves at least two considerations: (a) serviceability, or how the structure performs its function on a day-to-day basis, and (b) subjective safety, or how, in the judgment of expert engineers, the safety of the structure has been degraded by various distresses.

157. The inspection and rating procedure has been applied in two field tests (August 1988 and October 1988). The results of these tests were incorporated into the current version of the procedure. 


\section{Conclusions and Recommendations}

158. The inspection and rating procedure for miter lock gate structures presented in this report has had sufficient development and testing to warrant its distribution on a wider basis. However, it should still be considered in a developmental stage. Many of the concepts introduced, such as the structural condition index, the functional condition index, $x_{\max }$ values, and weighting factors, should be exposed to a broader range of engineers who work in the area. Modifications to the procedure are certainly expected; suggestions are welcomed. 
American Institute of Steel Construction 1980 . Manual of Steel Construction (AISC), 8th Ed., AISC, Chicago, IL.

Greimann, L., and Stecker, J. 1990. "Maintenance and Repair of Steel Sheet Pile Structures," draft Technical Report REMR-OM-106, U.S. Army Corps of Engineers.

US Army Corps of Engineers. 1963. "Working Stresses for Structural Design," Washington, DC.

US Army Corps of Engineers. 1984. "Lock Gates and Operating Equipment," Washington, DC.

US Army Corps of Engineers. 1987. "Microsoft Version, CMINV-Miter Gate Investigation," Washington, DC.

\section{BIBLIOGRAPHY}

Greimann, L., and Stecker, J. 1989. "Users' Manual: Inspection and Rating of Steel Sheet Pile Structures," Technical Report REMR-OM-3, US Army Corps of Engineers, Washington, DC.

US Army Corps of Engineers. 1988. "Criteria Specifications for and Validation of a Computer Program for the Design or Investigation of Horizontally Framed Miter Gates (CMITER)," washington, DC. US Army Corps of Engineers. 1988. "User's Guide for Design and Investigation of Horizontally Framed Miter Gates (CMITER), "Washington, DC. 


\section{APPENDIX: SAMPLE COMPUTER RESULTS}

1. Computer programs associated with inspection procedures and recordkeeping were developed on a personal computer. At some later date, various modules of the completed system will be integrated into a much larger maintenance management system currently under development by the US Army Corps of Engineers. However, during the initial testing period, the maintenance management program presented here was set up to operate as a stand-alone system. This system includes modules for forms generation, data input procedures, evaluation of condition index, and report writing.

2. The program is designed to operate on an IBM-compatible microcomputer with an MS-DOS operating system. The main program is written in C language that drives two FORTRAN-77 modules.

3. The structure of the project files is organized under the DOS directory and subdirectory system. The civilian work projects constitute the highest level, and many miter lock gate structures can be grouped under this project directory at a second level. Under each structure, data files pertaining to that structure and specific inspection data are in a third level of files. This file-handling system allows the grouping of separate inspections under the same work project.

4. Once the program is started and the project file structure is set up, the program is menu driven. In other words, all operations, including file management, operation selection, and report writing, are controlled from the main menu. Other menus further direct options.

5. After the program has been installed, the user begins by keying the responses entered on the inspection sheet. The computer monitor is set up to look like the inspection sheet so entries follow line by line. Several editing features are available for correcting or updating. Pages 1 through 9 can be printed as part of a report. Once all data have been entered; at the user's request the program will calculate the functional and the structural condition index by appropriate menu selections. A SUMMARY REPORT, page 10, which gives the condition indexes and summarizes the problems associated with this structure, can also be printed. The example forms in this report are presented again along with the computer-generated forms and SUMMARY REPORT. 
Miter Gate Structure: BARKLEY - UPR_GATE

\section{MITER data sheet 1}

NAME OF CIVIL WORKS PROJECT:

(1): BARKLEY LOCK \& DAM

(2): UPPER GATE

LOCATION OF CIVIL WORKS PROJECT:

(1): BARKLEY GATE

(2): GRAND RIVER, KY.

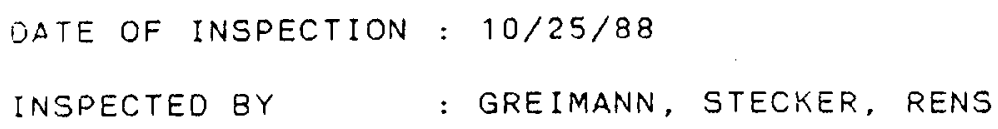


MITER data sheet 2

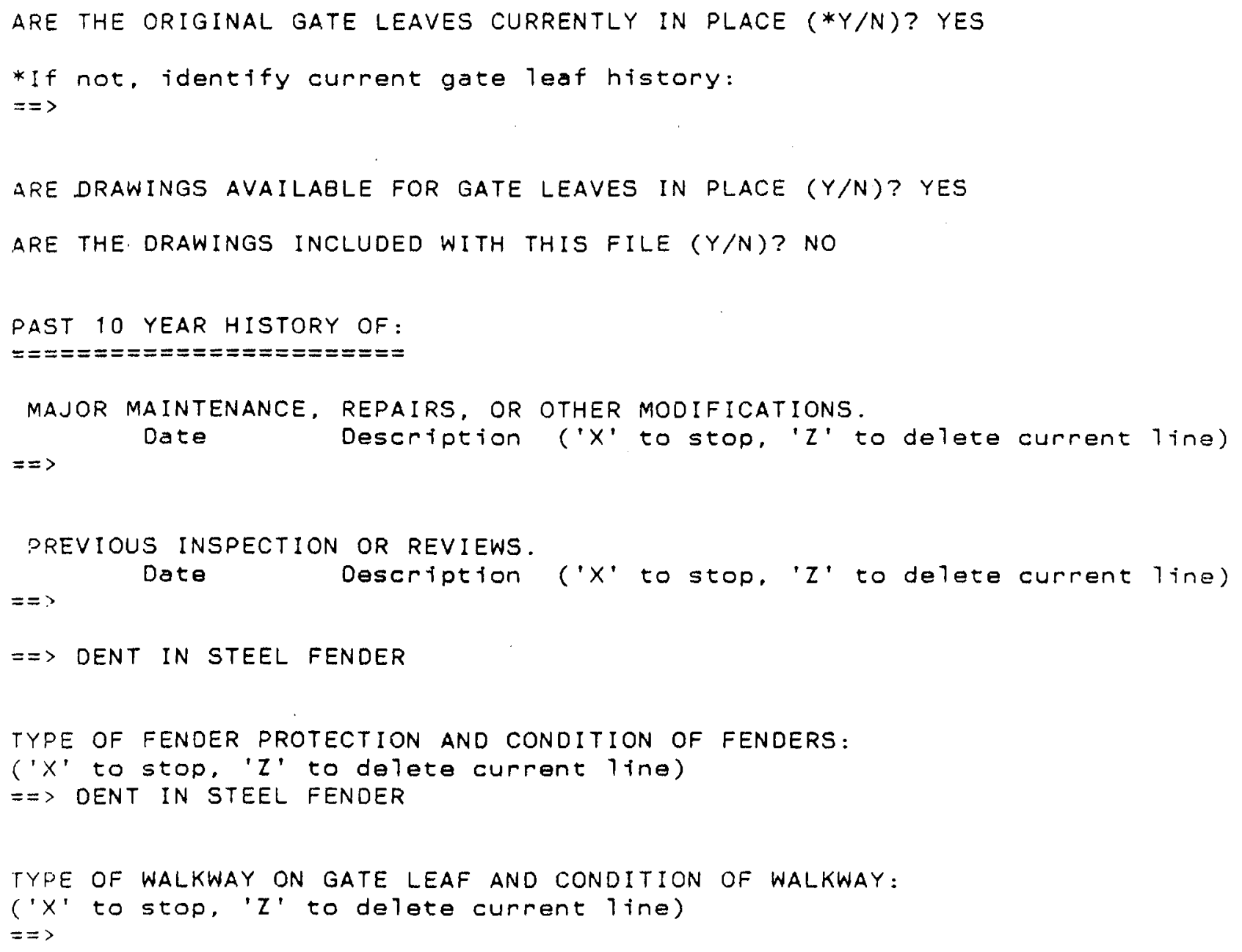


Miter Gate Structure: BARKLEY - UPR_GATE Tue Apr 111939

MITER data sheet 3

FACING DOWNSTREAM AT UPPER GATE, IDENTIFY LEAF

AS LAND OR RIVER SIDE

LEFT GATE LEAF = LANO

RIGHT GATE LEAF = RIVER

OPENING AND CLOSING OF GATE LEAVES

Closed

$(Y / N) \quad 25 \quad 50 \quad 75 \quad 100$

DO THE DIAGONALS FLAP? : Y

\section{$Y$}

DOES THE GATE JUMP?

IS THERE GATE NOISE? : N

DOES THE GATE VIBERATE?: N

ELEVATIONS OF GATE LEAF

Left leaf

Duoin

Miter

Right leaf

zuoin

Miter

Recessed
$: \quad 4.46$
$: 4.51$

$: \quad 4.46$

$: 4.53$

\section{Near}

Miter

4.47

4.54

4.47

4.56
Miter

1 ' head

4.47

4.55

4.47

4.55
Miter

Fult head

4.47

4.53

ANCHORAGE SYSTEM MEASUREMENT

Is the Concrete Cracked or Spalled at Location 4?

Paral 1 e1(Y/N)

Left gate

Perpendicular $(Y / N): Y$

Left gate

Arm 0 im.(in)

Recessed

Parallel 4

$: 0.438$

Paral1e 5

$: 43.125$

Parallel 6

$: 12.875$

Perpendicular $4: 0.324$

Perpendicular $5: 24.5$

Parpendicular $6: 18.563$

Pight gate

Arm Dim.(in)

Recessed

Paratiel 4

0.345

Paral 7 e 5

43.375

טaral1อ1 6

12.625

Perpendicular 4 : 0.193

Perpendicular $5: 20.25$

Gerpendicular $6: 21.75$

Near

Miter

0.438

43.125

12.813

0.319

24.563

18.563

\section{Near}

Miter

0.347

43.375

12.563

0. 193

20.25

21.313
Right gate

$Y$

Y
4.48

4. 54
Closed $25 \quad 50 \quad 75 \quad 100$

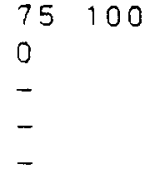




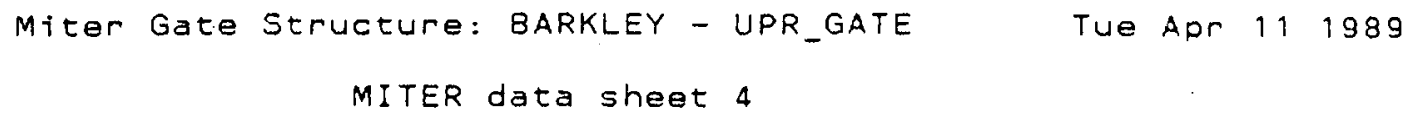
Measurement (in)

$: 0$

$: \quad .0157$$$
.0396
$$$$
0
$$$$
: 0
$$

LONGITUDNAL POSITION OF MITER POINT (Dim. 10 Fig. 1)

\begin{tabular}{llll} 
& \multicolumn{2}{c}{ Measurement (in) } \\
Location & 1 head & Ful1 head \\
TOP & $: 4.875$ & 4.5 \\
DSWL & $: .875$ & 1.25
\end{tabular}

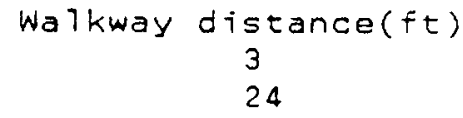

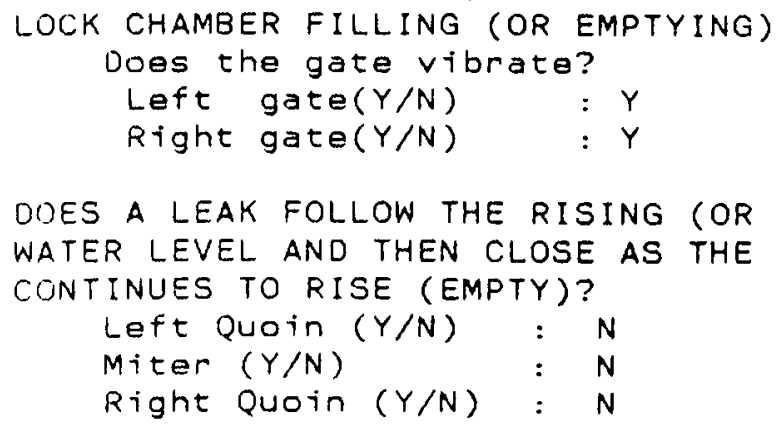




\section{MITER data sheet 5}

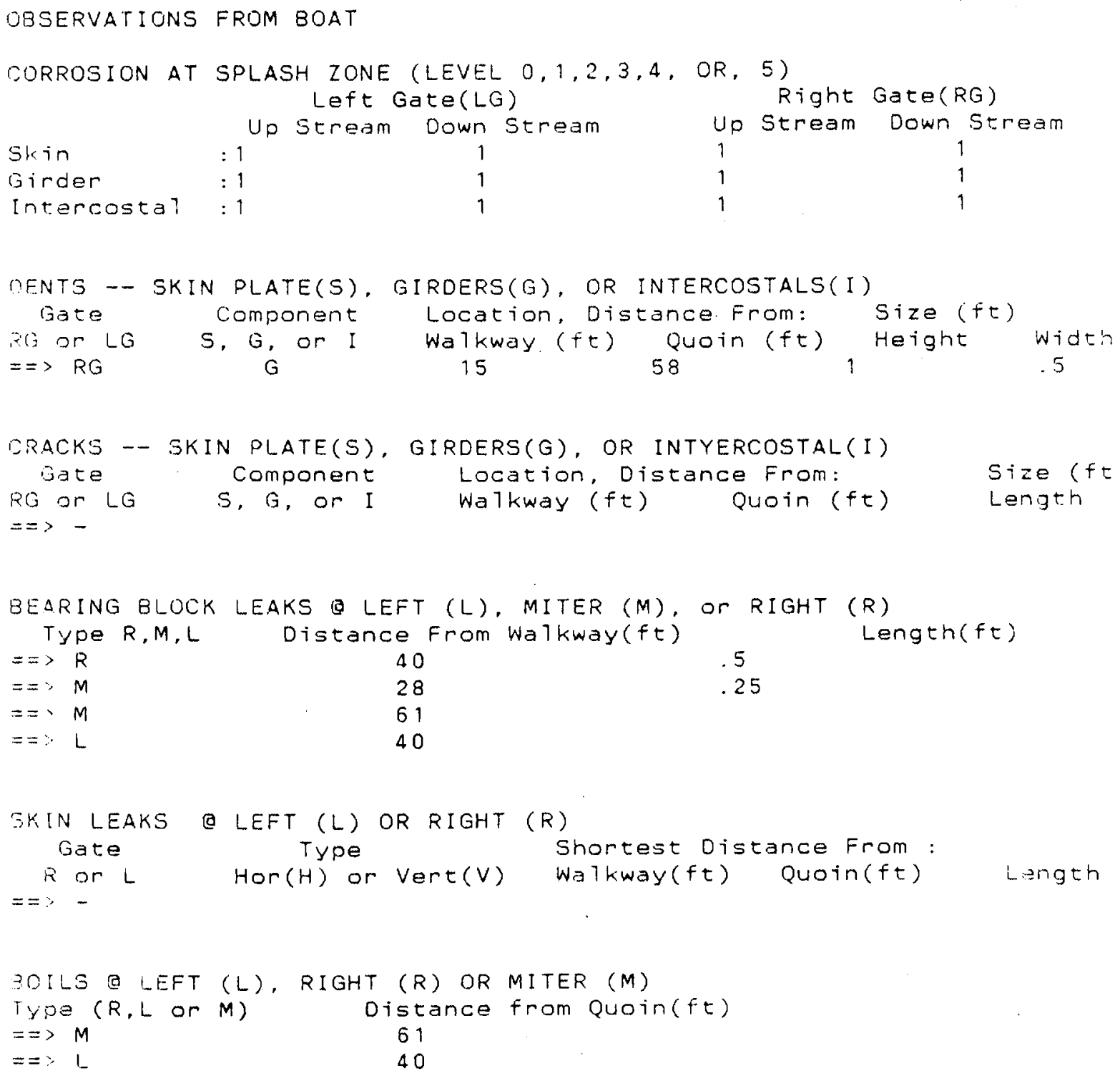


MITER data sheet 6

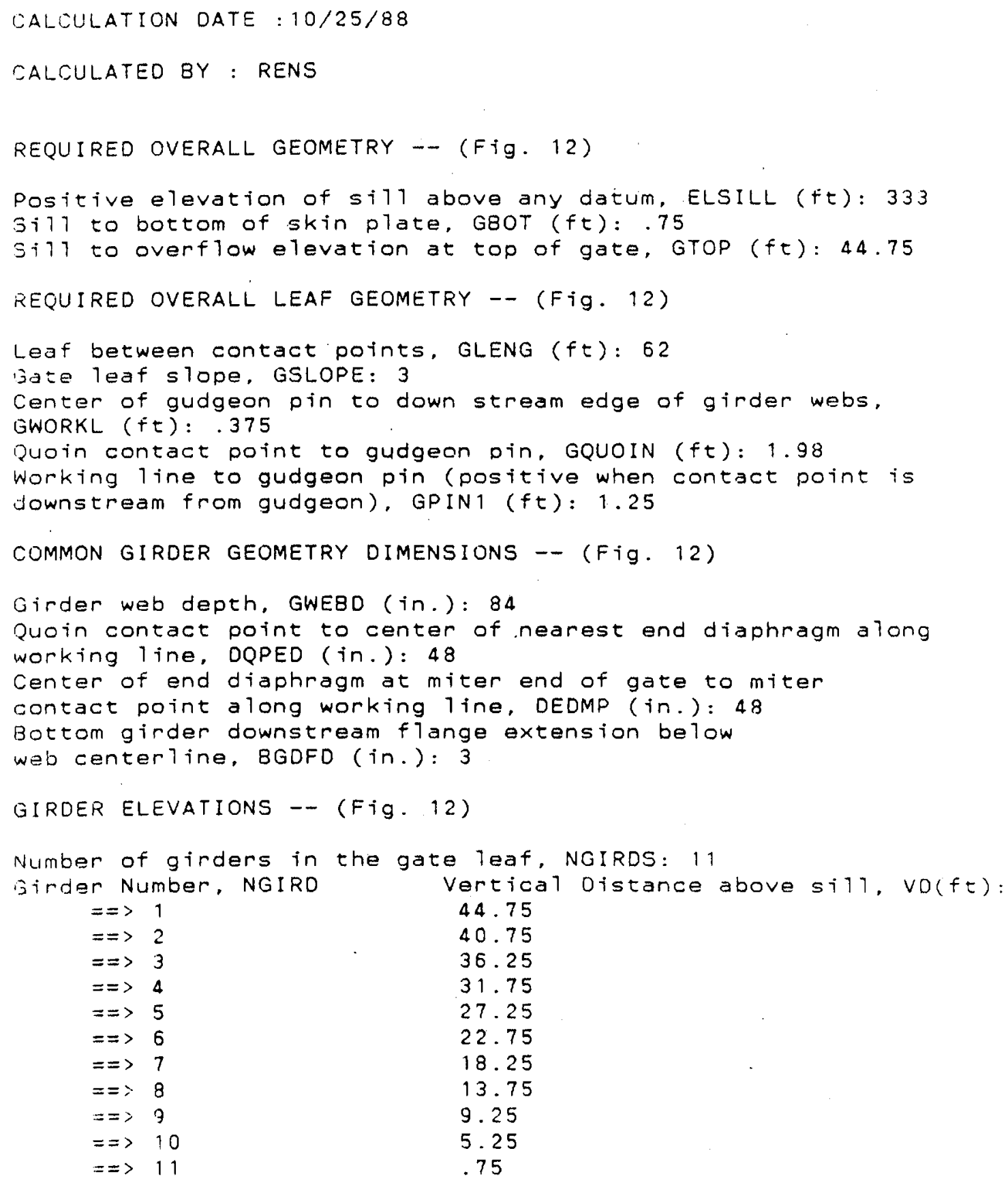


GIRDER DIAPHRAGM SPACING - - (Fig. 14)

Top girder Bottom girder Space between Intercostal spaces of similar pnl of similar pnl end diaphragms between adjacent

\begin{tabular}{|c|c|c|}
\hline NPANLI & NPANLN & NOS \\
\hline$=\Rightarrow \quad 1$ & 11 & 4 \\
\hline
\end{tabular}

DEAD AND LIVE LOADS:

Additional dead load, including ice, mud, walkway, gusset plates, etc. ADEAD (1bs): 6642

Quoin contact point to centroid of ADEAD along working

line, XDEAD $(f t): 31$

Downstream edge of girder web to centroid

of ADEAD, ZOEAD (in.): 0

Buoyancy force of acting on dry weight of gate, ABUoy (7bs.): 90900

Quoin contact point to centroid of ABUoY along working

line, XBUOY $(\mathrm{ft}): 31$

Downstream edge of girder web to centroid of ABUOY, ZBUoY (in.): 31

Applied live load, including walkway and bridgeway, ALIVE (lbs): 0

REQUIRED WATER ELEVATIONS - - (FEET ABOVE ELSILL) :

Elevation of upper pool, ELUP $(f t): 375$

Elevation of lower pool. ELLP ( $f t): 302$

Ful 17 submergence elevation. ELFS $(f t): 378: 125$

uparating water elevation, ELOW $(f t): 375$

STEEL YIELD STRENGTH (KSI):

$\begin{array}{lccc}\text { Misc. } & \text { Webs } & \text { Flanges } & \text { Skin } \\ ==>36 & 36 & 36 & 36 \\ \text { Stiffners } & \text { Intercostals } & \text { Quoin } & \text { Diaphragms } \\ =>36 & 36 & 36 & 36\end{array}$




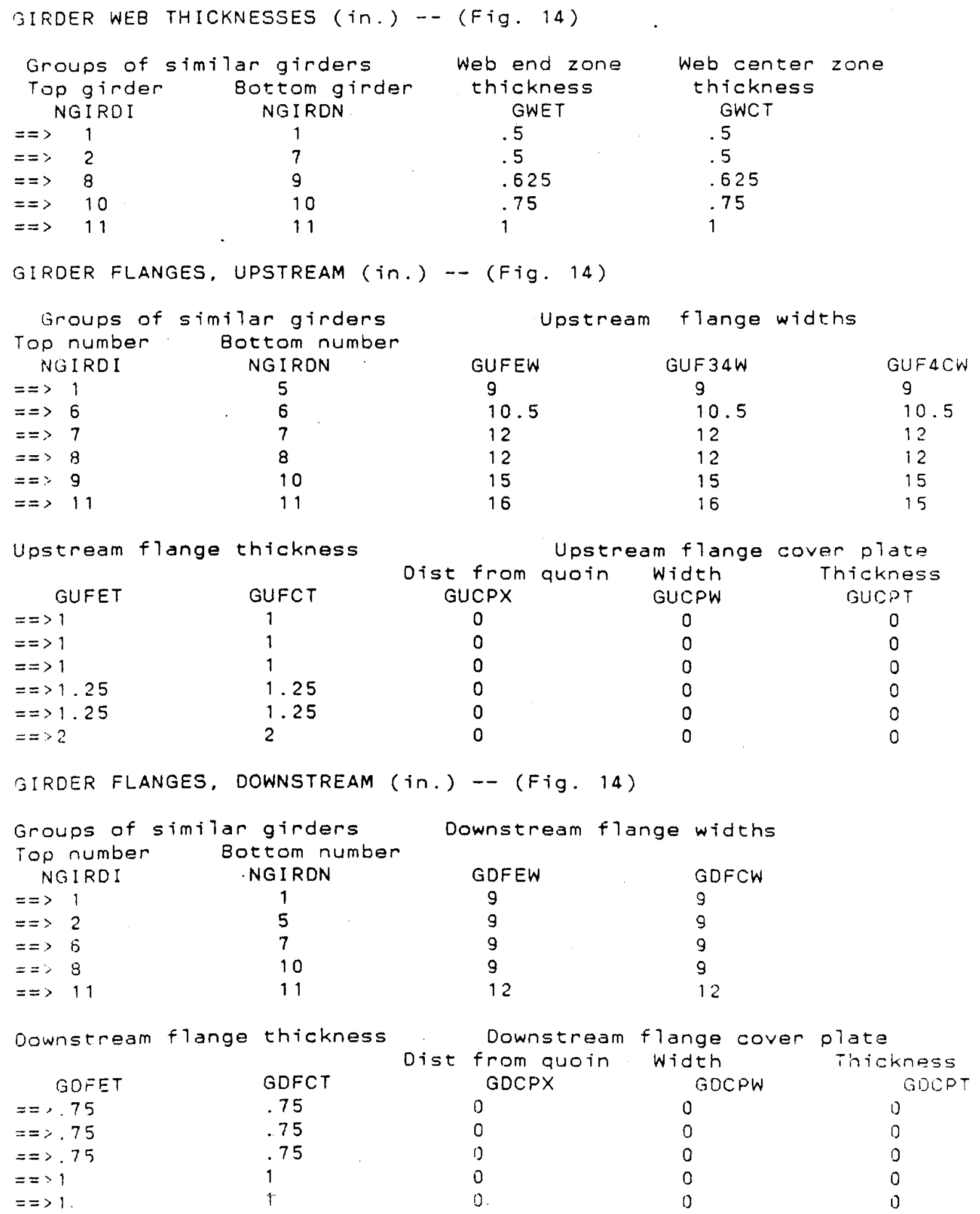


MITER data sheet 9

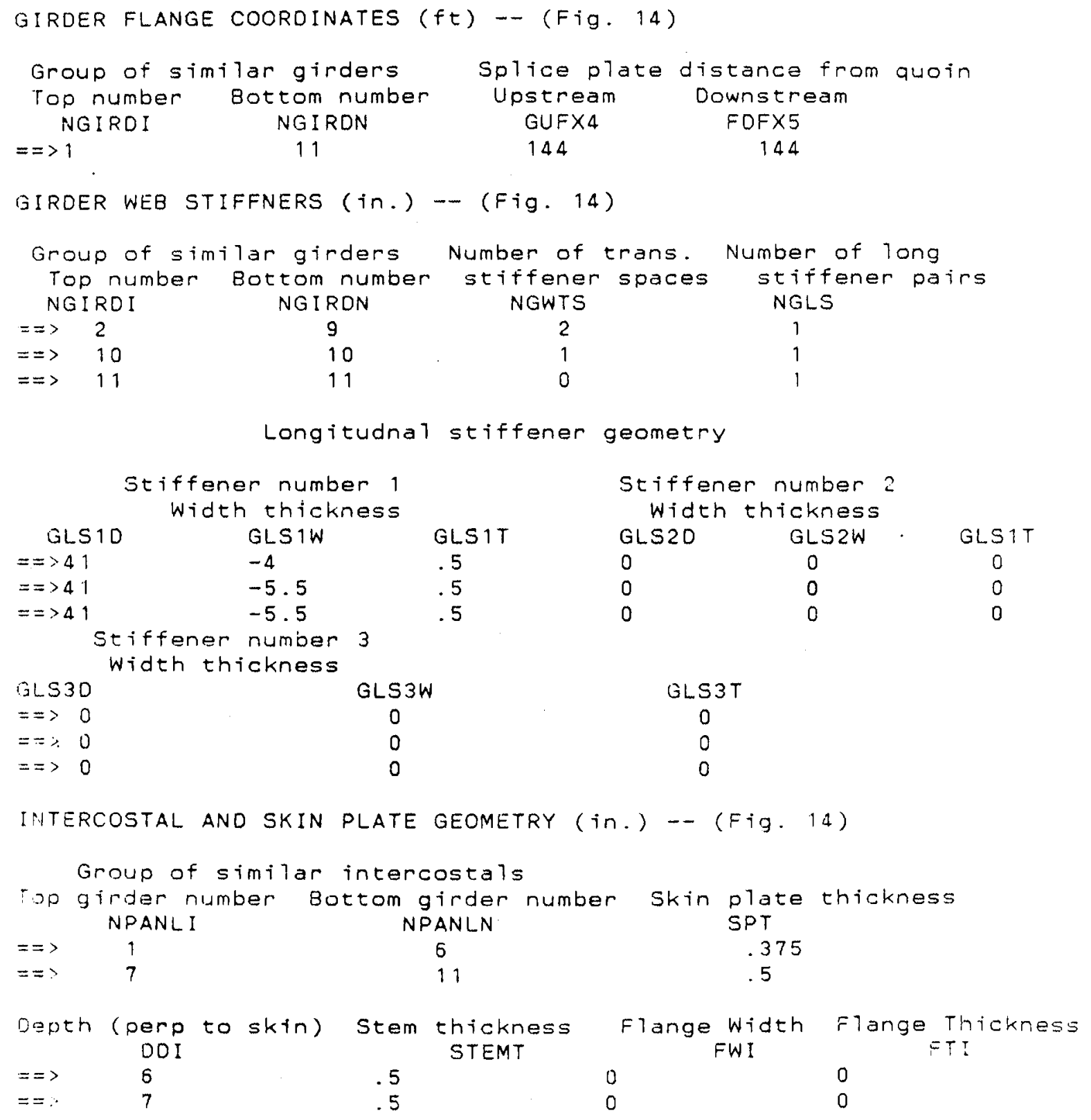




$$
\text { Miter Gate Structure: BARKLEY - UPR_GATE }
$$

PROJECT NAME:

SARKLEY LOCK \& DAM

UPPER GATE

LOCATION :

BARKLEY GATE

GRAND RIVER, KY.

INSPECTION DATE: $10 / 25 / 88$

INSPECTED BY: GREIMANN, STECKER, RENS

Condition Index Right Gate Left Gate

$\begin{array}{llrr}\text { ANCHOR SYSTEM } & : & 60 & 71 \\ \text { LONG. MOVEMENT } & : & 74 & 74 \\ \text { NOISE JUMP } & : & 100 & 100 \\ \text { OFFSET CI } & : & 65 & 65 \\ \text { GAP CI } & : & 85 & 94 \\ \text { CORROSION } & : & 74 & 74 \\ \text { DENTS } & : & 40 & 100 \\ \text { CRACKS } & : & 100 & 100 \\ \text { LEAKS\& BOILS } & : & 70 & 58 \\ \text { ELEVATION } & : & 83 & 69 \\ \text { COMBINED CI } & : & 70 & 76\end{array}$

STRUCTURAL CI

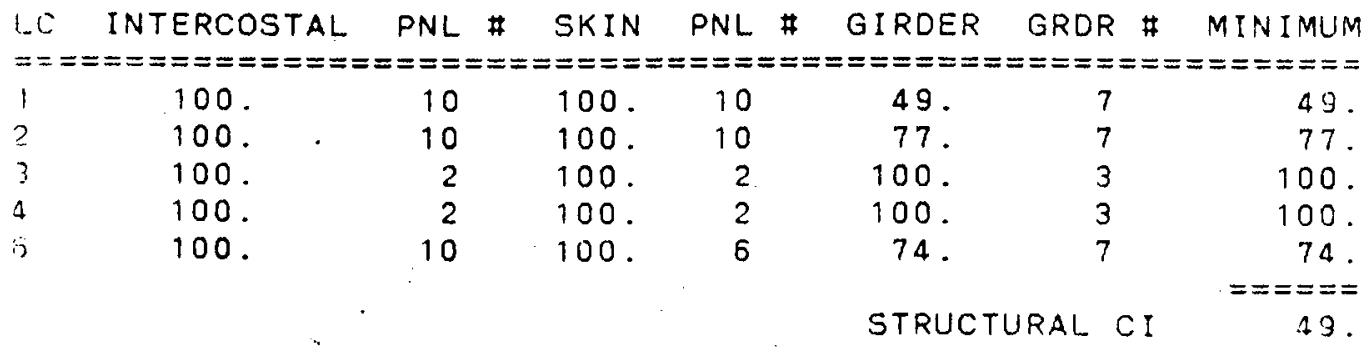

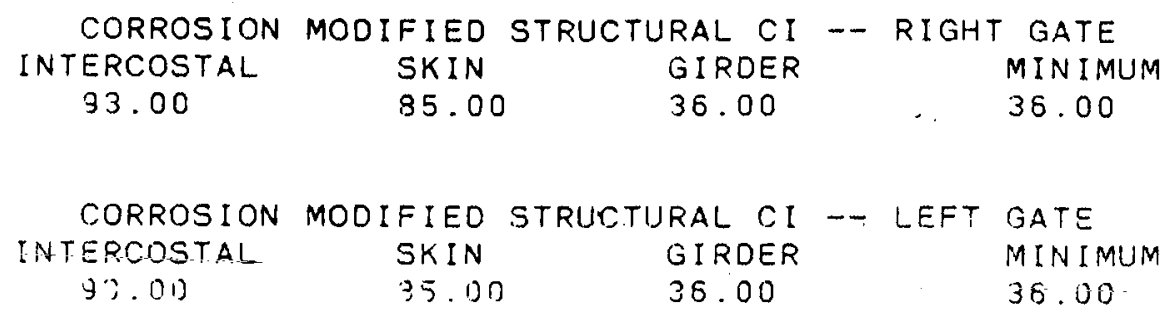

